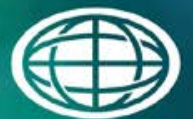

Savannah River

National Laboratory "m

OPERATED BY SAVANNAH RIVER NUCLEAR SOLUTIONS

Characterization of Solids in Fouled

Modular Caustic Side Solvent Extraction

Unit (MCU) Prefilter/Coalescer Media

S. H. Reboul

T. B. Peters

F. F. Fondeur

July 2014

SRNL-STI-2014-00097 


\section{DISCLAIMER}

This work was prepared under an agreement with and funded by the U.S. Government. Neither the U.S. Government or its employees, nor any of its contractors, subcontractors or their employees, makes any express or implied:

1. warranty or assumes any legal liability for the accuracy, completeness, or for the use or results of such use of any information, product, or process disclosed; or

2. representation that such use or results of such use would not infringe privately owned rights; or

3. endorsement or recommendation of any specifically identified commercial product, process, or service.

Any views and opinions of authors expressed in this work do not necessarily state or reflect those of the United States Government, or its contractors, or subcontractors.

\section{Printed in the United States of America \\ Prepared for U.S. Department of Energy}


Keywords: $M C U$, coalescer, prefilter, dissolved salt solution, strip effluent

Retention: Permanent

\title{
Characterization of Solids in Fouled Modular Caustic Side Solvent Extraction Unit (MCU) Prefilter/Coalescer Media
}

\author{
S. H. Reboul \\ T. B. Peters \\ F. F. Fondeur
}

July 2014 


\section{REVIEWS AND APPROVALS}

\section{AUTHORS:}

S. H. Reboul, Advanced Characterization and Processing Date

T. B. Peters, Advanced Characterization and Processing

Date

F. F. Fondeur, Separation and Actinide Science

Date

TECHNICAL REVIEW:

C. A. Nash, Advanced Characterization and Processing

Date

\section{APPROVAL:}

F. M. Pennebaker, Manager

Date

Environmental \& Chemical Process Technology Research Programs

S. L. Marra, Manager

Date

Environmental \& Chemical Process Technology Research Programs

D. J. Martin, Manager

Date

Tank Farm Facility Engineering Treatment Processes 


\section{ACKNOWLEDGEMENTS}

The following individuals are acknowledged for contributing to this task: D. J. Wheeler, for her support in preparing and processing the coalescer samples in the Shielded Cells; H. M. Ajo, for performing the scanning electron microscopy and energy dispersive spectroscopy analyses; D. M. Missimer, for performing the X-ray diffraction analyses; and J. E. Young, for performing the inductively coupled atomic emission spectroscopy analyses. The assistance of each of these individuals is appreciated. 


\section{EXECUTIVE SUMMARY}

Prefilters and coalescers utilized during the Modular Caustic Side Solvent Extraction Unit (MCU) processing of Salt Batches 5 and 6 were sampled and submitted to SRNL for characterization, for the purpose of identifying solid phase constituents potentially fouling the pores. Specifically, three samples were received and characterized: 1) a decontaminated salt solution (DSS) prefilter (PF) sample; 2) a DSS coalescer sample; and 3) a strip effluent (SE) coalescer sample. Aliquots of the samples were analyzed by X-ray Diffraction (XRD), Fourier Transform Infrared (FTIR) Spectroscopy, and Scanning Electron Microscopy (SEM)/Energy Dispersive Spectroscopy (EDS). Other aliquots of the samples were leached in acid solution, and the leachates were analyzed by Inductively Coupled Plasma Atomic Emission Spectroscopy (ICP-AES). In addition, modeling was performed to provide a basis for comparison of the analytical results.

Several constituents were identified as being present in the samples and being likely contributors to the $\mathrm{PF} /$ coalescer fouling. Other constituents identified through laboratory analysis were thought to be artifacts of the rinse solution used to flush the media, rather than constituents present during processing. Other constituents expected to deposit during processing were apparently removed during rinsing and/or remained present following rinsing, but found to be undetectable by the analytical methods utilized. The primary constituents associated with fouling of the DSS PF were thought to be aluminum hydroxide; sodium oxalate; components associated with monosodium titanate (MST); entrained sludge particles; entrained stainless steel fines; and sodium aluminosilicate (NAS). In contrast, the constituents associated with fouling of the DSS coalescer were thought to be the same as those for the PF, with exception of the entrained sludge particles and stainless steel fines (which were effectively removed by the PF), and addition of the MCU modifier. Although entrained sludge particles and stainless steel fines were removed by the PF, it is likely that a portion of the components associated with the sludge and stainless steel fines partitioned to the liquid phase, and ultimately migrated to the DSS coalescer. In contrast, the primary constituents associated with fouling of the SE coalescer were thought to be components associated with a) entrained sludge particles, b) stainless steel fines, and c) MST; NAS; silica; iron oxide; MCU modifier; and possibly components associated with solder. Consistent with the deposited solids, the porosities of the PF/coalescer samples were significantly lower than those of unused $\mathrm{PF} /$ coalescer media. Because of the wide range of constituents contributing to PF/coalescer fouling, potential treatment options for reducing the fouling would likely require use of multiple sequential cleaning solutions, with various compositions tailored to target removal of those constituents driving the fouling. Such treatment options would require demonstration/optimization prior to implementation, as they may be incapable of reversing fouling, despite effectively removing solids.

Recommendations for future characterization activities include: a) use of DSS PF/coalescer rinsing solutions chosen to maintain the integrity of the original depositing compounds; and b) use of an additional analytical technique for identifying potential sodium oxalate solids. 


\section{TABLE OF CONTENTS}

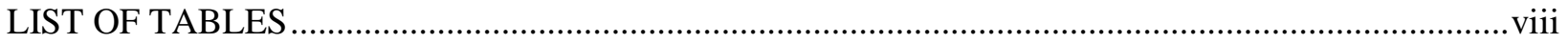

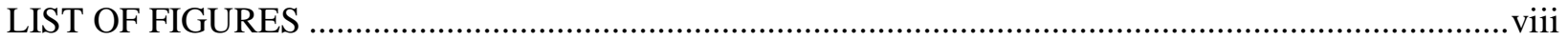

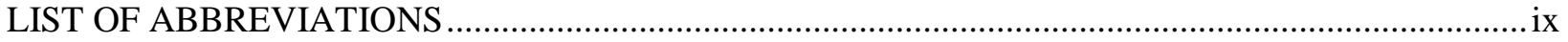

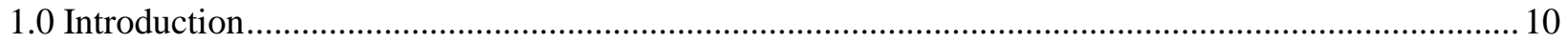

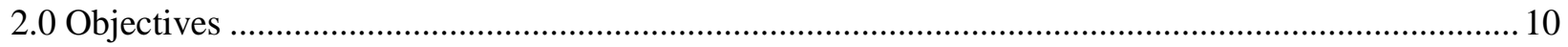

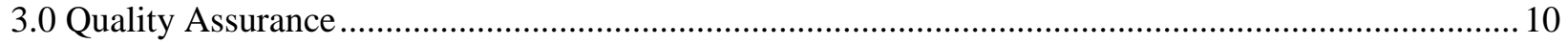

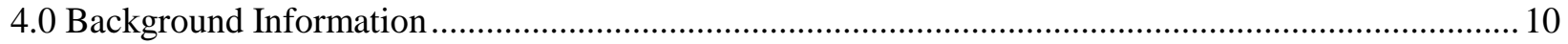

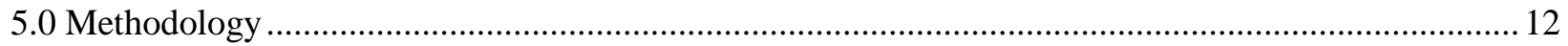

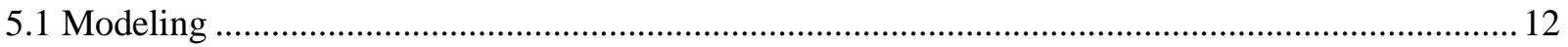

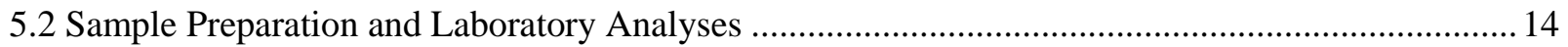

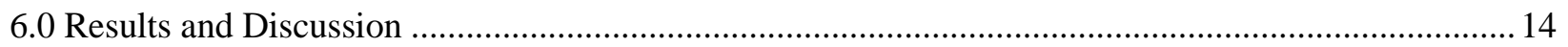

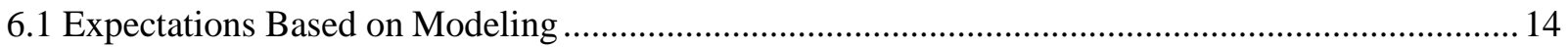

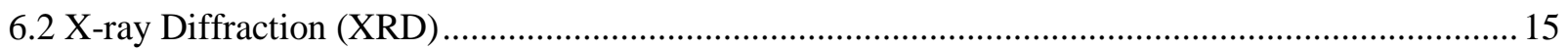

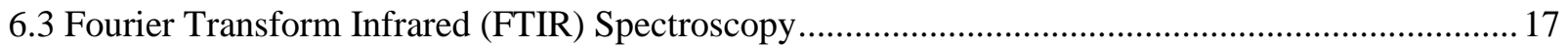

6.4 Scanning Electron Microscopy (SEM)/Energy Dispersive Spectroscopy (EDS) ........................... 21

6.5 Inductively Coupled Atomic Emission Spectroscopy (ICP-AES) of PF/Coalescer Leachates.......... 22

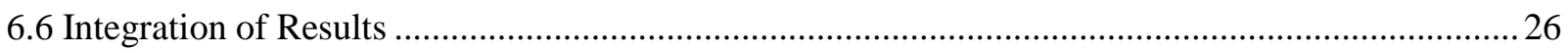

6.7 Potential Treatment Options for Cleaning Fouled PF/Coalescer Media ........................................ 27

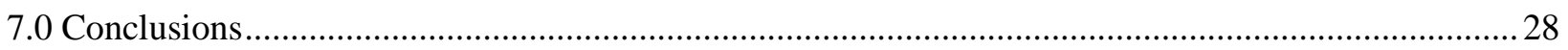

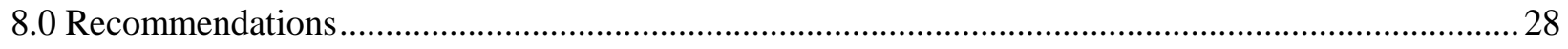

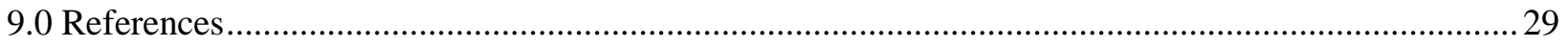

Appendix A : SEM Images and EDS Results for the DSS PF Sample..................................... 30

Appendix B : SEM Images and EDS Results for the DSS Coalescer Sample..........................47

Appendix C : SEM Images and EDS Results for the SE Coalescer Sample ............................58 


\section{LIST OF TABLES}

Table 5-1. Inputs for Equilibrium Modeling of Solids in the DSS Coalescer and PF 13

Table 5-2. Inputs for Equilibrium Modeling of Solids in the SE Coalescer ........................................... 13

Table 6-1. Solid Phase Compounds Expected to Precipitate Out of Solution .......................................... 14

Table 6-2. Summary of Constituents Identified by XRD ..................................................................... 15

Table 6-3. Summary of Constituents Identified by FTIR .................................................................... 17

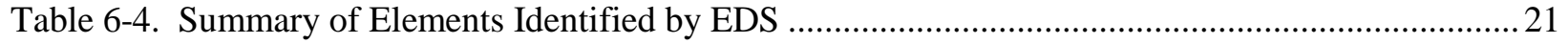

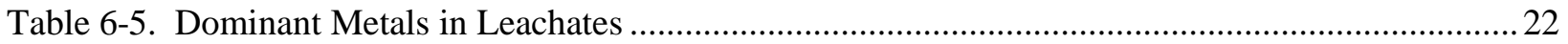

Table 6-6. Elemental Constituent Concentrations in DSS PF, DSS Coalescer, and SE Coalescer

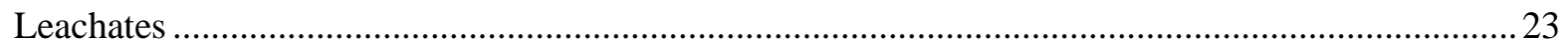

Table 6-7. Ratios of Elemental Concentrations in DSS Coalescer Leachate to those in PF Leachate ....... 26

\section{LIST OF FIGURES}

Figure 4-1. Pressure Drop Across the DSS Prefilter............................................................................. 11

Figure 4-2. Pressure Drop Across the DSS Coalescer ........................................................................... 11

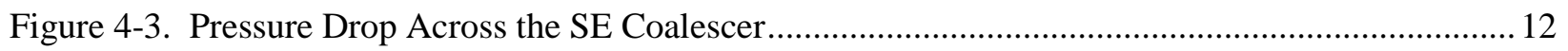

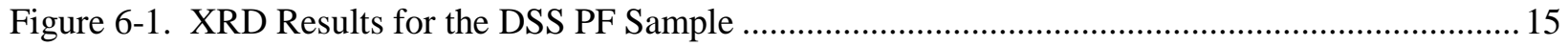

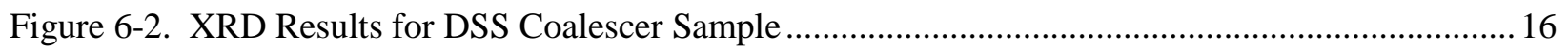

Figure 6-3. XRD Results for the SE Coalescer Sample ......................................................................... 16

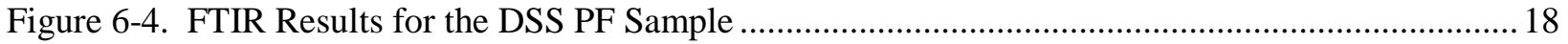

Figure 6-5. FTIR Results for the DSS Coalescer Sample .................................................................... 19

Figure 6-6. FTIR Results for the SE Coalescer Sample....................................................................... 20

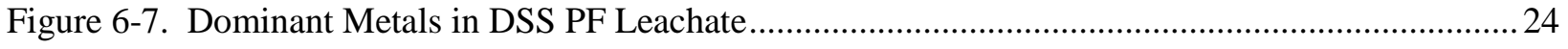

Figure 6-8. Dominant Metals in DSS Coalescer Leachate ................................................................ 24

Figure 6-9. Dominant Metals in SE Coalescer Leachate .................................................................... 25 


\section{LIST OF ABBREVIATIONS}

$\begin{array}{ll}\text { DSS } & \text { Dissolved salt solution } \\ \text { EDS } & \text { Energy dispersive spectroscopy } \\ \text { FTIR } & \text { Fourier transform infrared } \\ \text { ICP-AES } & \text { Inductively coupled plasma atomic emission spectroscopy } \\ \text { MCU } & \text { Modular caustic side solvent extraction unit } \\ \text { MST } & \text { Monosodium titanate } \\ \text { NAS } & \text { Sodium aluminosilicate } \\ \text { PF } & \text { Prefilter } \\ \text { SB } & \text { Salt batch } \\ \text { SE } & \text { Strip effluent } \\ \text { SEM } & \text { Scanning electron microscopy } \\ \text { XRD } & \text { X-ray diffraction }\end{array}$




\subsection{Introduction}

During operations of the Modular Caustic Side Solvent Extraction Unit (MCU), pressure drops across the MCU coalescers have been found to increase over time as the volume of solution processed through the coalescer increases. Such pressure drop increases have been attributed to fouling of the coalescers associated with accumulation of inorganic/organic compounds and/or changes in the characteristics of the coalescer fibers. The net result is reduction in coalescer porosity.

When pressure drops reach a level impeding normal operations, the coalescers are replaced so that effective processing operations can resume. Alternatively, the coalescers or prefilters are replaced opportunistically as a routine maintenance practice when other facility outages occur. This applies to the Dissolved Salt Solution (DSS) coalescers, the Strip Effluent (SE) coalescers, and the DSS coalescer Prefilters (PFs). A potential alternative to replacement of spent coalescers is a treatment that results in the dissolution of accumulated compounds and/or restoration of the original coalescer/PF fiber characteristics. Clearly, the potential to identify such a treatment requires a sound understanding of the compounds accumulated within the coalescers and the nature of any such coalescer fiber changes.

In this document, characterization of spent DSS coalescer, SE coalescer, and PF samples is reported. This information is addressed in the context of understanding the potential bases for coalescer/PF fouling and in deciding whether treatment of fouled coalescer/PF media (as opposed to replacement) is appropriate.

\subsection{Objectives}

1) Identify the primary constituents accumulating within coalescer/PF media;

2) Identify the physical characteristics associated with the fouled coalescer/PF media;

3) Identify differences between the spent DSS coalescers, SE coalescers, and PF media; and

4) Address potential treatment options for cleaning fouled coalescer/PF media.

\subsection{Quality Assurance}

This report was developed in accordance with the protocols identified in Task Technical and Quality Assurance Plan SRNL-RP-2013-00536. ${ }^{1}$

Requirements for performing reviews of technical reports and the extent of review are established in manual E7 2.60. SRNL documents the extent and type of review using the SRNL Technical Report Design Checklist contained in WSRC-IM-2002-00011, Rev. 2.

\subsection{Background Information}

The coalescer/PF samples addressed in this report are those associated with MCU operations during all of Salt Batch 5 (SB5) and part of Salt Batch 6 (SB6). Specifics of the coalescer/PF media from which the samples were collected are summarized below.

The DSS PF was installed on August 27, 2012 and remained in operations until September 19, 2013. A total of 1.53M gallons of DSS solution was processed through the PF. Prior to sampling (but following completion of the normal PF operations), the PF was rinsed with 100 gallons of 30 weight percent sodium 
hydroxide solution ( 10 M sodium hydroxide). A plot of the pressure drop as a function of the processing volume is given in Figure 4-1.

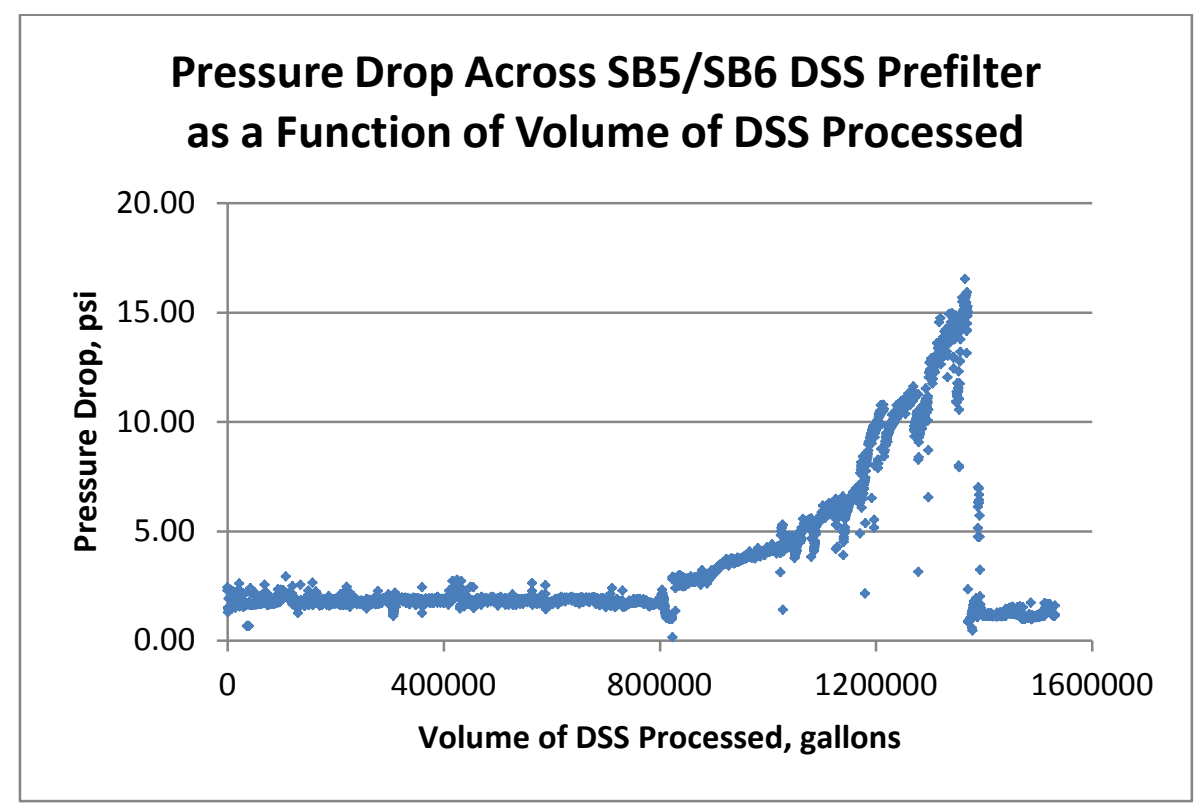

Figure 4-1. Pressure Drop Across the DSS Prefilter

The DSS coalescer was installed on August 30, 2012 and remained in operations until April 16, 2013. A total of $823 \mathrm{~K}$ gallons of DSS was processed through the coalescer. Prior to sampling (but following completion of normal coalescer operations), the DSS coalescer was rinsed with 100 gallons of 30 weight percent sodium hydroxide solution ( $10 \mathrm{M}$ sodium hydroxide). A plot of pressure drop as a function of the processing volume is given in Figure 4-2.

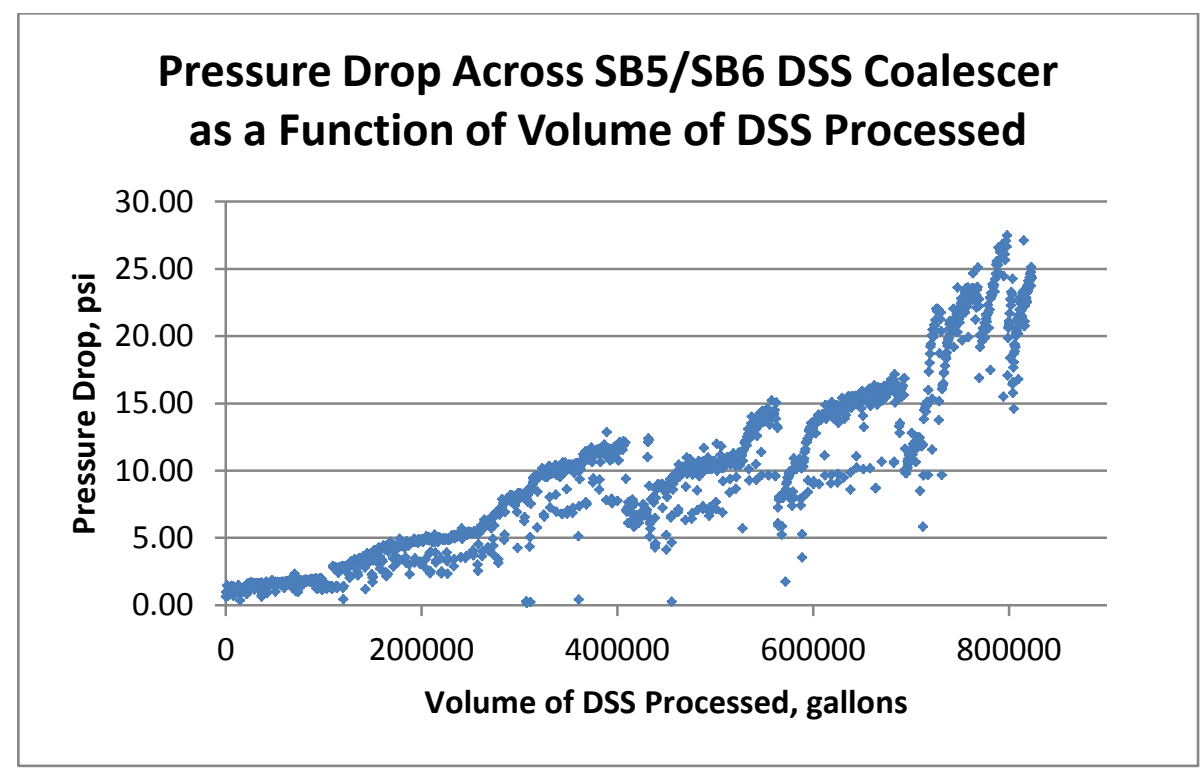

Figure 4-2. Pressure Drop Across the DSS Coalescer 
The SE coalescer was installed on August 30, 2012 and remained in operations until May 21, 2013. A total of $64.7 \mathrm{~K}$ gallons of SE solution was processed through the coalescer. Prior to sampling (but following completion of the normal coalescer operations), the SE coalescer was rinsed with 500 gallons of $0.001 \mathrm{M}$ nitric acid solution. A plot of pressure drop as a function of the processing volume is given in Figure 4-3.

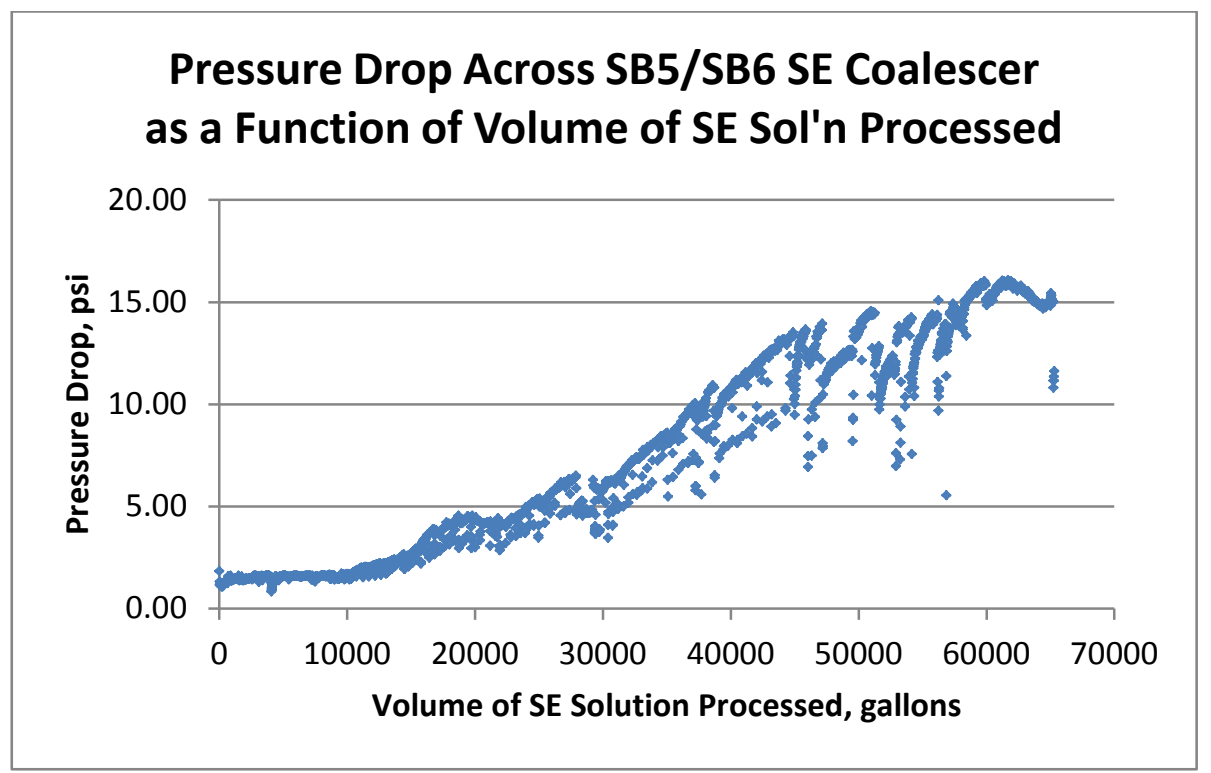

Figure 4-3. Pressure Drop Across the SE Coalescer

The SB5/6 coalescer/PF sample characterization activities at SRNL began in late October 2013. Given this time frame, it is clear that the lag times between the sample collection dates and sample analysis dates were on the order of: a) 6 months for the DSS coalescer sample; b) 5 months for the SE coalescer sample; and c) 1 month for the PF sample. The lag times provide an indication of the extent that solids aged prior to analysis.

Upon receipt into the SRNL shielded cells, the coalescer and PF samples were visually inspected for flaws and/or defects. No such abnormalities were found.

\subsection{Methodology}

\subsection{Modeling}

Expectations regarding potential precipitation of solids in the coalescer and PF samples were developed using equilibrium modeling of typical SB5 DSS and SE solutions. The modeling was performed using OLI Analyzer Studio version 9.0, with the MSE $\left(\mathrm{H}_{3} \mathrm{O}^{+}\right.$ion) databank selected, the redox option selected, the Helgeson direct equilibrium constant selected, and the isothermal calculation assuming a temperature of $25^{\circ} \mathrm{C}$.

For DSS, the inputs to the model were the concentrations of principal sodium salts as indicated by the characterization of the Macrobatch 5 Tank $21 \mathrm{H}$ qualification samples, ${ }^{3}$ with adjustments made for the lower sodium hydroxide concentrations present during normal processing operations and the higher sodium hydroxide concentrations present during rinsing (post-processing). The assumed DSS input 
species and concentrations are identified in Table 5-1, along with the methods used to quantify the concentrations. Note that the concentrations in the feed solution were reduced by approximately $15 \%$ when monosodium titanate (MST), water, and scrub solution were introduced into the stream. This dilution was not taken into account in the modeling, as the goal was to identify potential solids precipitating prior to or after MST additions.

Table 5-1. Inputs for Equilibrium Modeling of Solids in the DSS Coalescer and PF

\begin{tabular}{|l|c|l|}
\hline Species & Concentration, M & Quantification Method \\
\hline \hline \multirow{3}{*}{ Sodium nitrate } & 2.82 & Ion chromatography \\
\hline Sodium hydroxide & $\begin{array}{c}2.08 \\
\text { (processing conditions) }\end{array}$ & Base titration \\
\cline { 2 - 3 } & $\begin{array}{c}10.0 \\
\text { (post-processing conditions) }\end{array}$ & Process knowledge \\
\hline Sodium aluminate & 0.560 & Ion chromatography \\
\hline Sodium carbonate & 0.264 & ICP-AES (for Al) \\
\hline Sodium sulfate & 0.238 & Total inorganic carbon \\
\hline Sodium orthophosphate & 0.0917 & ICP-AES (for S) \\
\hline Sodium oxalate & 0.00542 & ICP-AES (for P) \\
\hline Sodium metasilicate & 0.00275 & Ion chromatography \\
\hline
\end{tabular}

For SE solution, the inputs to the model were the concentrations of principal nitrate salts as indicated by the characterization of routine samples collected from the SE hold tank, ${ }^{4}$ with adjustments made for assessing iron present as Fe(II) versus Fe(III), and for assessing impacts of the observed constituent concentration fluctuations. As such, four sets of SE modeling calculations were performed, one assuming $\mathrm{Fe}(\mathrm{II})$ and the lowest constituent concentrations, one assuming Fe(II) and the highest constituent concentrations, one assuming $\mathrm{Fe}(\mathrm{III})$ and the lowest constituent concentrations, and one assuming $\mathrm{Fe}(\mathrm{III})$ and the highest constituent concentrations. The assumed SE solution input species and concentrations are identified in Table 5-2. The method used to quantify all of the concentrations for the SE solution case was Inductively Coupled Plasma Atomic Emission Spectroscopy (ICP-AES). Note that silicon concentrations, while not reported in Reference 4, were part of the original ICP-AES data set and therefore utilized when developing the inputs shown in Table 5-2.

Table 5-2. Inputs for Equilibrium Modeling of Solids in the SE Coalescer

\begin{tabular}{|l|c|c|}
\hline \multirow{2}{*}{ Species } & \multicolumn{2}{|c|}{ Concentration, M } \\
\cline { 2 - 3 } & Low & High \\
\hline \hline Nitric acid & $1.00 \mathrm{E}-03$ & $1.00 \mathrm{E}-03$ \\
\hline Sodium nitrate & $6.72 \mathrm{E}-04$ & $2.92 \mathrm{E}-03$ \\
\hline Zinc nitrate & $1.93 \mathrm{E}-04$ & $2.65 \mathrm{E}-04$ \\
\hline Ferrous or ferric nitrate & $1.88 \mathrm{E}-04$ & $2.78 \mathrm{E}-04$ \\
\hline Aluminum nitrate & $1.46 \mathrm{E}-04$ & $9.37 \mathrm{E}-04$ \\
\hline Calcium nitrate & $1.40 \mathrm{E}-04$ & $1.95 \mathrm{E}-04$ \\
\hline Sodium metasilicate & $8.37 \mathrm{E}-05$ & $2.54 \mathrm{E}-04$ \\
\hline
\end{tabular}




\subsection{Sample Preparation and Laboratory Analyses}

Upon arrival at SRNL, the samples were placed in the Shielded Cells, where they were visually inspected and then prepared for analysis. Two one-inch wide "ring" segments of each sample were removed from each respective solid core. One of the "ring" segments from each sample was submitted to the laboratory "as is," for solids characterization by X-ray Diffraction (XRD), Fourier Transform Infrared (FTIR) spectroscopy, Scanning Electron Microscopy (SEM), and Energy Dispersive Spectroscopy (EDS). The other "ring" segment from each sample was placed in its own "leaching bottle" and immersed in $400 \mathrm{~mL}$ of $3 \mathrm{M}$ nitric acid, at ambient temperature and quiescent conditions. Leachate aliquots were removed from each bottle after periods of $1,7,14$, and 28 days. The respective leachate aliquots were submitted to the laboratory for elemental analysis by ICP-AES.

\subsection{Results and Discussion}

\subsection{Expectations Based on Modeling}

Based on the modeling results, a number of solid phase compounds were expected to precipitate out of solution during normal DSS and SE operations, and during post-processing rinsing operations. Such solids had the potential to accumulate within the coalescer and PF media, fouling the media and reducing the porosities. A summary of the expected precipitating solids is given in Table 6-1.

Table 6-1. Solid Phase Compounds Expected to Precipitate Out of Solution

\begin{tabular}{|c|c|c|}
\hline Waste Stream & Processing Conditions & Solids Expected to Precipitate Out of Solution \\
\hline \multirow[b]{2}{*}{ DSS } & Routine processing $\left(\left[\mathrm{OH}^{-}\right] \approx 2 \mathrm{M}\right)$ & $\begin{array}{l}\text { - Aluminum hydroxide } \\
\text { - Sodium oxalate } \\
\text { - Cancrinite monohydrate }\end{array}$ \\
\hline & Post-processing $\left(\left[\mathrm{OH}^{-}\right] \approx 10 \mathrm{M}\right)$ & $\begin{array}{l}\text { - Sodium nitrate } \\
\text { - Sodium oxalate } \\
\text { - Sodium carbonate monohydrate } \\
\text { - Hexasodium carbonate disulfate* } \\
\text { - Hydroxysodalite dihydrate }\end{array}$ \\
\hline \multirow{4}{*}{ SE solution } & $\begin{array}{l}\text { Low constituent concentrations } \\
\text { Iron present as } \mathrm{Fe}(\mathrm{II})\end{array}$ & - No solids expected to precipitate \\
\hline & $\begin{array}{l}\text { High constituent concentrations } \\
\text { Iron present as } \mathrm{Fe}(\mathrm{II})\end{array}$ & - Silica \\
\hline & $\begin{array}{l}\text { Low constituent concentrations } \\
\text { Iron present as Fe(III) }\end{array}$ & - Iron oxide \\
\hline & $\begin{array}{l}\text { High constituent concentrations } \\
\text { Iron present as } \mathrm{Fe}(\mathrm{III})\end{array}$ & $\begin{array}{l}\text { - Iron oxide } \\
\text { - Silica }\end{array}$ \\
\hline
\end{tabular}

*OLI's library identified this salt using two terminologies - hexasodium carbonate bisulfate and hexasodium carbonate disulfate. The latter terminology was used in this report, since it seemed most descriptive.

As shown in the table, under routine DSS processing operations, the primary solid compounds expected to precipitate out of solution include aluminum hydroxide, sodium oxalate, and cancrinite monohydrate (a sodium aluminosilicate [NAS] compound). As the hydroxide concentration is raised during rinsing (just prior to sampling), any precipitated aluminum hydroxide solids are expected to at least partially dissolve back into solution and therefore be mostly flushed from the DSS coalescer and PF media. Precipitated sodium oxalate is expected to remain insoluble during post-processing and any solid phase cancrinite monohydrate should be converted to hydroxysodalite dihydrate, another NAS compound, during post- 
processing. Additional impacts of the high hydroxide rinse include precipitation of sodium nitrate, sodium carbonate monohydrate, and hexasodium carbonate disulfate.

In contrast, under routine SE processing operations, the primary solid compounds expected to precipitate out of solution include silica and iron oxide. As shown in the table, the precipitating solids are functions of the redox state of the iron, and of the magnitude of the constituent concentrations. If the iron is present as Fe(II), silica is the only solid phase compound expected to precipitate, but only under conditions where sufficient silicon is present (no solid phase silica is expected when the silicon concentration is "low"). If the iron is present as Fe(III), iron oxide is also expected to precipitate, under both "low" and "high" iron concentration conditions.

The list of solids expected to precipitate out of solution should not be considered definitive or complete, since it is based on limited modeling performed for a select set of compositional inputs. Instead, the results should be used as a starting point for identifying examples of potential solid phase compounds that could accumulate within the coalescer/PF media.

\subsection{X-ray Diffraction (XRD)}

A summary of the solid-phase constituents identified by XRD is given in Table 6-2, and the corresponding XRD spectra are given in Figures 6-1, 6-2, and 6-3. Note that the polyphenylene sulfide compound identified in each XRD spectrum is the primary structural component of the coalescer/PF media. As such, it should not be considered a solid-phase compound accumulating during processing and/or contributing to coalescer/PF fouling.

Table 6-2. Summary of Constituents Identified by XRD

\begin{tabular}{|l||c|c|c|c||}
\hline $\begin{array}{l}\text { Sample } \\
\text { Descriptor }\end{array}$ & $\begin{array}{c}\mathrm{NaNO}_{3} \\
\text { (Nitratine) }\end{array}$ & $\begin{array}{c}\mathrm{NaNO}_{2} \\
\text { (Sodium Nitrite) }\end{array}$ & $\begin{array}{c}\mathrm{Na}_{2} \mathrm{CO}_{3} \cdot \mathrm{H}_{2} \mathrm{O} \\
\text { (Thermonatrite) }\end{array}$ & None \\
\hline \hline DSS PF & $\mathrm{X}$ & & & \\
\hline DSS Coalescer & $\mathrm{X}$ & $\mathrm{X}$ & $\mathrm{X}$ & $\mathrm{X}$ \\
\hline SE Coalescer & & & & \\
\hline
\end{tabular}

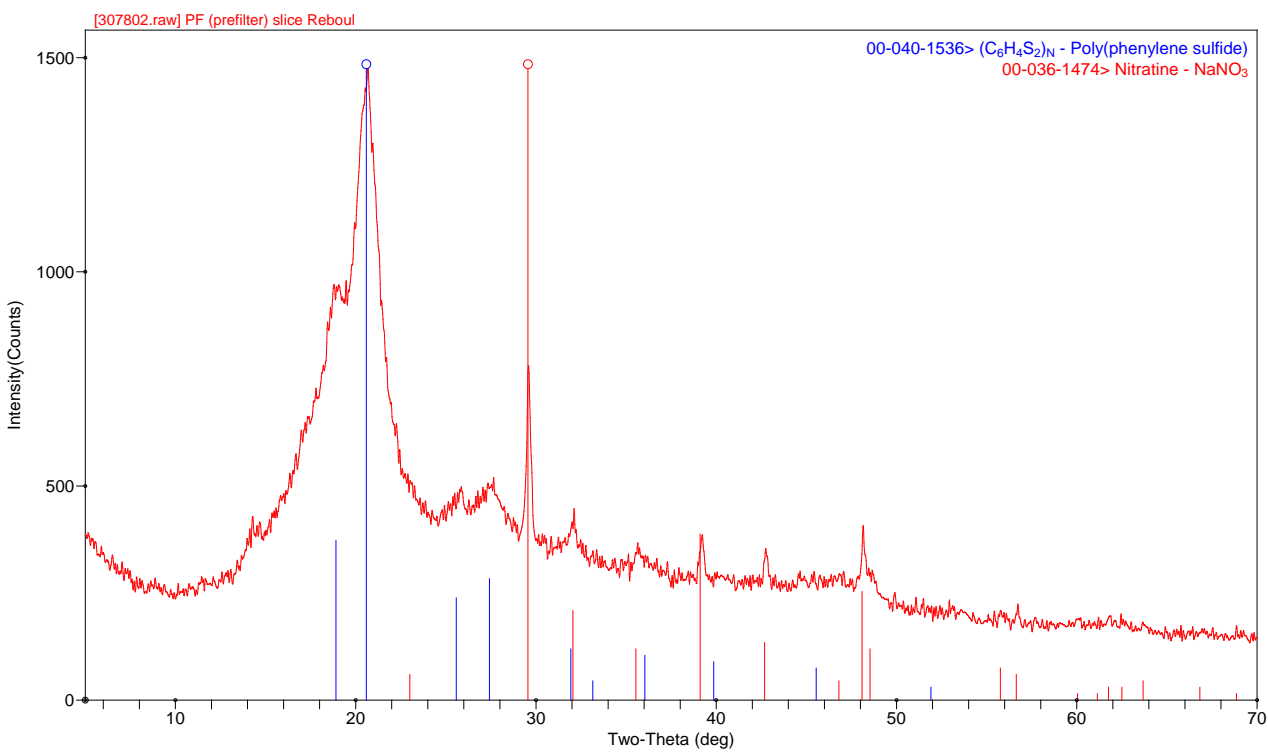

Figure 6-1. XRD Results for the DSS PF Sample 


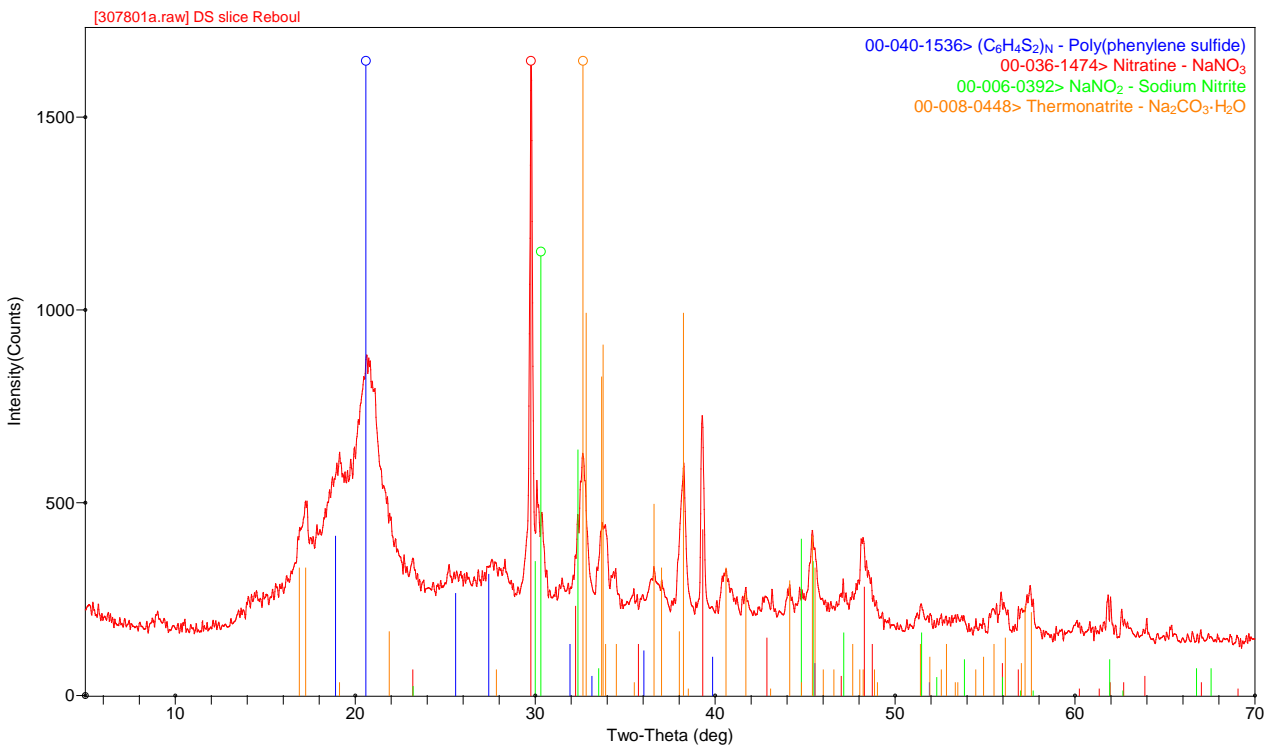

Figure 6-2. XRD Results for DSS Coalescer Sample

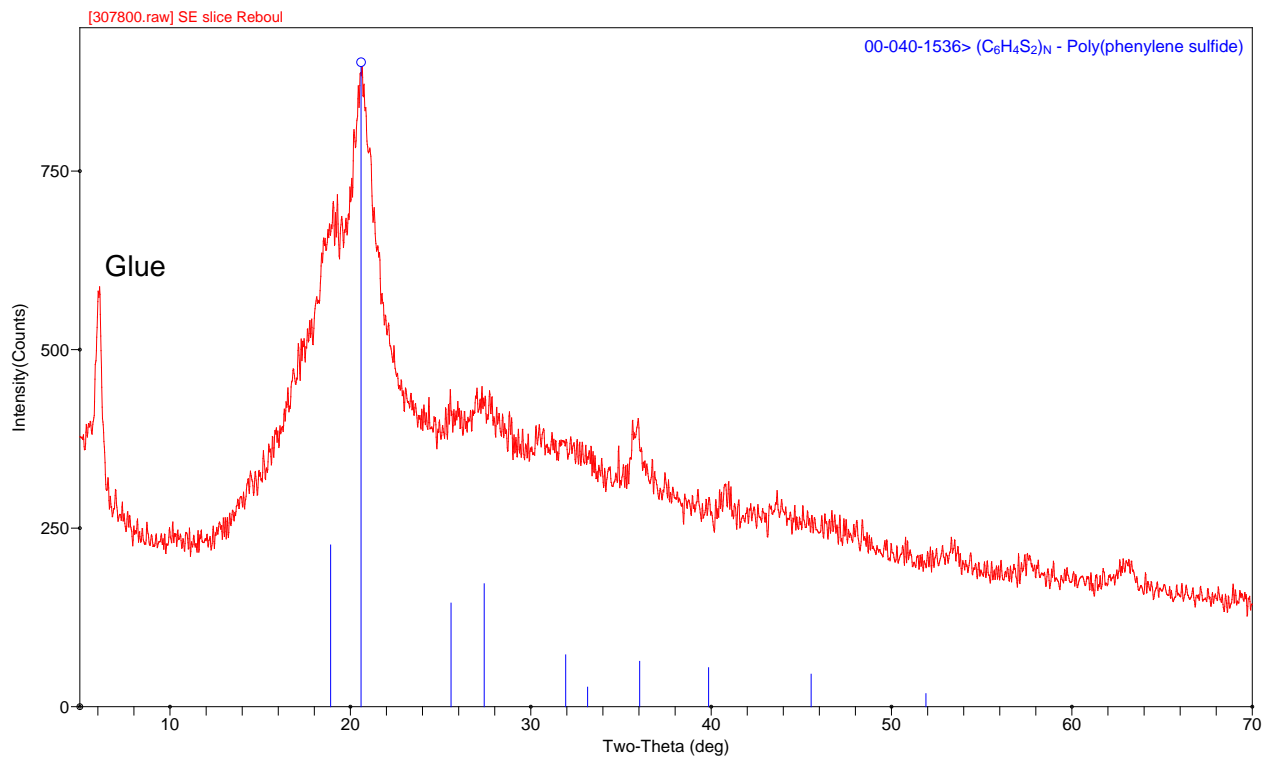

Figure 6-3. XRD Results for the SE Coalescer Sample

Sodium nitrate (nitratine) was the sole solid-phase constituent detected by XRD in the DSS PF sample. In contrast, three solid-phase constituents were detected in the DSS coalescer sample: sodium nitrate; sodium nitrite; and sodium carbonate monohydrate (thermonatrite). The existence of sodium nitrate and sodium carbonate monohydrate is consistent with expectations based on OLI modeling, given the conditions of the high hydroxide post-processing rinse. The existence of solid-phase sodium nitrite, although not predicted by modeling, is reasonable, given its presence in the DSS stream and the expectation that evaporation of water from the coalescer sample would result in residual sodium nitrite solids. 
Non-detection of the other solid-phase constituents predicted for the DSS stream (sodium oxalate, hexasodium carbonate disulfate, and hydroxysodalite dihydrate) does not necessarily mean that these constituents were absent from the samples, but it indicates that such constituents did not dominate the solids and/or were not present in crystalline form. Also, given the likely spatial variations associated with solids precipitating in $\mathrm{PF} /$ coalescer media, there is the understanding that concentrations of deposited solids in one segment of a given sample can be markedly different from those in another segment.

For the SE coalescer sample, no solid-phase constituents were detected by XRD. As discussed above, this non-detection does not assure the absence of solids - it merely indicates that solid-phase constituents were not present in high concentrations and/or that existing solids were non-crystalline.

\subsection{Fourier Transform Infrared (FTIR) Spectroscopy}

A summary of the constituents identified by FTIR is given in Table 6-3, with the supporting data presented in Figures 6-4, 6-5, and 6-6.

Table 6-3. Summary of Constituents Identified by FTIR

\begin{tabular}{|l||c|c|c|c|c|c||}
\hline $\begin{array}{l}\text { Sample } \\
\text { Descriptor }\end{array}$ & $\begin{array}{c}\mathrm{NaNO}_{3} \\
\text { (Nitratine) }\end{array}$ & $\begin{array}{c}\mathrm{NaNO}_{2} \\
\text { (Sodium Nitrite) }\end{array}$ & $\begin{array}{c}\mathrm{CO}_{3}-\mathrm{SO}_{4} \\
\text { (Natrone) }\end{array}$ & NAS & Modifier* & $\begin{array}{c}\text { sec- } \\
\text { butylphenol }\end{array}$ \\
\hline \hline DSS PF & $\mathrm{X}$ & $\mathrm{X}$ & $\mathrm{X}$ & $\mathrm{X}$ & & \\
\hline DSS Coalescer & $\mathrm{X}$ & $\mathrm{X}$ & & $\mathrm{X}$ & $\mathrm{X}$ & $\mathrm{X}$ \\
\hline SE Coalescer & & & & $\mathrm{X}$ & $\mathrm{X}$ & \\
\hline
\end{tabular}

*1-(2,2,3,3-Tetrafluoropropoxy)-3-(4-sec-butylphenoxy)-2-propanol

Four constituents were detected in the DSS PF sample: sodium nitrate (nitratine); sodium nitrite; a sodium carbonate and sodium sulfate mineral known as natrone; and NAS. Three of these constituents were also found in the DSS coalescer sample (sodium nitrate, sodium nitrite, and NAS), along with detectable quantities of the MCU modifier [1-(2,2,3,3-Tetrafluoropropoxy)-3-(4-sec-butylphenoxy)-2-propanol] and sec-butylphenol, a degradation product of the modifier. Non-detection of the organic compounds in the PF sample may be an artifact of the larger surface area of the PF making it more difficult to locate these species and therefore suggesting the abundance is low. Given the known process chemistry and the anticipated precipitation tendencies, all of the constituents identified by FTIR are consistent with expectations. Note that the OLI modeling identified a solid-phase hexasodium carbonate disulfate constituent that is chemically very similar to the natrone mineral. The approximate diameters of the NAS particles were: a) 20-30 $\mu \mathrm{m}$ in the DSS PF sample; and b) 3-4 $\mu \mathrm{m}$ in the DSS coalescer sample.

Three constituents were detected in the SE coalescer sample: NAS; MCU modifier; and sec-butylphenol. The existence of NAS, although not predicted by the modeling, is reasonable, given the widespread presence of NAS in MCU operations. Also reasonable is the presence of MCU modifier and secbutylphenol, given the known process chemistry. The diameters of the NAS particles were $\sim 10 \mu \mathrm{m}$ in the SE coalescer sample. 


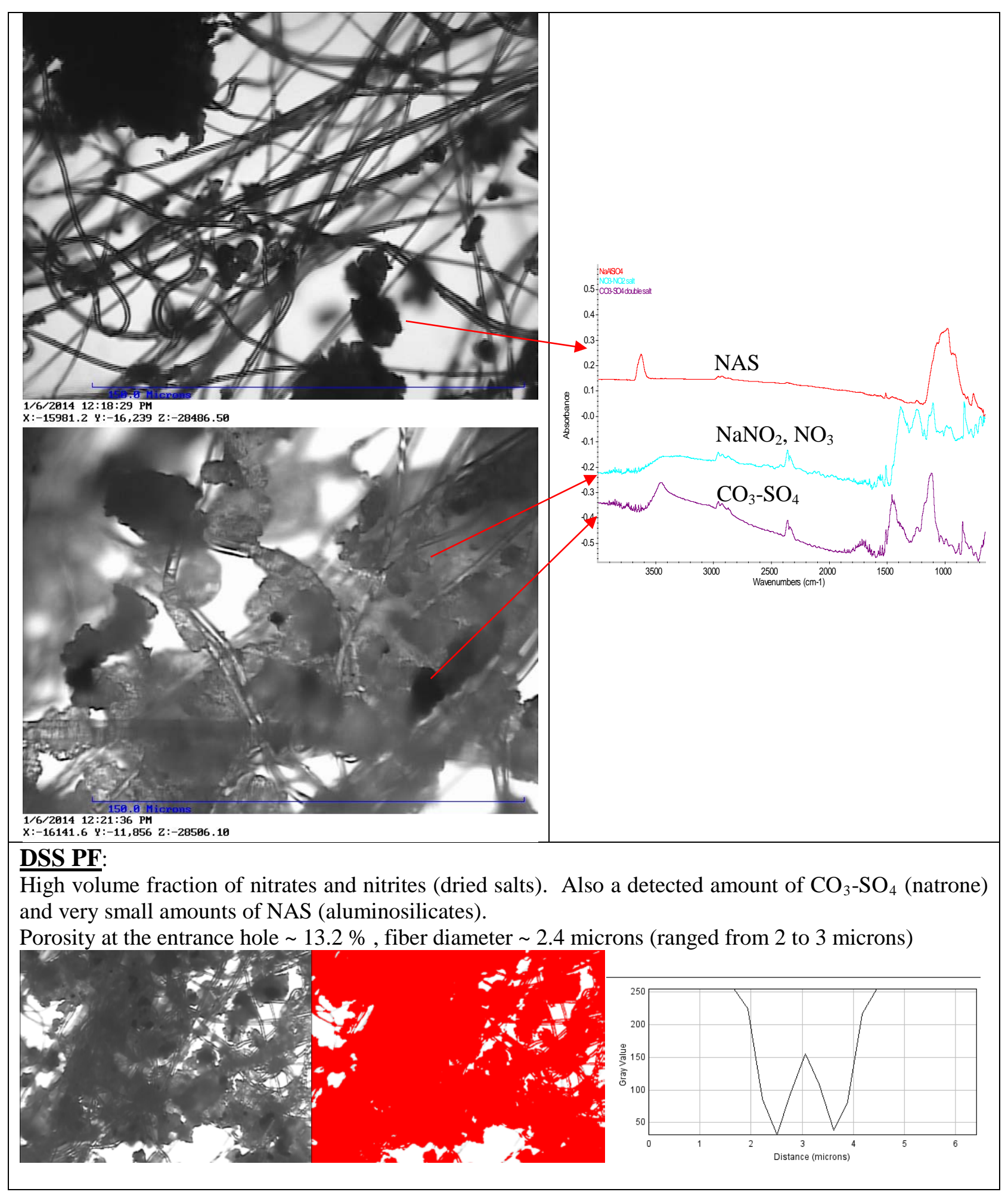

Figure 6-4. FTIR Results for the DSS PF Sample 


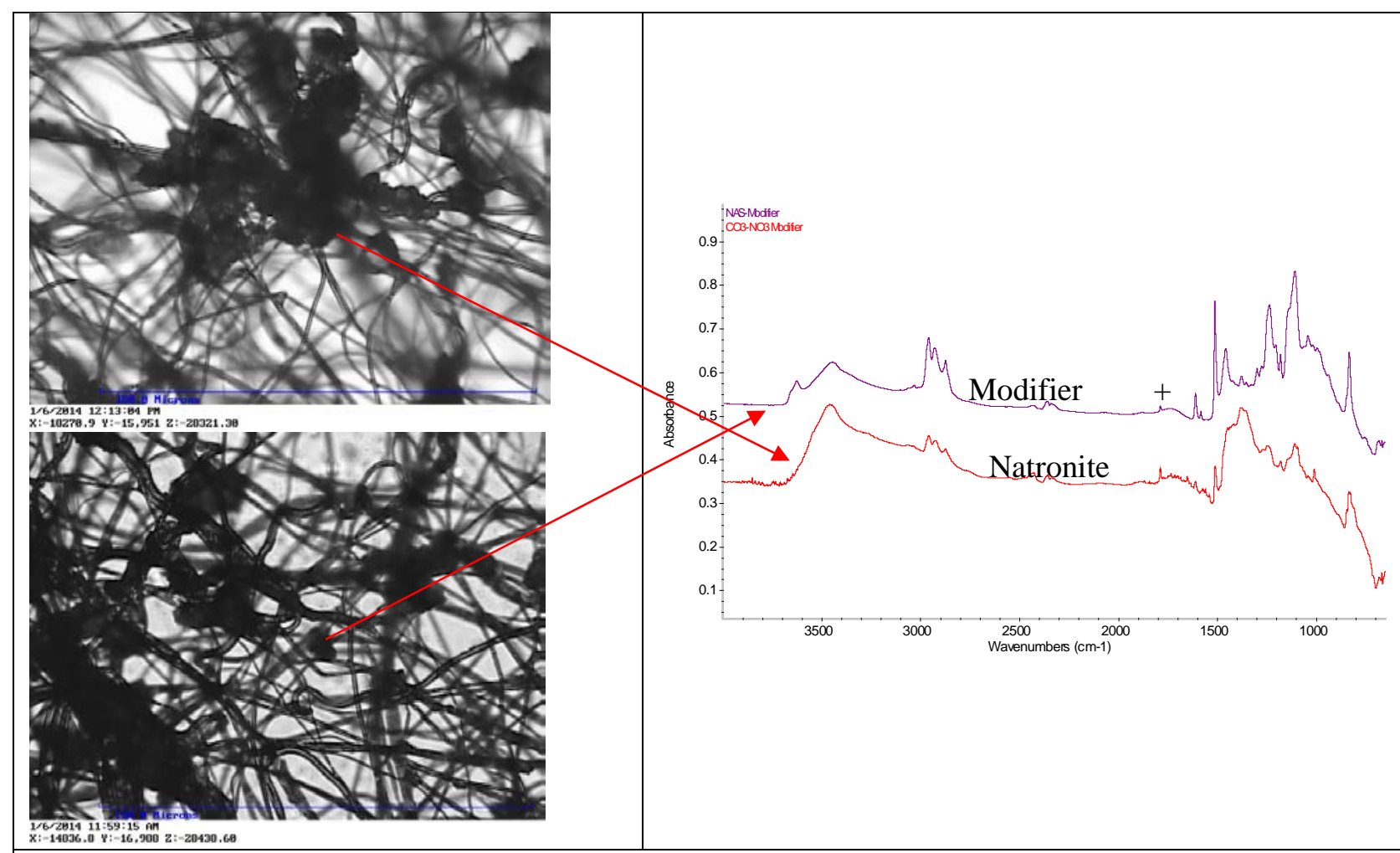

\section{DSS coalescer:}

Mostly nitrates and nitrites. Detectable amounts of modifier and a small amount of sec-butylphenol. Small amount of NAS was also seen.

Average fiber diameter: 2 microns. Lateral porosity at the coalescer entrance holes $\sim 36 \%$.

Lateral porosity away from the entrance holes (no solid deposited) 40\%.

Original image:
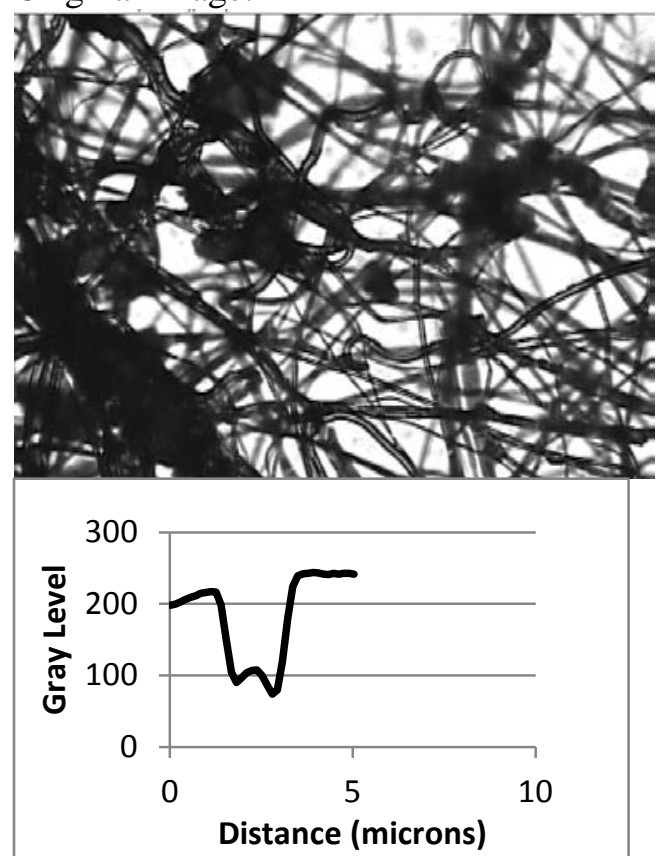

Figure 6-5. FTIR Results for the DSS Coalescer Sample 


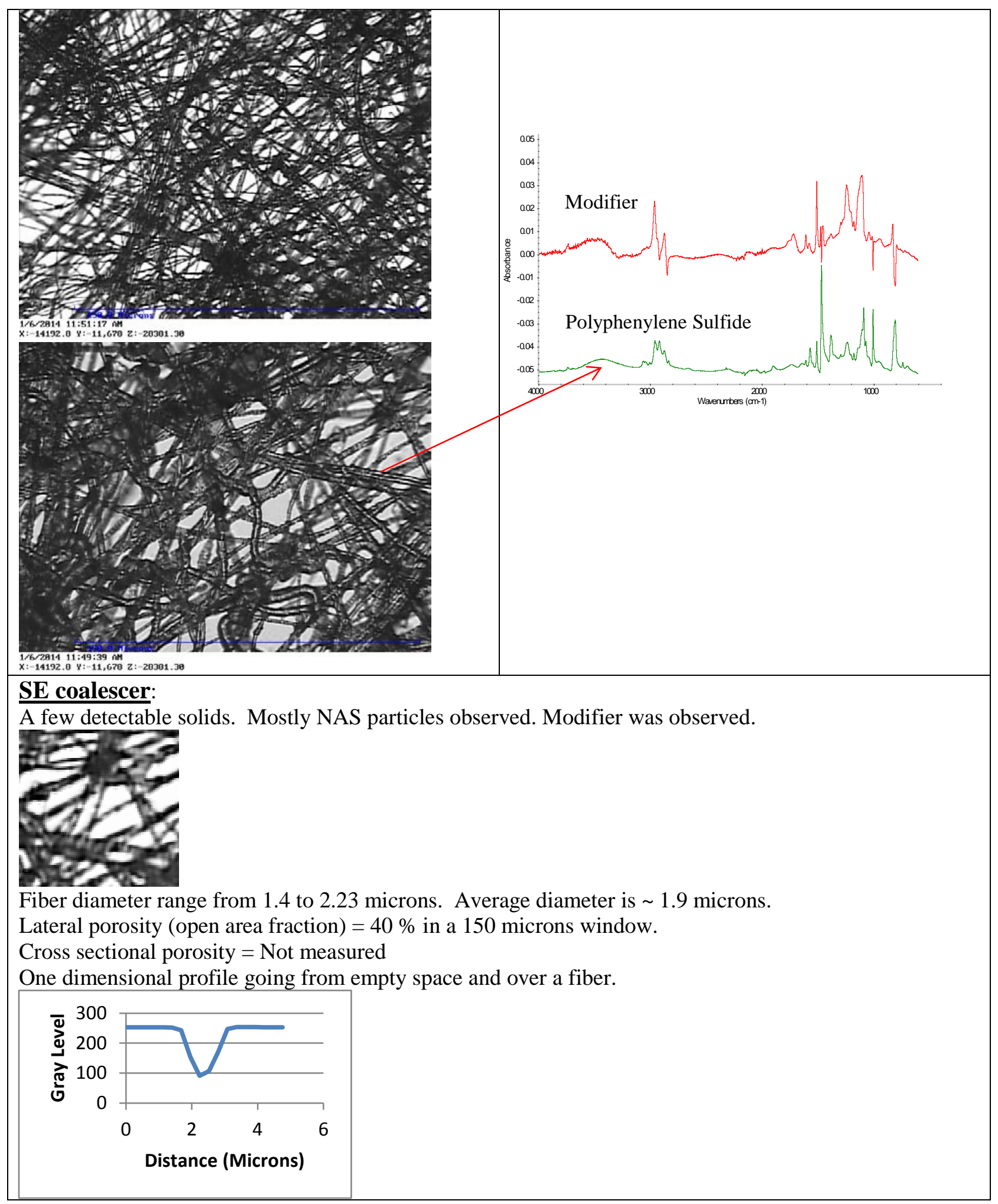

Figure 6-6. FTIR Results for the SE Coalescer Sample 
Lateral porosities of the DSS PF, DSS coalescer, and SE coalescer samples were estimated to be approximately 13, 36, and 51\%, respectively. (Lateral porosity refers to the porosity of the thinnest layer being observed along the X-Y scale. In this case, a 200 micron thick layer is being analyzed. Throughthickness porosity refers to porosity along the thickness direction of a "thick" sample). These porosities reflect the impacts of solids accumulation, as the porosities of unused PF/coalescer media are around 75\%. However, it is worthwhile to acknowledge that the porosities vary with location, the sample collection and preparation method can distort the surface, and the laboratory measurements were performed over a very limited set of conditions. As such, the measured porosities should not be considered representative of all PF/coalescer conditions. Furthermore, in the case of the DSS PF and DSS coalescer, the accumulated solids are highly a function of the rinsing conditions (10 M sodium hydroxide), so the porosities may be very different from those present prior to rinsing. Nonetheless, the reduced porosities demonstrate the impact of accumulated solids.

The average fiber diameter for all three coalescers (DSS, SE, and PF) was measured to be one micron. Previous coalescers (DSS and SE) had average diameters as large as six microns. ${ }^{5,6}$ When the fiber diameter is smaller, the coalescer will have lower porosity and will trap more droplets of smaller diameter. This means the effluent will have a lower concentration of suspended droplets, but at the cost of higher initial pressure drop as shown in Figures 4-1, 4-2, and 4-3. Based on the data, the pressure drops in the DSS and SE coalescers rise to the same extent in the same time period possibly indicating the same fouling mechanism in both coalescers. The most dominant pressure drop rise mechanism is the adsorption of oil onto the PPS fibers followed by the formation of water in oil (WO) emulsions on the PPS fibers. The time it takes to sorb oil on the fibers and to form a WO emulsion on these coalesce is about the same. Based on these data, the initial lateral porosity changed from $40 \%$ to about $13 \%$ and the volumetric porosity changed from $90 \%$ to $13 \%$ using the Kozeny-Carma equation. ${ }^{7}$ Oil sorption and WO emulsion formation accounts for a pressure drop rise to $12 \mathrm{psi}$. The remaining pressure drop rise from 13 to 20 (20 psi is the two sigma lower operation limit for coalesce operation at MCU) is accounted for by the solid deposits on the fibers. Solid deposits on fibrous media cannot be dislodged by flow reversal or pulsing. It requires chemical cleaning couple with thrusting hydrodynamics.

\subsection{Scanning Electron Microscopy (SEM)/Energy Dispersive Spectroscopy (EDS)}

A summary of the elemental constituents identified by EDS is given in Table 6-4, with the individual SEM images and EDS results presented in Appendices A, B, and C.

Table 6-4. Summary of Elements Identified by EDS

\begin{tabular}{|l||c|c|c|c|c|c|c|c|c|c|c|c|c|c|}
\hline \hline Sample Descriptor & $\mathrm{Al}$ & $\mathrm{C}$ & $\mathrm{Ca}$ & $\mathrm{Cr}$ & $\mathrm{Fe}$ & $\mathrm{K}$ & $\mathrm{Mg}$ & $\mathrm{Na}$ & $\mathrm{Ni}$ & $\mathrm{O}$ & $\mathrm{P}$ & $\mathrm{S}$ & $\mathrm{Si}$ & $\mathrm{Ti}$ \\
\hline \hline DSS PF & $\mathrm{X}$ & $\mathrm{X}$ & $\mathrm{X}$ & $\mathrm{X}$ & $\mathrm{X}$ & $\mathrm{X}$ & $\mathrm{X}$ & $\mathrm{X}$ & $\mathrm{X}$ & $\mathrm{X}$ & & $\mathrm{X}$ & $\mathrm{X}$ & $\mathrm{X}$ \\
\hline DSS Coalescer & $\mathrm{X}$ & $\mathrm{X}$ & & & $\mathrm{X}$ & $\mathrm{X}$ & & $\mathrm{X}$ & & $\mathrm{X}$ & & $\mathrm{X}$ & $\mathrm{X}$ & $\mathrm{X}$ \\
\hline SE Coalescer & $\mathrm{X}$ & $\mathrm{X}$ & & $\mathrm{X}$ & $\mathrm{X}$ & $\mathrm{X}$ & & & $\mathrm{X}$ & $\mathrm{X}$ & $\mathrm{X}$ & $\mathrm{X}$ & $\mathrm{X}$ & $\mathrm{X}$ \\
\hline
\end{tabular}

Based on results of the EDS analyses, a relatively broad suite of elemental constituents was identified. Several elements were detected in all three samples, including $\mathrm{Al}, \mathrm{C}, \mathrm{Fe}, \mathrm{K}, \mathrm{O}, \mathrm{S}, \mathrm{Si}$, and Ti, all normal constituents of salt waste. Note that a dominant source of the carbon and sulfur is the polyphenylene sulfide comprising the coalescer/PF support medium. Additional elements that were detected in the DSS PF sample included $\mathrm{Ca}, \mathrm{Cr}, \mathrm{Mg}, \mathrm{Na}$, and $\mathrm{Ni}$. The only additional element that was detected in the DSS coalescer sample was Na. In contrast, the only additional elements detected in the SE coalescer sample were $\mathrm{Cr}, \mathrm{Ni}$, and $\mathrm{P}$.

The fact that more constituents were detected in the DSS PF sample than the DSS coalescer sample is to be expected, since the purpose of the PF is to remove insoluble constituents prior to the DSS coalescer. 
Such insoluble constituents could be suspended sludge particles present as a result of solids carryover and/or stainless steel metal fines generated through mechanical operations. Elements such as $\mathrm{Ca}$ and $\mathrm{Mg}$ are likely present in DSS as insoluble carbonate salts, while elements such as $\mathrm{Cr}$ and Ni may be introduced into DSS and SE solution through introduction of stainless steel fines. Phosphorous is typically undetectable in the SE stream, but may participate in reactions that generate measurable quantities of insoluble phosphate compounds over time.

Based on the SEM images, it is clear that all three of the PF/coalescer samples (DSS PF, DSS coalescer, and SE coalescer) have regions containing major solids accumulations and other regions containing only minor solids accumulations. This large observed range of accumulation is consistent with the expectation that deposits of solids within PF/coalescer media vary with location. In the cases where the solids accumulations are major, the high volume of solids appear to overwhelm the PF/coalescer media fibers, leaving only small cavities of open space for fluid to flow - in other words, significantly reduced porosities. In contrast, in the cases where the solids accumulations are minor, the solids can be seen as individual particles clinging to fibers, with only slight reductions in porosity expected.

\subsection{Inductively Coupled Atomic Emission Spectroscopy (ICP-AES) of PF/Coalescer Leachates}

A summary of the most dominant metals found in the PF/coalescer leachate solutions at the end of the leaching period ( $\mathrm{t}=28$ days) is given in Table 6-5. For the DSS PF and DSS coalescer leachates, the relative concentrations of the dominating metals were: $\mathrm{Na}>>\mathrm{Ti}>\mathrm{Al}>\mathrm{Fe}$. In contrast, for the $\mathrm{SE}$ coalescer leachate, the relative concentrations of the dominating metals were: $\mathrm{Fe}>\mathrm{Ti}>\mathrm{Na}>\mathrm{Al}$. Clearly, the differences in relative constituent abundances were due to a combination of the $\mathrm{pH}$ effects (high $\mathrm{pH}$ for the DSS and low pH for the SE stream) and the compositional differences between the DSS and the SE solution. Regardless, the dominance of these four metals reflects the contributions of salt waste (Na and $\mathrm{Al}$ ), MST (Ti), sludge (Fe and $\mathrm{Al}$ ), and/or steel fines (Fe).

Table 6-5. Dominant Metals in Leachates

\begin{tabular}{|l||c|c|c|c||}
\hline \multicolumn{1}{|l||}{$\begin{array}{l}\text { Sample } \\
\text { Descriptor }\end{array}$} & \multicolumn{4}{|c|}{ Metal Concentration, $\mathrm{mg} / \mathrm{L}(\mathrm{t}=28$ days $)$} \\
\cline { 2 - 5 } & $\mathrm{Na}$ & $\mathrm{Ti}$ & $\mathrm{Al}$ & $\mathrm{Fe}$ \\
\hline \hline DSS PF & 2200 & 170 & 95 & 33 \\
\hline DSS Coalescer & 7800 & 660 & 430 & 81 \\
\hline SE Coalescer & 13 & 16 & 10 & 31 \\
\hline \hline
\end{tabular}

A complete listing of the ICP-AES results, for all of the elemental constituents measured, is given as a function of the leaching time in Table 6-6. Additionally, graphical depictions of the major constituent concentrations as functions of the leaching time are given in Figures 6-7, 6-8, and 6-9. 
Table 6-6. Elemental Constituent Concentrations in DSS PF, DSS Coalescer, and SE Coalescer Leachates

\begin{tabular}{|c|c|c|c|c|c|c|c|c|c|c|c|c|}
\hline \multirow{3}{*}{ Element } & \multicolumn{12}{|c|}{ Concentration, mg/L } \\
\hline & \multicolumn{4}{|c|}{ PF Leachate } & \multicolumn{4}{|c|}{ DSS Coalescer Leachate } & \multicolumn{4}{|c|}{ SE Coalescer Leachate } \\
\hline & $t=1$ day & $t=7$ days & $t=14$ days & $t=28$ days & $t=1$ day & $t=7$ days & $t=14$ days & $t=28$ days & $t=1$ day & $t=7$ days & $t=14$ days & $t=28$ days \\
\hline $\mathrm{Ag}$ & $<<0.135$ & $<<0.135$ & $<0.135$ & $<<0.135$ & $<<0.135$ & $<<0.135$ & $<0.135$ & $<0.135$ & $<0.0680$ & $<0.0680$ & $<<0.0680$ & $<<0.0680$ \\
\hline $\mathrm{Al}$ & 89.2 & 93.7 & 95.2 & 95.1 & 460 & 434 & 431 & 432 & 6.12 & 9.12 & 9.85 & 10.2 \\
\hline $\mathrm{B}$ & 0.796 & 0.733 & 0.753 & 0.737 & 3.00 & 2.77 & 2.78 & 2.73 & $<0.267$ & $<0.267$ & $<0.267$ & $<0.267$ \\
\hline $\mathrm{Ba}$ & 0.889 & 0.690 & 0.703 & 0.691 & 1.06 & 1.01 & 1.01 & 1.02 & 0.0520 & 0.104 & 0.123 & 0.147 \\
\hline $\mathrm{Be}$ & $<0.0100$ & $<0.0100$ & $<0.0100$ & $<0.0100$ & 0.0250 & 0.0260 & 0.0250 & 0.0260 & $<0.00500$ & $<0.00500$ & $<0.00500$ & $<0.00500$ \\
\hline $\mathrm{Ca}$ & 15.0 & 14.8 & 15.1 & 15.2 & 31.2 & 28.7 & 28.5 & 28.6 & 0.566 & 0.688 & 0.668 & 0.659 \\
\hline $\mathrm{Cd}$ & 2.70 & 2.73 & 2.79 & 2.81 & 7.41 & 6.81 & 6.77 & 6.81 & $<0.070$ & $<0.0700$ & $<0.0700$ & $<0.0700$ \\
\hline $\mathrm{Ce}$ & $<1.13$ & $<1.13$ & $<1.13$ & $<1.13$ & $<1.13$ & $<1.13$ & $<1.13$ & $<1.13$ & $<0.566$ & $<0.566$ & $<0.566$ & $<0.566$ \\
\hline Co & 2.42 & 2.41 & 2.44 & 2.43 & 1.44 & 1.50 & 1.49 & 1.51 & $<0.120$ & 0.118 & 0.132 & 0.140 \\
\hline $\mathrm{Cr}$ & 12.1 & 12.5 & 12.7 & 12.7 & 25.2 & 25.4 & 25.5 & 25.7 & 1.17 & 1.85 & 2.21 & 2.51 \\
\hline $\mathrm{Cu}$ & 1.29 & 1.32 & 1.32 & 1.32 & 3.41 & 3.28 & 4.12 & 3.24 & $<0.138$ & $<0.138$ & 0.124 & 0.137 \\
\hline $\mathrm{Fe}$ & 29.5 & 30.6 & 32.2 & 32.5 & 76.3 & 78.9 & 80.0 & 81.2 & 11.4 & 25.0 & 29.2 & 31.1 \\
\hline $\mathrm{Gd}$ & $<0.572$ & $<0.572$ & $<0.572$ & $<0.572$ & $<0.572$ & $<0.572$ & $<0.572$ & $<0.572$ & $<0.286$ & $<0.286$ & $<0.286$ & $<0.286$ \\
\hline $\mathrm{K}$ & 6.43 & 6.03 & 6.39 & 5.53 & 22.2 & 21.6 & 21.5 & 22.1 & $<2.60$ & $<2.60$ & $<2.60$ & $<2.60$ \\
\hline $\mathrm{La}$ & $<0.142$ & $<0.142$ & $<0.142$ & $<0.142$ & $<0.142$ & $<0.142$ & $<0.142$ & $<0.142$ & $<0.0710$ & $<0.0710$ & $<0.0710$ & $<0.0710$ \\
\hline $\mathrm{Li}$ & 3.17 & 3.12 & 2.90 & 3.12 & 18.2 & 17.6 & 15.7 & 17.3 & $<0.914$ & $<0.914$ & $<0.914$ & $<0.914$ \\
\hline $\mathrm{Mg}$ & 20.8 & 21.0 & 21.3 & 21.1 & 17.5 & 16.0 & 16.0 & 16.1 & $<0.482$ & $<0.482$ & $<0.482$ & $<0.482$ \\
\hline $\mathrm{Mn}$ & 0.507 & 0.497 & 0.510 & 0.513 & 0.581 & 0.614 & 0.647 & 0.641 & 0.0848 & 0.231 & 0.271 & 0.284 \\
\hline Mo & $<1.49$ & $<1.49$ & $<1.49$ & $<1.49$ & $<1.49$ & $<1.49$ & $<1.49$ & $<1.49$ & $<0.747$ & $<0.747$ & $<0.747$ & $<0.747$ \\
\hline $\mathrm{Na}$ & 2120 & 2160 & 2170 & 2170 & 8490 & 7880 & 7650 & 7840 & 11.2 & 11.3 & 11.5 & 12.7 \\
\hline $\mathrm{Ni}$ & 13.9 & 14.3 & 14.5 & 14.4 & 23.8 & 22.7 & 22.8 & 23.0 & 1.01 & 2.89 & 3.50 & 3.89 \\
\hline $\mathrm{P}$ & 9.38 & 10.4 & 10.7 & 10.8 & 23.6 & 26.9 & 27.5 & 28.2 & 2.86 & 4.82 & 5.42 & 5.58 \\
\hline $\mathrm{Pb}$ & $<14.7$ & $<14.7$ & $<14.7$ & $<14.7$ & $<14.7$ & $<14.7$ & $<14.7$ & $<14.7$ & $<7.36$ & $<7.36$ & $<7.36$ & $<7.36$ \\
\hline$S$ & $<150$ & $<150$ & $<150$ & $<150$ & 137 & 125 & $<150$ & $<150$ & $<75.0$ & $<75.0$ & $<75.0$ & $<75.0$ \\
\hline $\mathrm{Sb}$ & $<2.90$ & $<2.90$ & $<2.90$ & $<2.90$ & $<2.90$ & $<2.90$ & $<2.90$ & $<2.90$ & $<1.45$ & $<1.45$ & $<1.45$ & $<1.45$ \\
\hline $\mathrm{Si}$ & 2.86 & 3.28 & 3.46 & 3.68 & 16.9 & 17.2 & 17.3 & 17.2 & $<0.967$ & $<0.967$ & $<0.967$ & 1.08 \\
\hline Sn & 15.6 & 16.1 & 17.4 & 17.5 & 28.2 & 27.6 & 28.3 & 28.9 & 5.13 & 11.1 & 13.1 & 14.2 \\
\hline $\mathrm{Sr}$ & $<1.49$ & $<1.49$ & $<1.49$ & $<1.49$ & $<1.49$ & $<1.49$ & $<1.49$ & $<1.49$ & $<0.746$ & $<0.746$ & $<0.746$ & $<0.746$ \\
\hline Th & 25.5 & 25.5 & 24.7 & 24.9 & 17.5 & 18.8 & 16.7 & 18.8 & $<0.596$ & $<0.596$ & $<0.596$ & $<0.596$ \\
\hline $\mathrm{Ti}$ & 162 & 164 & 166 & 165 & 618 & 660 & 656 & 658 & 13.8 & 15.3 & 15.6 & 15.7 \\
\hline $\mathrm{U}$ & 10.1 & 8.82 & 9.04 & 7.41 & 26.6 & 26.5 & 26.0 & 26.0 & $<3.46$ & $<3.46$ & $<3.46$ & $<3.46$ \\
\hline $\mathrm{V}$ & $<0.0710$ & $<0.0710$ & $<0.0710$ & $<0.0710$ & $<0.0710$ & $<0.0710$ & $<0.0710$ & $<0.0710$ & $<0.0360$ & $<0.0360$ & $<0.0360$ & $<0.0360$ \\
\hline $\mathrm{Zn}$ & 2.84 & 2.98 & 3.02 & 3.03 & 3.00 & 2.82 & 3.34 & 2.83 & 0.219 & 0.270 & 0.273 & 0.258 \\
\hline $\mathrm{Zr}$ & 1.75 & 1.85 & 1.82 & 1.73 & 8.69 & 9.27 & 9.16 & 9.02 & $<1.10$ & $<1.10$ & $<1.10$ & $<1.10$ \\
\hline
\end{tabular}




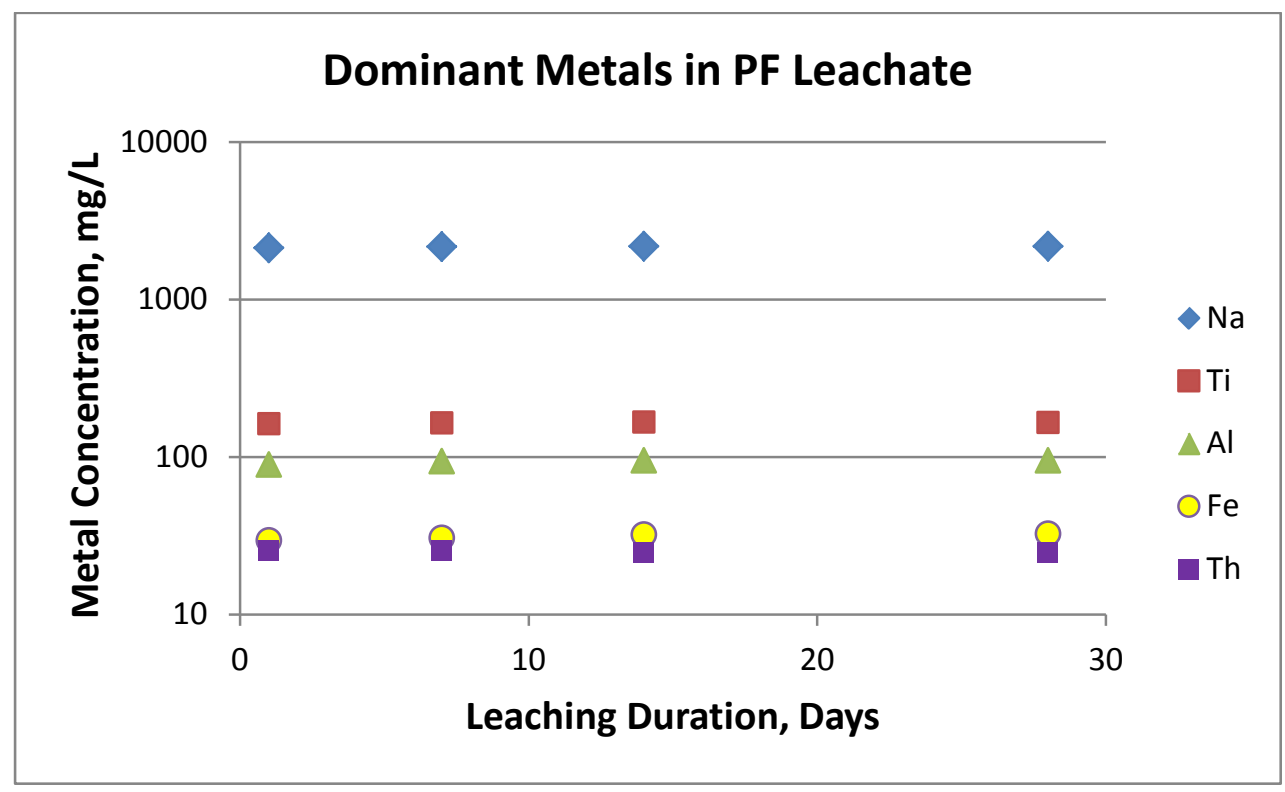

Figure 6-7. Dominant Metals in DSS PF Leachate

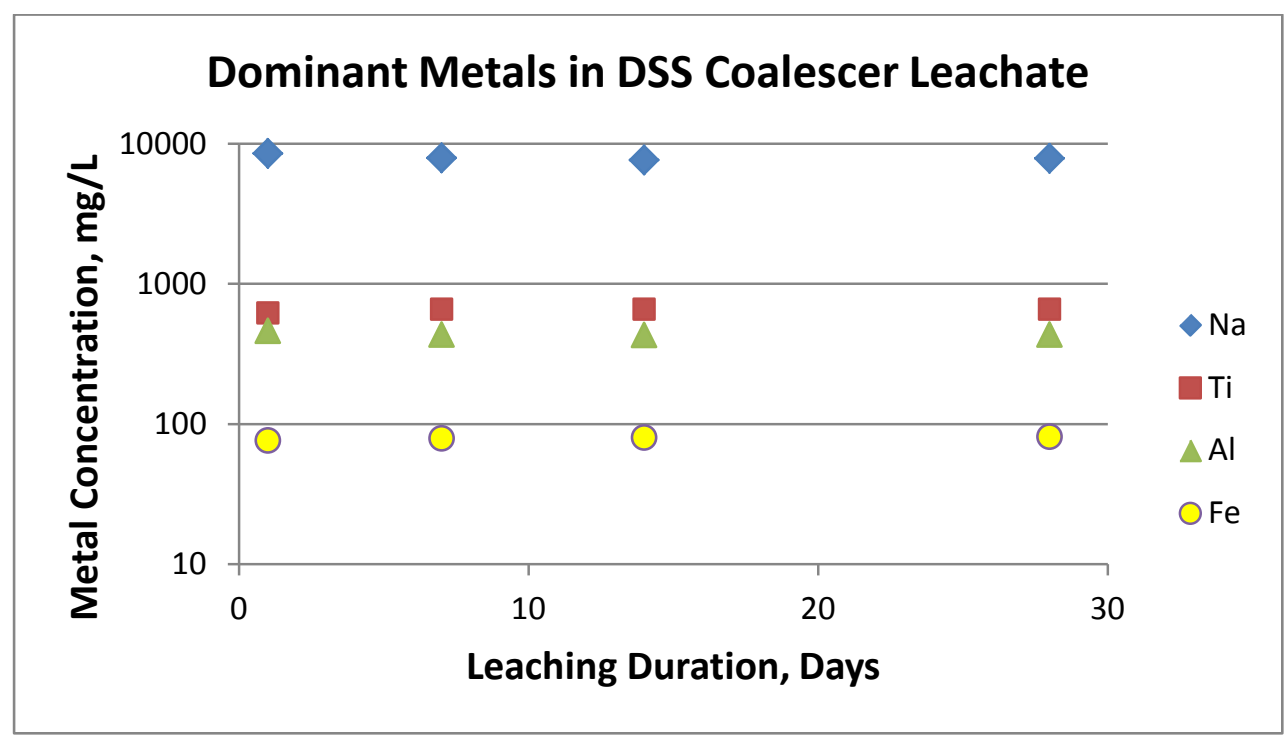

Figure 6-8. Dominant Metals in DSS Coalescer Leachate 


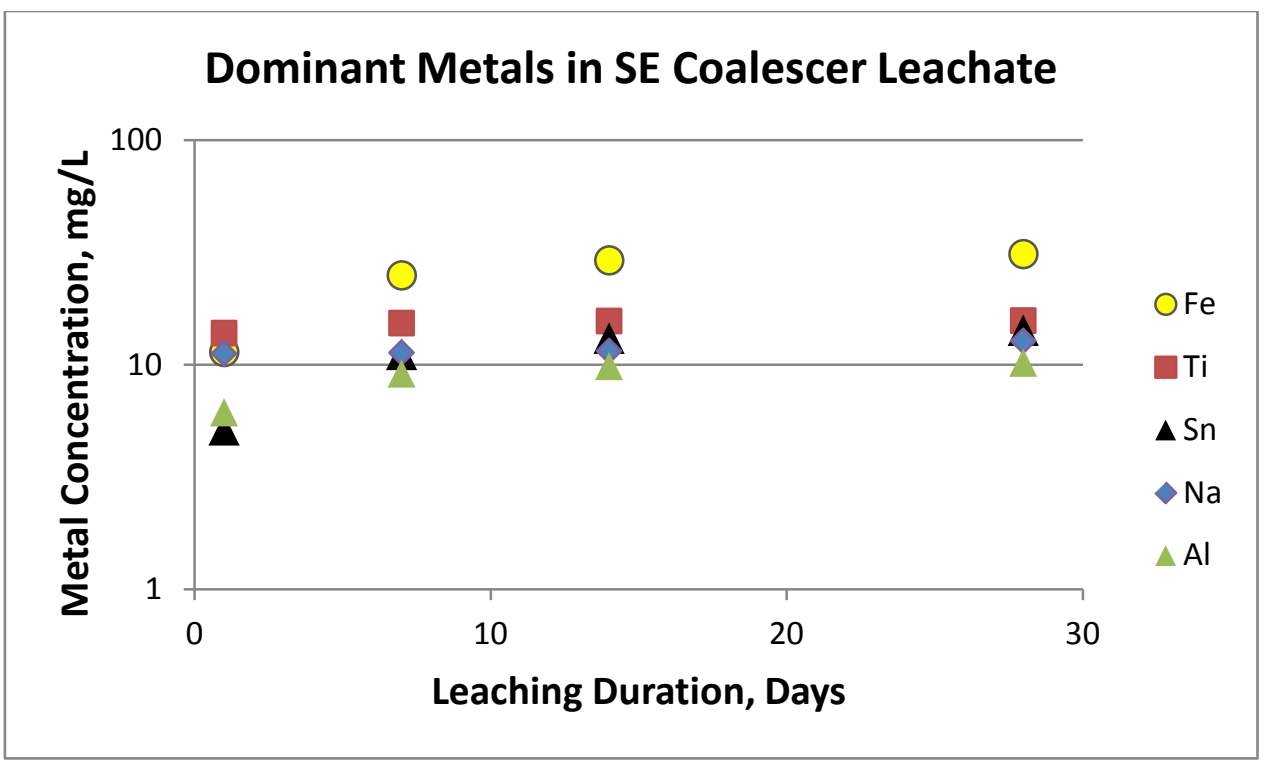

Figure 6-9. Dominant Metals in SE Coalescer Leachate

As shown in Figures 6-7 and 6-8, the leach rates of the major constituents in the DSS PF and DSS coalescer samples were relatively quick, with maximum concentrations being attained by the end of the first leaching period ( $t=1$ day). In both cases, the relative concentrations of the major constituents followed the same general trends, although individual concentrations varied from the DSS PF sample to the DSS coalescer sample. These differences were attributed to spatial variations within the samples, as opposed to clear differences between the sample contents. One point worth noting is the relative quantity of Th in the DSS PF leachate, where it is the fifth most dominant elemental constituent, with a concentration about one-ninetieth that of the Na concentration. In contrast, in the DSS coalescer leachate, Th is the twelfth most dominant constituent, with a concentration about one-four hundreth that of the $\mathrm{Na}$ concentration. This difference suggests that a large portion of the Th was present in the form of suspended insoluble solids, which were captured by the PF and thus absent from the DSS coalescer media.

As shown in Figure 6-9, the leach rates of the major constituents in the SE coalescer were not as rapid as those of the DSS PF and DSS coalescer, with the SE constituents typically requiring 14-28 days to reach maximum concentrations in the leachate solution. This suggests the constituents in the SE coalescer were more refractory and thus would be potentially more difficult to remove via on-line cleaning operations. When comparing the SE coalescer leachates to those of the DSS PF/coalescer leachates, one important difference to note is the high relative dominance of $\mathrm{Sn}$ in the SE coalescer leachate case. As shown in Table 6-6, Sn was the third most dominant elemental constituent in the SE coalescer leachate, as opposed to being seventh in the DSS PF leachate and fifth in the DSS coalescer leachate. Such dominance may be reflective of chemical interactions occurring between the acidic SE stream and the material such as solder present in the SE processing piping/hardware.

Ratios of the elemental concentrations in the DSS coalescer leachate to those in the DSS PF leachate are given in Table 6-7, along with the relative magnitudes of the ratios. These ratios were calculated based on the average element concentrations observed over the 1-28 day leaching period. For constituents that are highly soluble (Al, B, K, Li, Na, Si, Ti, and $\mathrm{Zr}$ ), the magnitudes of the ratios are relatively high (3.65.6). In contrast, for constituents that are less soluble (Ba, Ca, Co, Cr, Mg, Mn, Ni, Sn, Th, and Zn), the magnitudes of the ratios are relatively low (0.61-2.0). Based on the differences between the ratios, it is concluded that more of the less soluble constituents were captured in the DSS PF than in the DSS coalescer. This is consistent with expectations, given that the purpose of the PF is to remove insoluble solids from the DSS prior to the coalescer. 
Table 6-7. Ratios of Elemental Concentrations in DSS Coalescer Leachate to those in PF Leachate

\begin{tabular}{|l|c|c|c|c||}
\hline \multirow{2}{*}{ Element } & \multirow{2}{*}{$\begin{array}{c}\text { Mean } \\
\text { Conc. Ratio }\end{array}$} & \multicolumn{3}{|c|}{ Relative Magnitude } \\
\cline { 3 - 5 } & 4.7 & High & Med & Low \\
\hline $\mathrm{Al}$ & 3.7 & $\mathrm{X}$ & & \\
\hline $\mathrm{B}$ & 1.4 & & & $\mathrm{X}$ \\
\hline $\mathrm{Ba}$ & 1.9 & & & $\mathrm{X}$ \\
\hline $\mathrm{Ca}$ & 2.5 & & $\mathrm{X}$ & \\
\hline $\mathrm{Cd}$ & 0.61 & & & $\mathrm{X}$ \\
\hline $\mathrm{Co}$ & 2.0 & & & $\mathrm{X}$ \\
\hline $\mathrm{Cr}$ & 2.7 & & $\mathrm{X}$ & \\
\hline $\mathrm{Cu}$ & 2.5 & & $\mathrm{X}$ & \\
\hline $\mathrm{Fe}$ & 3.6 & $\mathrm{X}$ & & \\
\hline $\mathrm{K}$ & 5.6 & $\mathrm{X}$ & & \\
\hline $\mathrm{Li}$ & 0.78 & & & $\mathrm{X}$ \\
\hline $\mathrm{Mg}$ & 1.2 & & & $\mathrm{X}$ \\
\hline $\mathrm{Mn}$ & 3.7 & $\mathrm{X}$ & & \\
\hline $\mathrm{Na}$ & 1.6 & & & $\mathrm{X}$ \\
\hline $\mathrm{Ni}$ & 2.6 & & $\mathrm{X}$ & \\
\hline $\mathrm{P}$ & 5.2 & $\mathrm{X}$ & & \\
\hline $\mathrm{Si}$ & 1.7 & & & $\mathrm{X}$ \\
\hline $\mathrm{Sn}$ & 0.71 & & & $\mathrm{X}$ \\
\hline $\mathrm{Th}$ & 3.9 & $\mathrm{X}$ & & \\
\hline $\mathrm{Ti}$ & 3.0 & & $\mathrm{X}$ & \\
\hline $\mathrm{U}$ & 1.0 & & & $\mathrm{X}$ \\
\hline $\mathrm{Zn}$ & 5.1 & $\mathrm{X}$ & & \\
\hline $\mathrm{Zr}$ & & & & \\
\hline
\end{tabular}

\subsection{Integration of Results}

\section{DSS PF Sample}

The primary constituents identified in the DSS PF sample included: a) sodium nitrate; b) hexasodium carbonate disulfate; c) sodium nitrite; d) components associated with MST; e) entrained sludge particles and stainless steel fines; and f) NAS. Note that the hexasodium carbonate disulfate is an artifact of the high hydroxide rinse. As such, this compound would not be expected to be present during normal PF operations (in the absence of the high hydroxide rinse).

Solid phase aluminum hydroxide was not identified in the PF sample, although it was expected to be present prior to rinsing with the high hydroxide solution. The absence of aluminum hydroxide is attributed to the effectiveness of the high caustic rinse solution as an aluminum dissolution agent.

Solid phase sodium oxalate was not detected in the PF sample, although it was likely present, albeit possibly at low concentrations and/or in an amorphous form (as opposed to a crystalline form). If identification of sodium oxalate is targeted in future characterizations, it would be worthwhile to supplement the standard suite of analyses with ion chromatography of water leachates. 


\section{DSS Coalescer Sample}

The primary constituents identified in the DSS coalescer sample included: a) sodium nitrate (which was also detected in the PF sample); b)sodium carbonate (which was not detected in the PF sample); c) sodium nitrite; d) components associated with MST, entrained sludge, and stainless steel fines (it is assumed that some portion of the components partitioned to the liquid phase, facilitating migration to the coalescers); e) NAS; and f) MCU modifier and modifier degradation product. Note that solid phase sodium carbonate is an artifact of the high hydroxide rinse. As such, this compound would not be expected to be present in the solid phase during normal DSS coalescer operations (in the absence of the high hydroxide rinse). However, following normal operations at low hydroxide concentrations, any existing liquid phase sodium carbonate would transition to solid phase sodium carbonate as water evaporates.

As in the PF sample case, solid phase aluminum hydroxide was not detected in the DSS coalescer sample, but was presumed to be present prior to rinsing with the high hydroxide solution. Also as in the PF sample case, solid phase sodium oxalate was not detected in the DSS coalescer sample, but was likely present, although not in a concentration/form conducive to the solid phase analytical techniques.

\section{SE Coalescer Sample}

The primary constituents identified in the SE coalescer sample include: a) components associated with entrained sludge particles, stainless steel fines, and MST; b) components possibly associated with solder; c) NAS; and d) MCU modifier. Although not identified by the solid phase analytical techniques, silica and iron oxide may be two of the compounds accumulating within the SE coalescer.

\subsection{Potential Treatment Options for Cleaning Fouled PF/Coalescer Media}

Given the range of compounds depositing within the PF/coalescer media, it is unlikely that a single cleaning agent will be capable of dissolving/removing all constituents fouling the PF/coalescer media. Instead, it is likely that multiple cleaning agents, introduced sequentially, would be necessary to remove sufficient deposition to have a significant impact on the rising pressure drops.

Based on the compounds identified, a potentially effective treatment approach may well require use of: a) a high $\mathrm{pH}$ solution for dissolving compounds such as aluminum hydroxide; b) a moderate $\mathrm{pH}$, low ionic strength solution for dissolving compounds such as sodium oxalate; c) a low $\mathrm{pH}$ solution for removing compounds such as NAS; and d) an organic solvent for removing compounds such as MCU modifier and degradation products. Discussions of the application of sodium hydroxide for dissolving aluminum hydroxide, low ionic strength aqueous solutions for dissolving sodium oxalate, and various inorganic and organic compounds for dissolving other typical solid-phase waste constituents (ones containing iron, aluminum, silicon, titanium, and other common waste constituents) are presented in various SRS technical documents. ${ }^{8,9,10,11}$

Of course, if the majority of deposition is due to one or two key compounds, there is the potential for limiting the range of cleaning solutions. However, regardless of the number of key compounds, it is expected that testing will be required to develop and optimize an effective treatment approach. Despite the unmistakable evidence of PF/coalescer fouling, it is possible that solids removal will not reduce the pressure drops of fouled PF/coalescer media to levels of new media. Clearly, the effectiveness of any such cleaning strategy will need to be demonstrated prior to implementation. 


\subsection{Conclusions}

1) Fouling of the DSS PF was most likely due to accumulations of:

- Aluminum hydroxide (species based on modeling results; Al based on analytical results)

- Sodium oxalate (based on modeling results)

- MST-related constituents (based on analytical results)

- Entrained sludge particles and stainless steel fines (based on analytical results)

- $\quad$ NAS compounds (based on modeling results and analytical results)

Solid-phase sodium nitrate, sodium nitrite, and hexasodium carbonate disulfate, although present in the DSS PF sample, were not responsible for fouling during operations, as they were soluble during operations and/or generated due to the post-processing high hydroxide rinse.

2) Fouling of the DSS coalescer was most likely due to accumulations of:

- Aluminum hydroxide (species based on modeling results; Al based on analytical results)

- Sodium oxalate (based on modeling results)

- Components associated with MST-related constituents, entrained sludge particles, and entrained stainless steel fines (based on analytical results)

- $\quad$ NAS compounds (based on modeling results and analytical results)

- MCU modifier (based on analytical results)

Solid-phase sodium nitrate, sodium nitrite, and sodium carbonate, although present in the DSS coalescer sample, were not responsible for fouling during operations, as they were soluble during operations and/or generated due to the post-processing high hydroxide rinse.

3) Fouling of the SE coalescer was most likely due to accumulations of:

- Components associated with entrained sludge particles, stainless steel fines, MST-related constituents, and possibly solder (based on analytical results)

- NAS (based on analytical results)

- Silica (species based on modeling results; Si based on analytical results)

- Iron oxide (species based on modeling results; Fe based on analytical results)

- MCU modifier (based on analytical results)

4) Treatment options for reducing $\mathrm{PF} /$ coalescer fouling will likely require use of sequential cleaning solutions ranging in $\mathrm{pH}$ and composition, due to the range of compounds driving fouling. Such potential treatment options will require demonstration/optimization through testing prior to implementation, as they may be incapable of reversing fouling, despite effectively removing solids.

\subsection{Recommendations}

If future DSS PF/coalescer sample characterization activities are planned, it is recommended that:

- rinsing of the PF/coalescer media be performed using solutions with the same approximate hydroxide concentration as the feed solution. In the case of the SB5/6 samples, a rinse solution containing approximately $2 \mathrm{M}$ sodium hydroxide would be best. Maintaining a consistent 
hydroxide concentration will maximize the chance that accumulated solids remain unchanged during rinsing.

- an additional analytical approach be performed to address the existence of solid phase sodium oxalate. Specifically, the DSS PF/coalescer samples would be leached with de-ionized water and the leachates analyzed by ion chromatography. This approach provides the potential for quantifying concentrations and forms of sodium oxalate that would be undetectable by XRD and FTIR methods.

\subsection{References}

1 Peters, T. B., A. L. Washington, II, and F. F. Fondeur, "Task Technical and Quality Assurance Plan for Routine Samples in Support of ARP and MCU,” SRNL-RP-2013-00536, Savannah River National Laboratory, September 2013.

2 “Savannah River National Laboratory Technical Report Design Check Guidelines,” WSRC-IM2002-00011, Rev. 2, Westinghouse Savannah River Company, August 2004.

$3 \quad$ Peters, T. B. and S. D. Fink, "Results of Initial Analyses of the Macrobatch 5 Tank 21H Qualification Samples,” SRNL-STI-2012-00025, Savannah River National Laboratory, January 2012.

$4 \quad$ Peters, T. B. and F. F. Fondeur, "Results of Routine Strip Effluent Hold Tank and Decontaminated Salt Solution Hold Tank Samples from Modular Caustic-Side Solvent Extraction Unit during Macrobatch 5 Operations,” SRNL-STI-2013-00194, Savannah River National Laboratory, April 2013.

$5 \quad$ Peters, T. B., F. F. Fondeur, and S. D. Fink, "Results of Analyses of Macrobatch 3 Decontaminated Salt Solution (DSS) Coalescer and Pre-filters,” SRNL-STI-2011-00513, Savannah River National Laboratory, June 2012.

$6 \quad$ Peters, T. B., F. F. Fondeur, and S. D. Fink, "Results From Analysis of the First and Second Strip Effluent Coalescer Elements From Radioactive Operations of the Modular Caustic-Side Solvent Extraction Unit,” SRNL-STI-2010-00888, Savannah River National Laboratory, June 2011.

$7 \quad$ Dullien, F. A. L, Porous Media: Fluid Transport and Pore Structure, Academic Press, New York, 1979.

Pike, J. A. and J. M. Gillam, “Flowsheet for Aluminum Removal from Sludge Batch 5,” LWOPIT-2007-00042, Rev. 2, Westinghouse Savannah River Company, September 2007.

Pike, J. A. and J. M. Gillam, "Flowsheet for Aluminum Removal from Sludge Batch 6,” SRNLSTI-2008-00389, Savannah River National Laboratory, December 2008. SRNL-STI-2009-00774, Rev. 1, Savannah River National Laboratory, May 2010.

Poirier, M. R. and S. D. Fink, "Investigation of Alternative Approaches for Cleaning Mott Porous Metal Filters,” WSRC-TR-2002-00526, Westinghouse Savannah River Company, November 2002. 


\section{Appendix A: SEM Images and EDS Results for the DSS PF Sample}
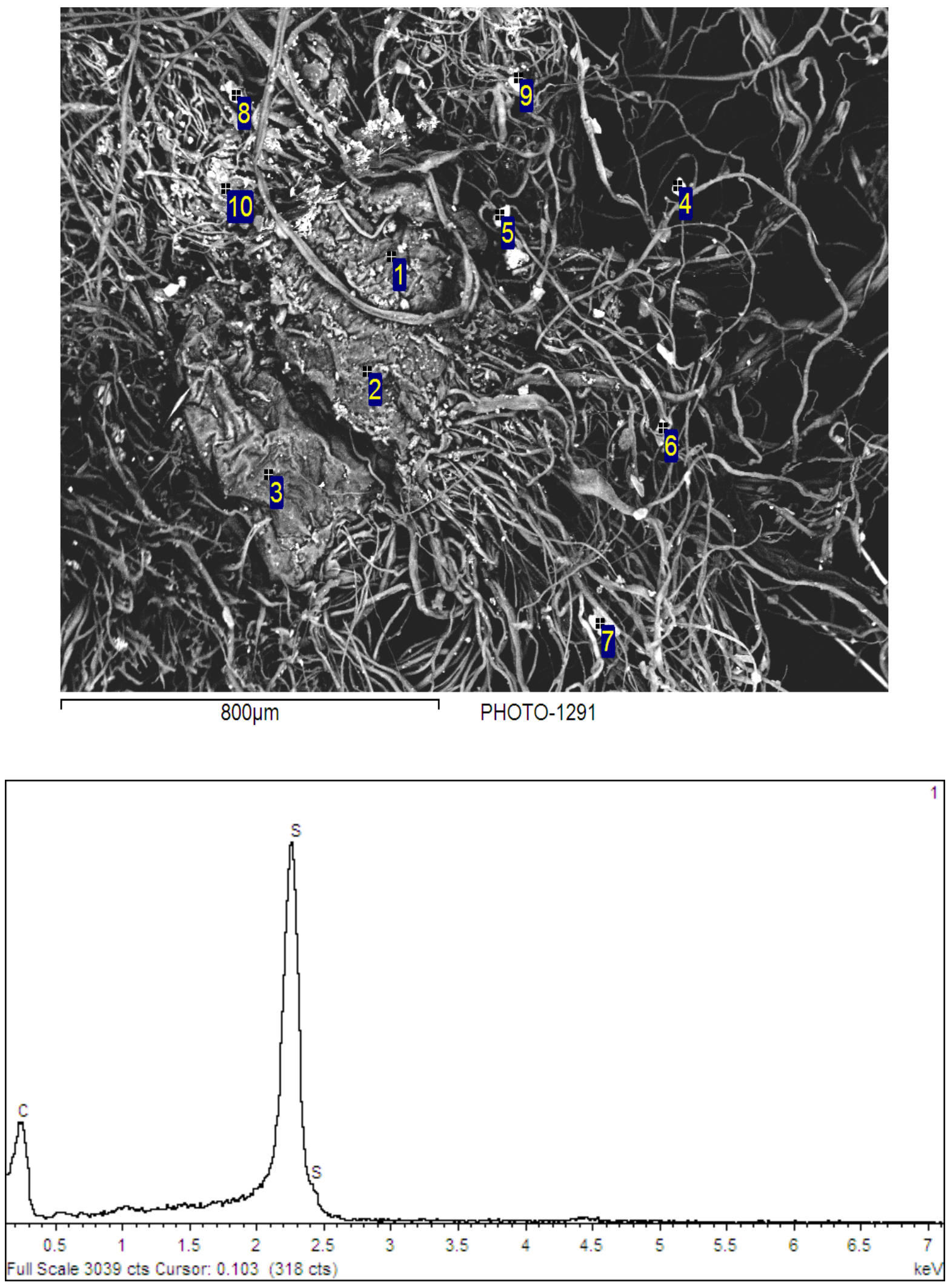
Appendix A: SEM Images and EDS Results for the DSS PF Sample (cont'd)
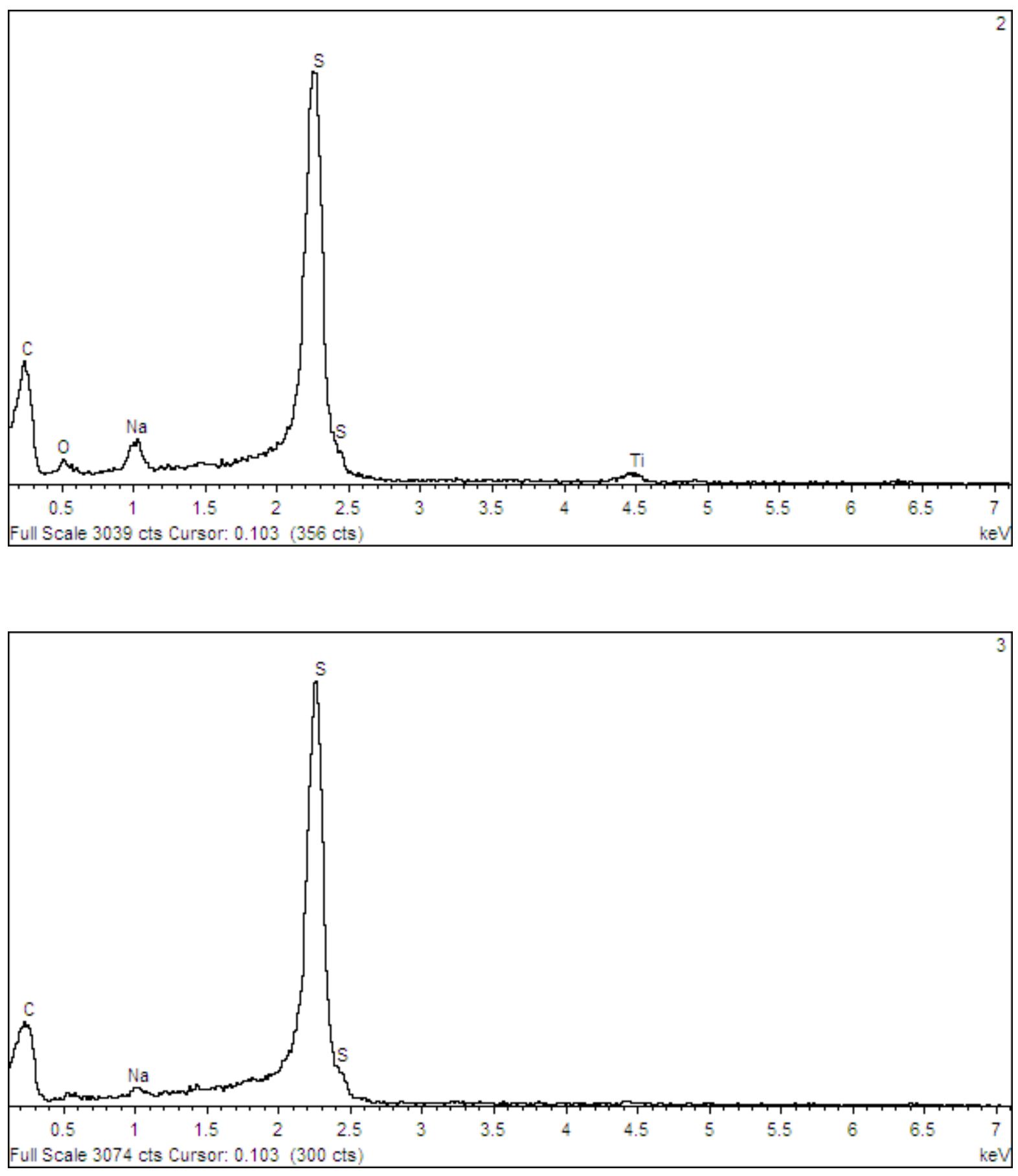
Appendix A: SEM Images and EDS Results for the DSS PF Sample (cont'd)
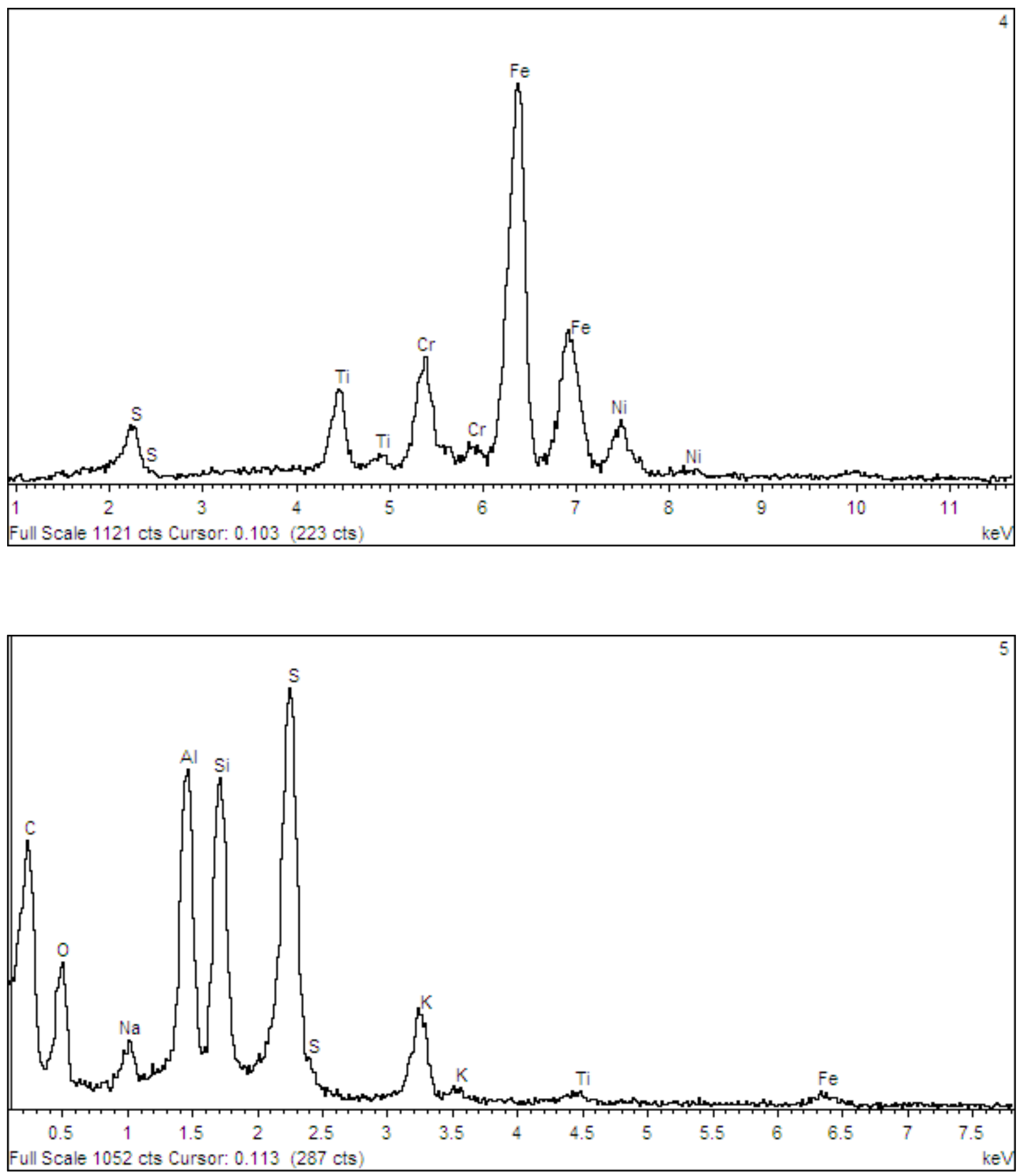
Appendix A: SEM Images and EDS Results for the DSS PF Sample (cont'd)
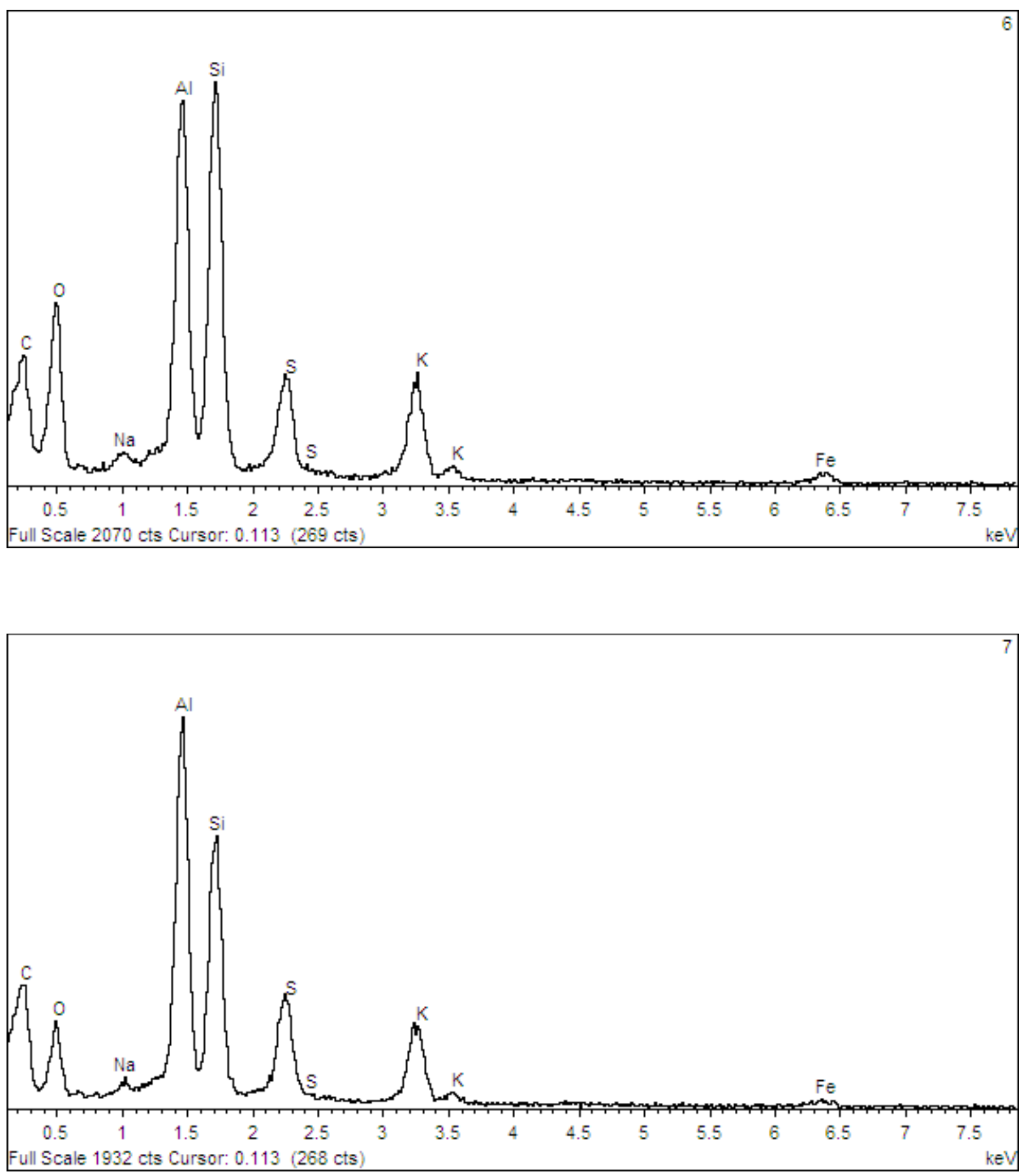
Appendix A: SEM Images and EDS Results for the DSS PF Sample (cont'd)
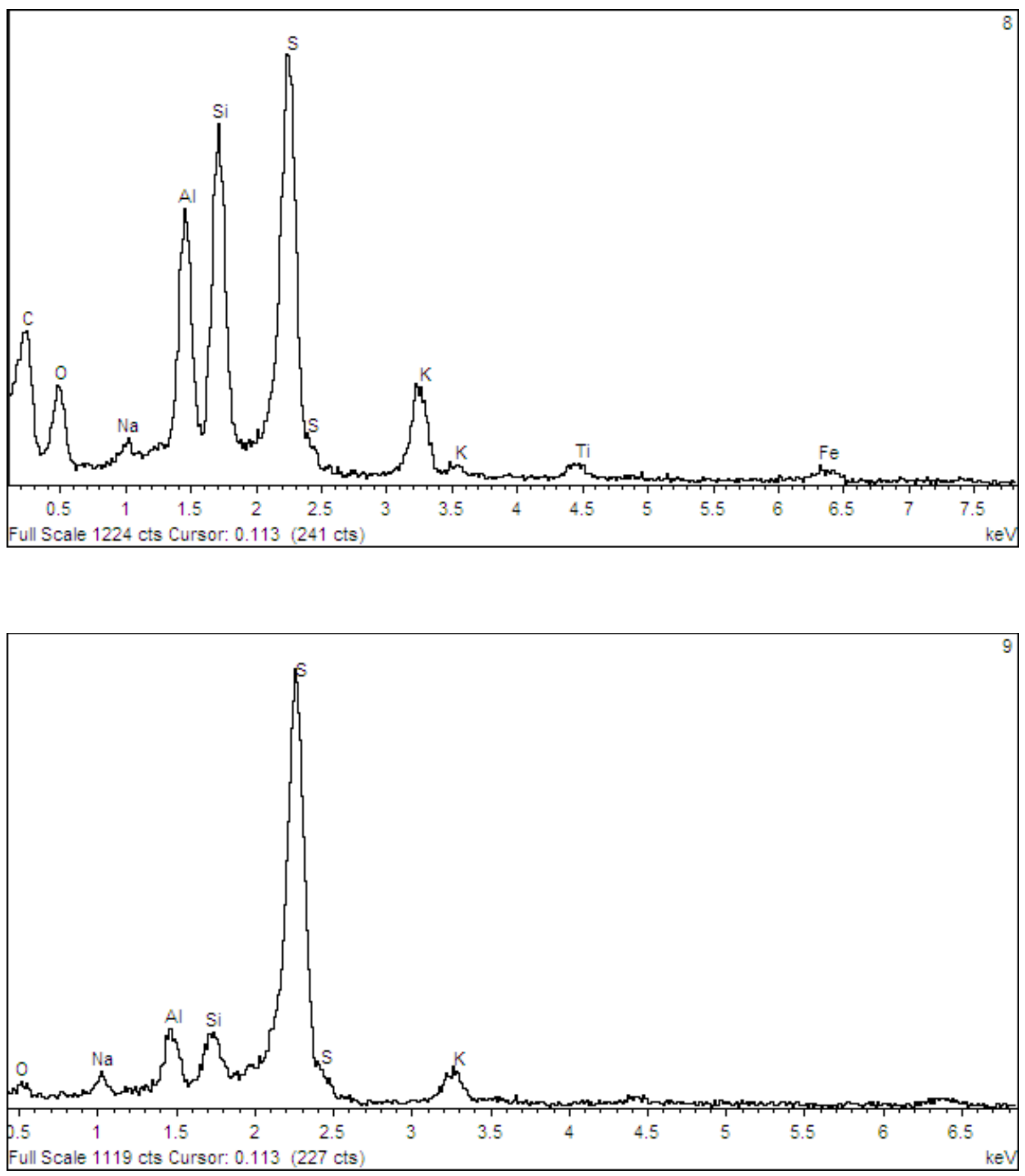
Appendix A: SEM Images and EDS Results for the DSS PF Sample (cont'd)
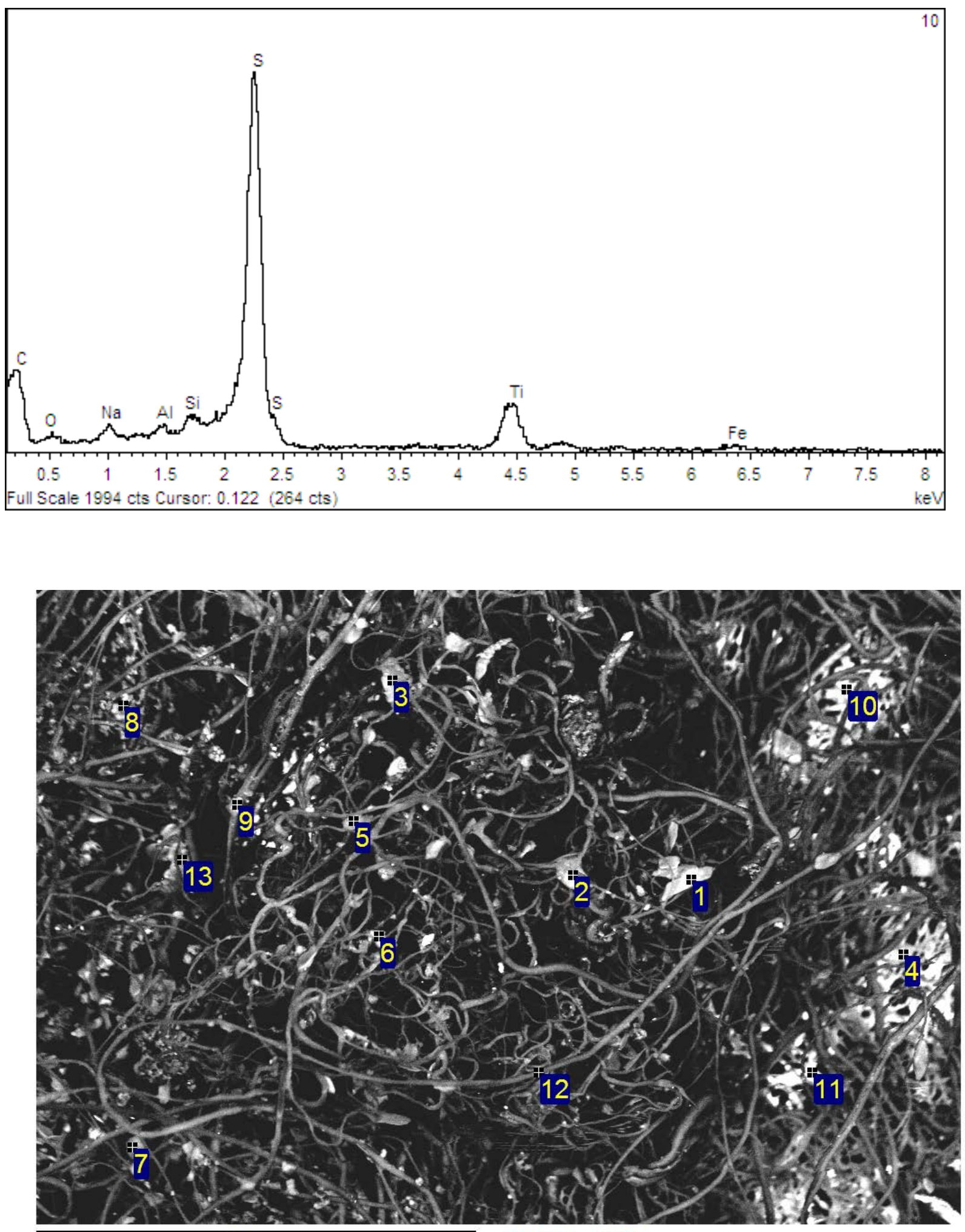
Appendix A: SEM Images and EDS Results for the DSS PF Sample (cont'd)
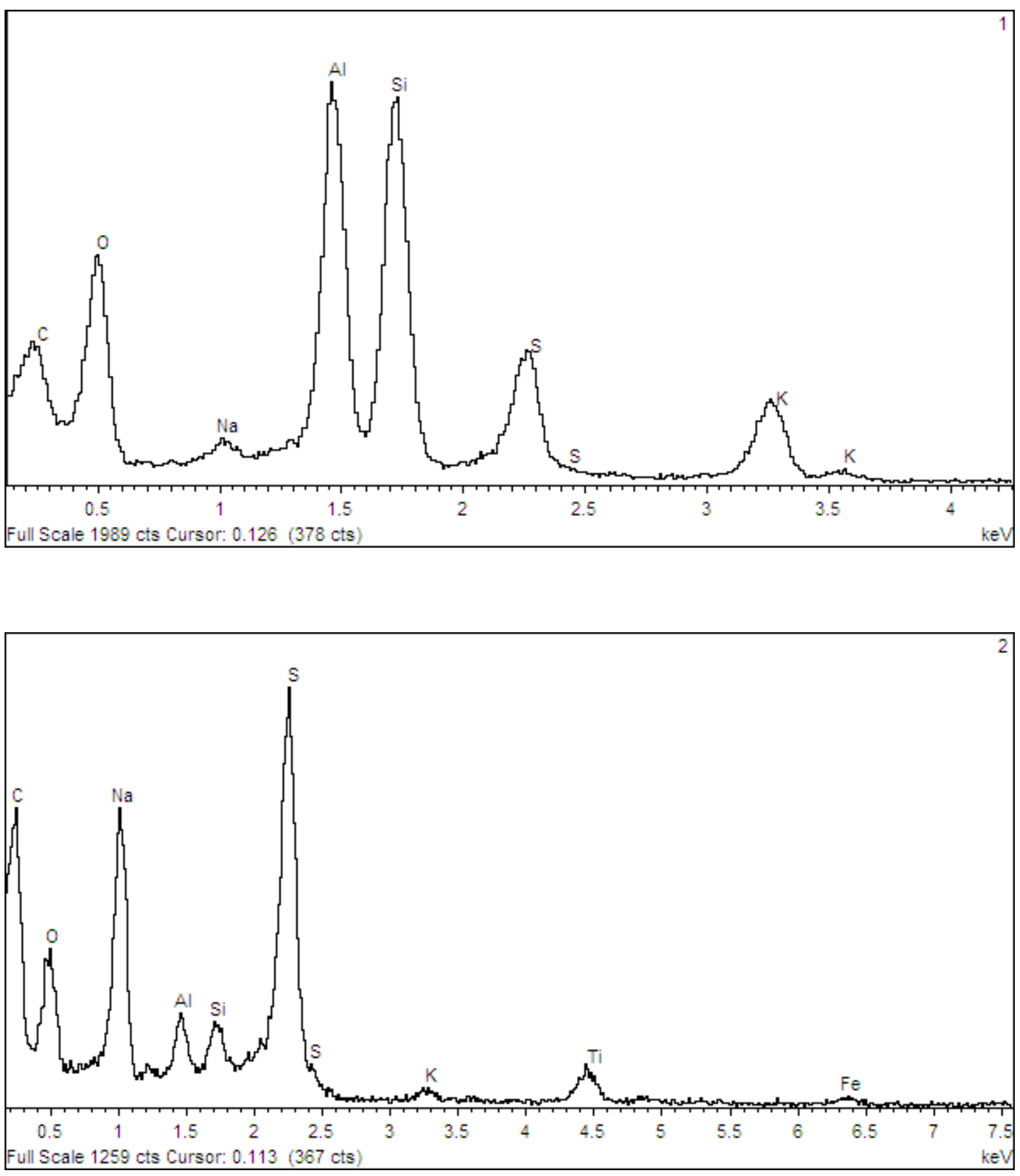
Appendix A: SEM Images and EDS Results for the DSS PF Sample (cont'd)
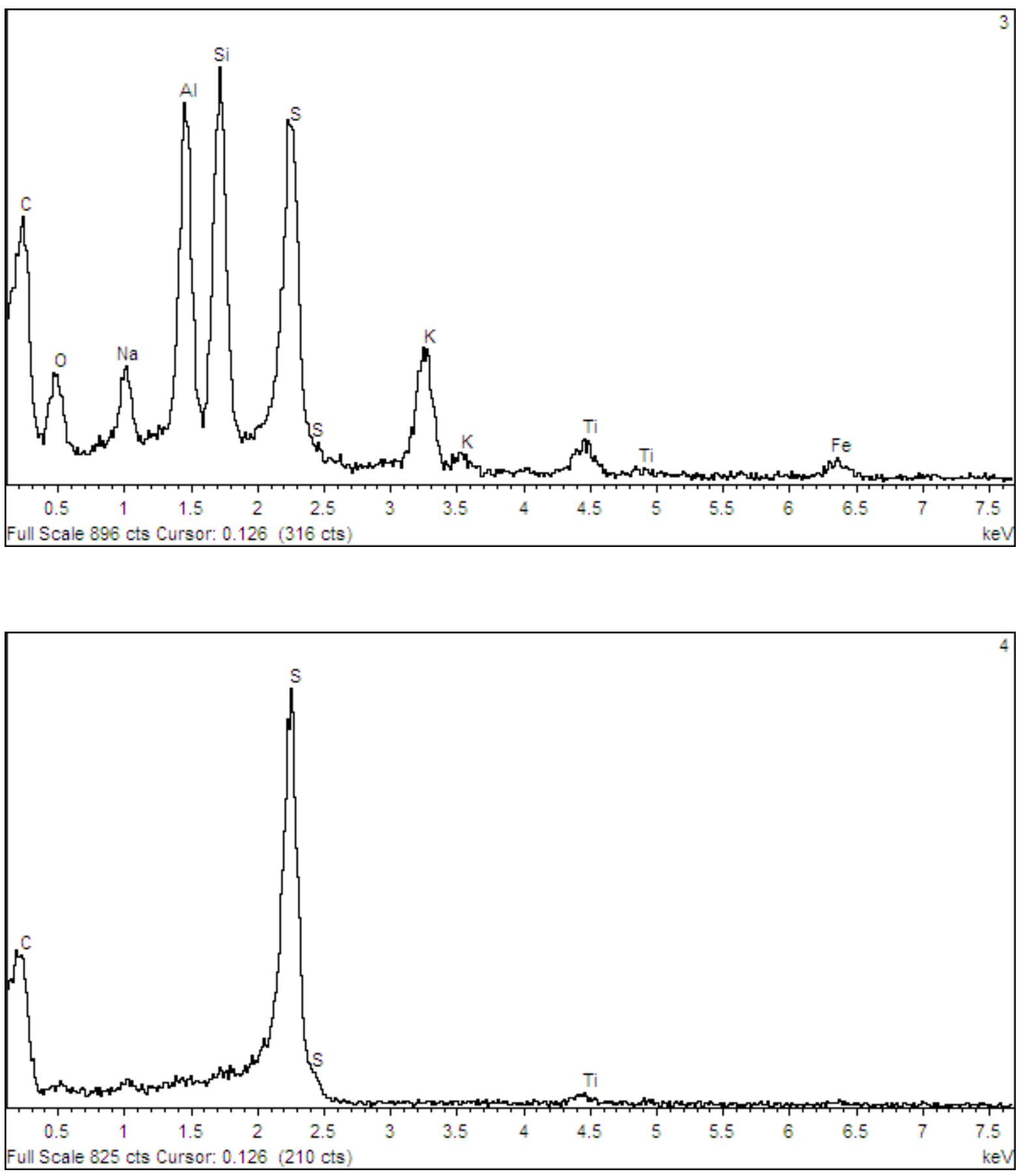


\section{Appendix A: SEM Images and EDS Results for the DSS PF Sample (cont'd)}
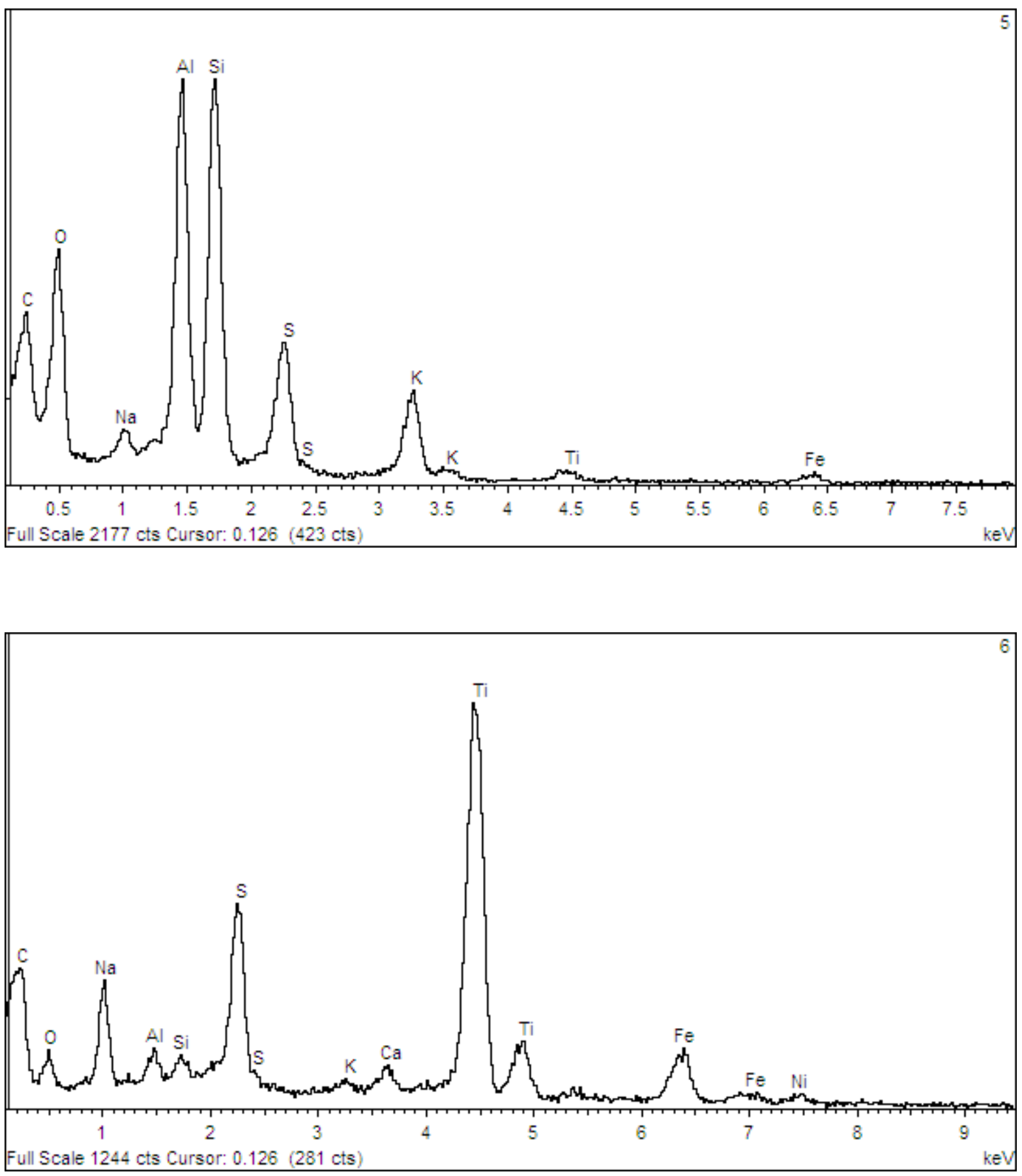
Appendix A: SEM Images and EDS Results for the DSS PF Sample (cont'd)
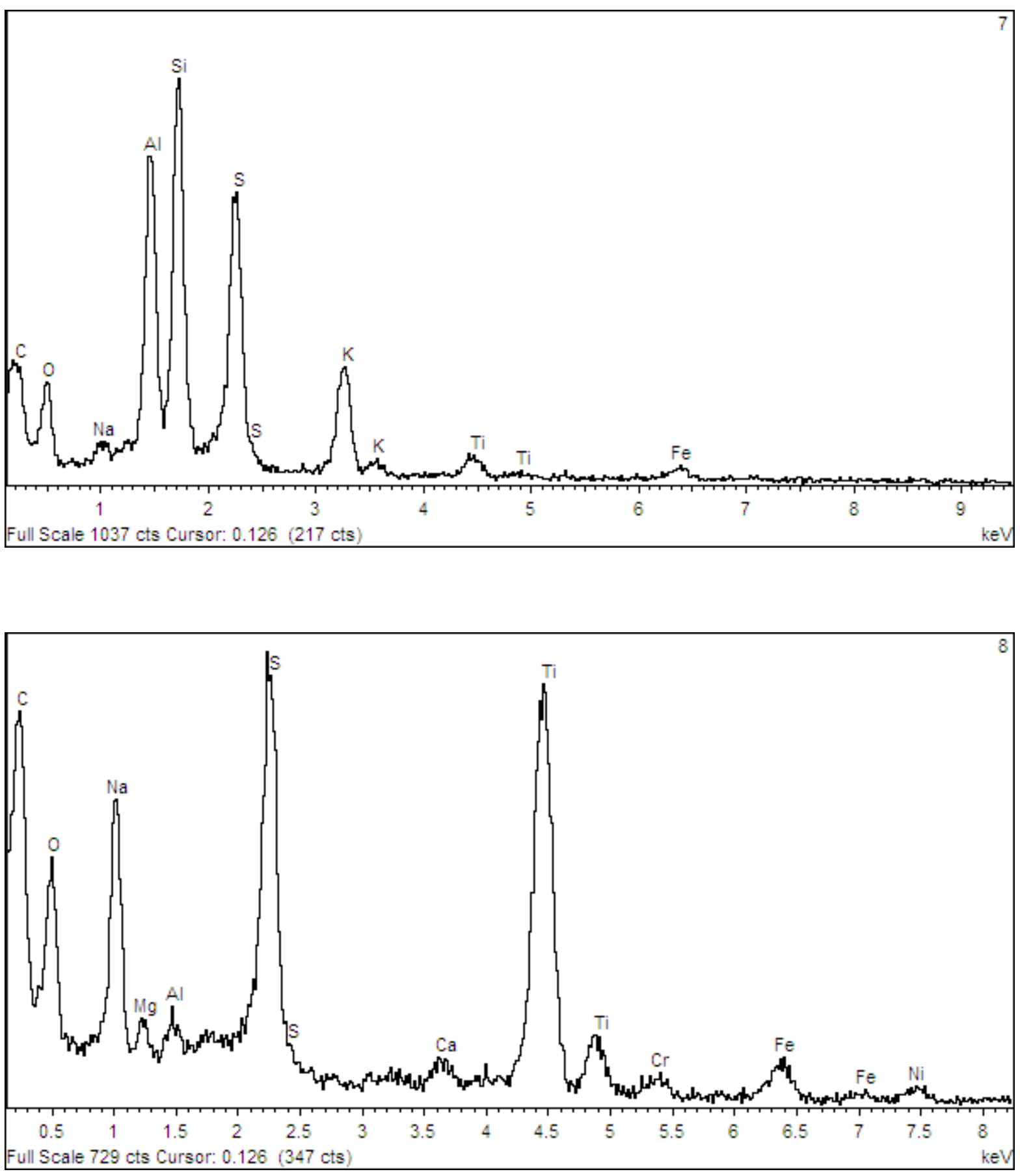
Appendix A: SEM Images and EDS Results for the DSS PF Sample (cont'd)
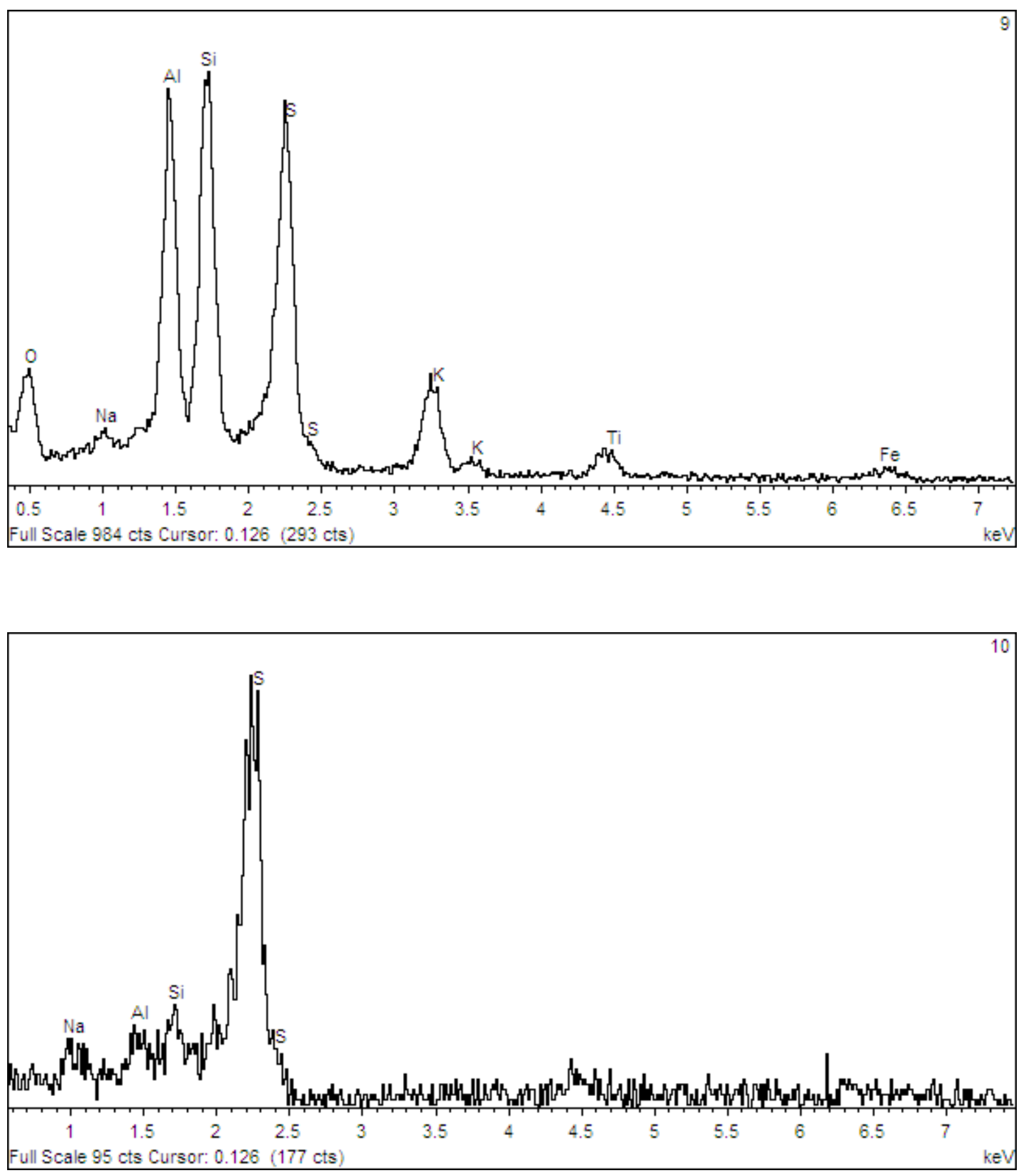
Appendix A: SEM Images and EDS Results for the DSS PF Sample (cont'd)
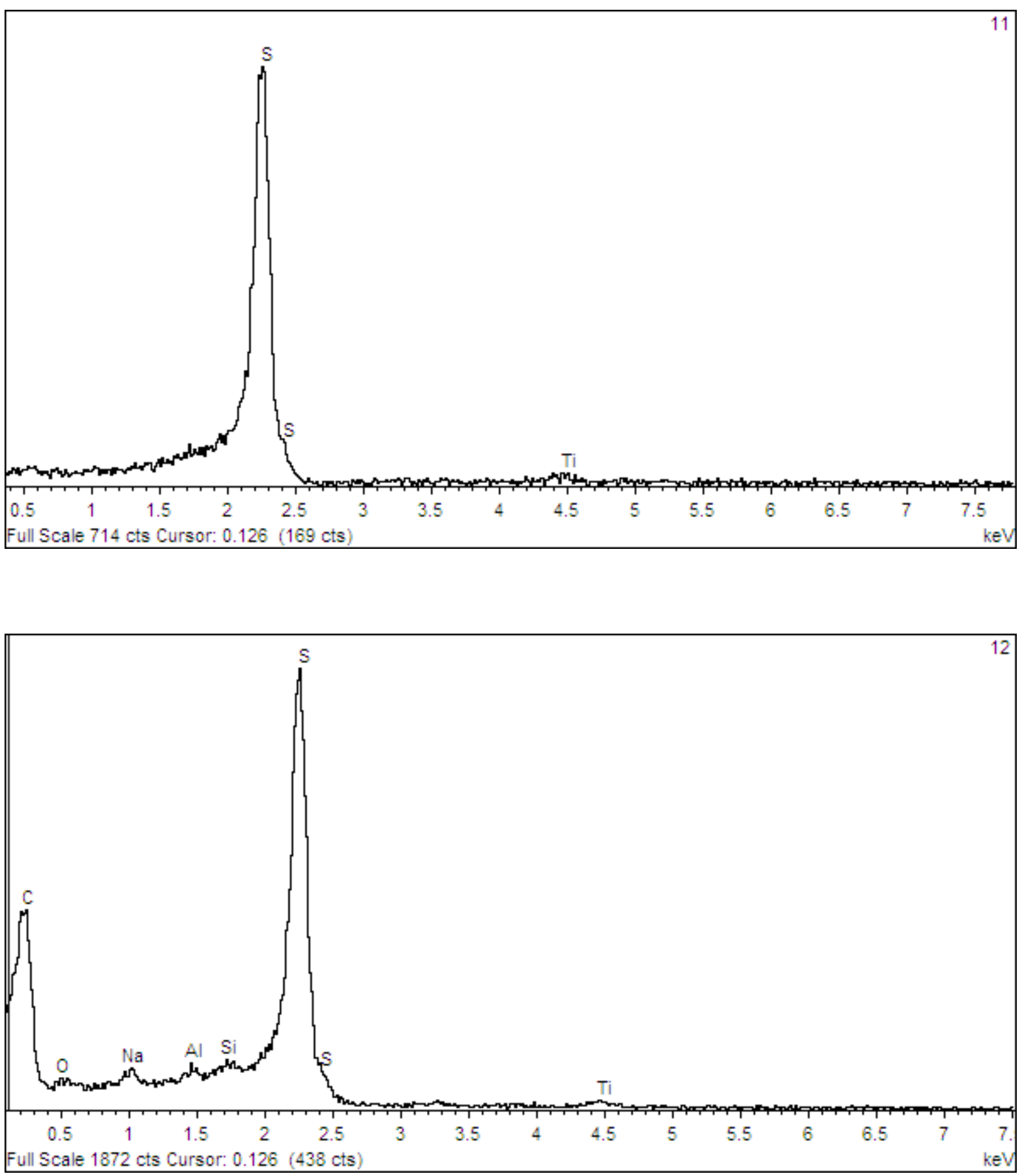
Appendix A: SEM Images and EDS Results for the DSS PF Sample (cont'd)
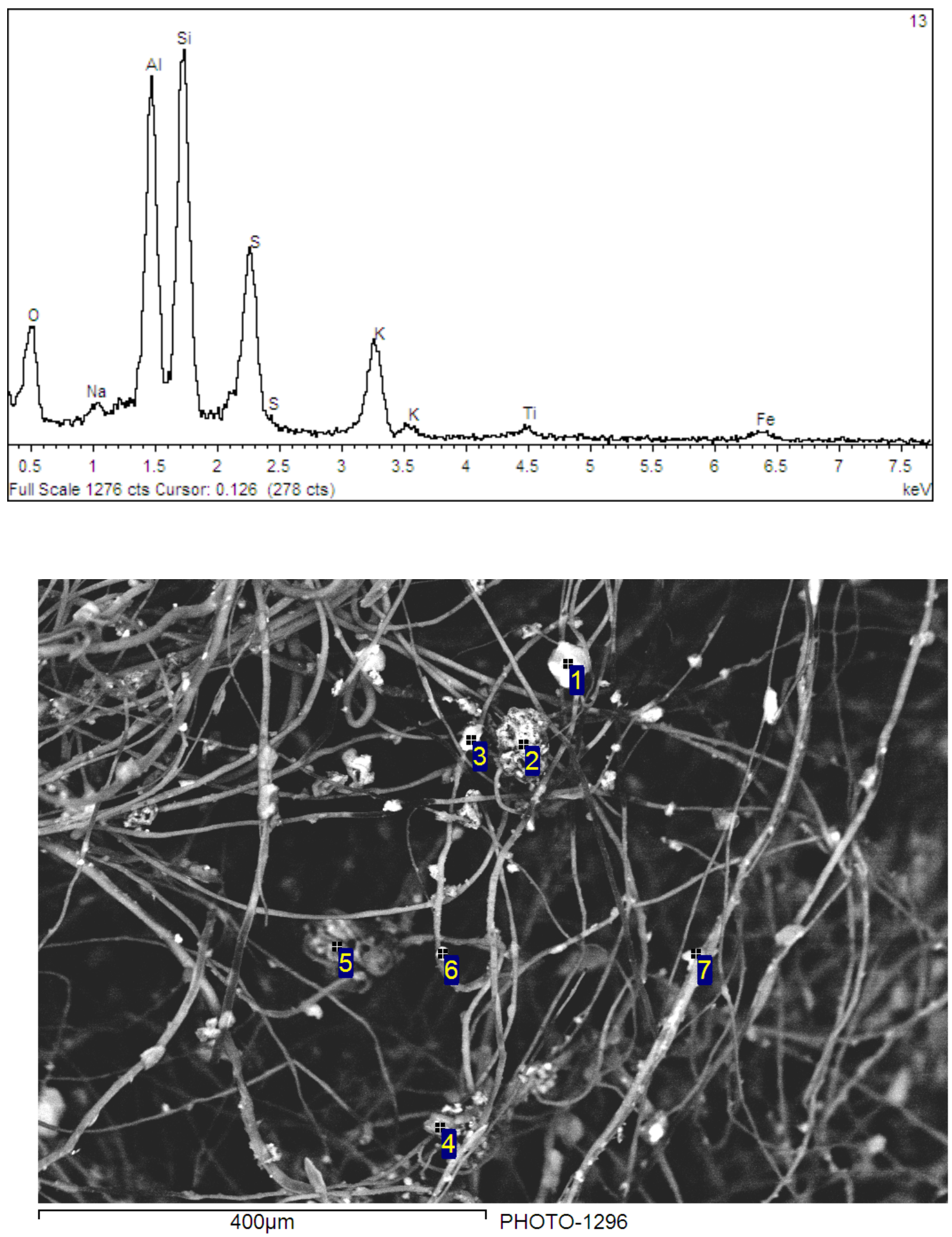
Appendix A: SEM Images and EDS Results for the DSS PF Sample (cont'd)
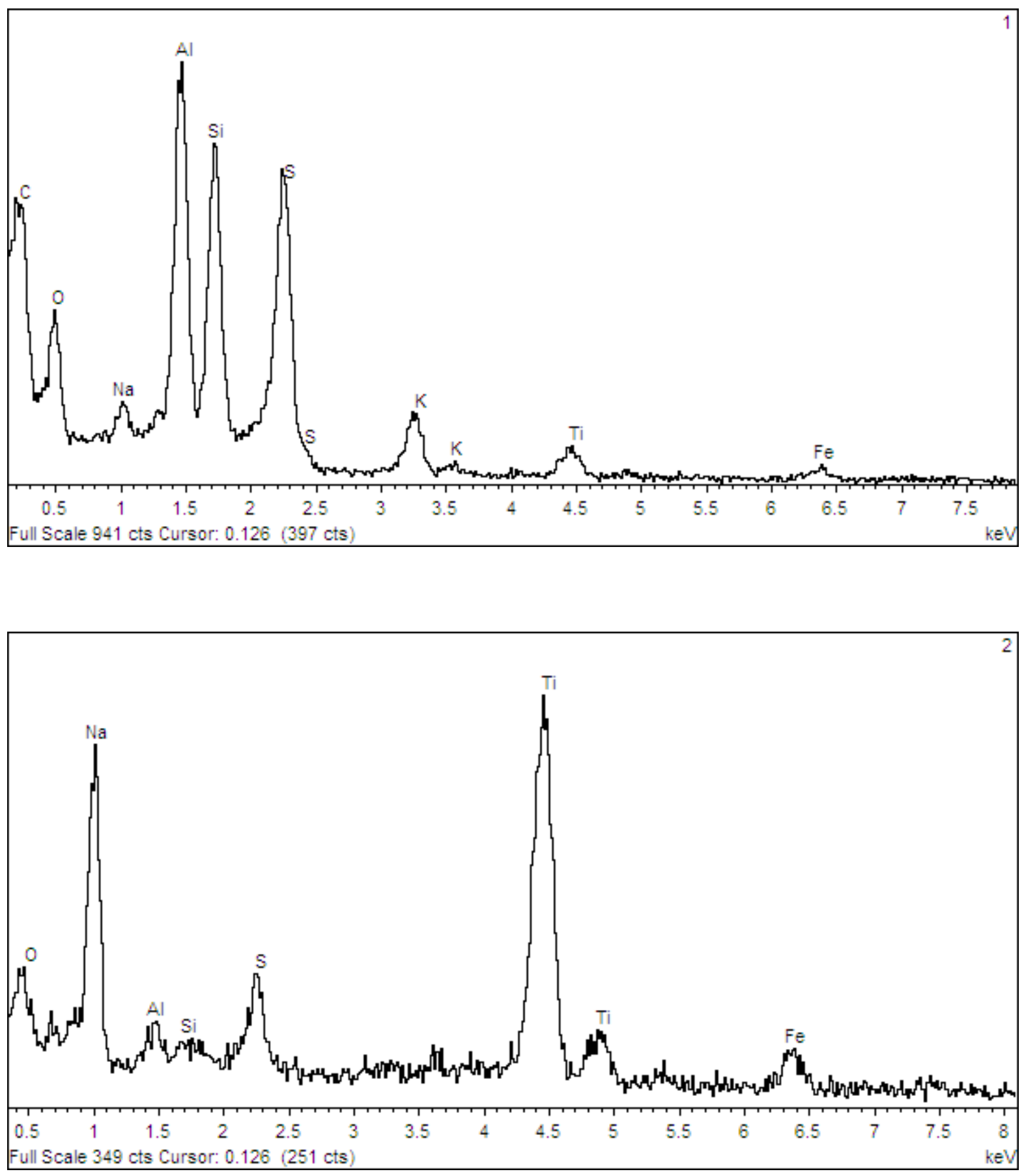
Appendix A: SEM Images and EDS Results for the DSS PF Sample (cont'd)
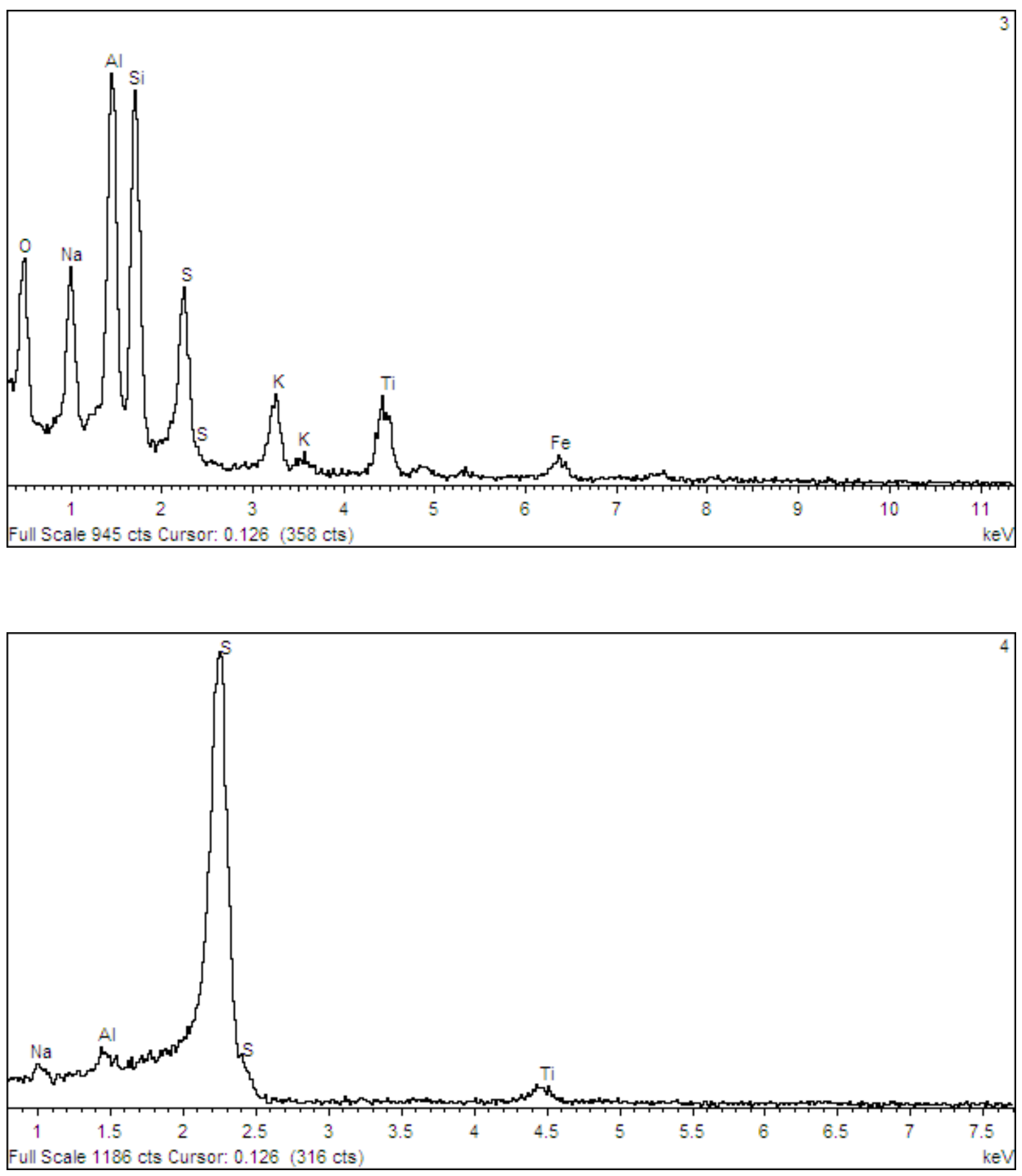
Appendix A: SEM Images and EDS Results for the DSS PF Sample (cont'd)
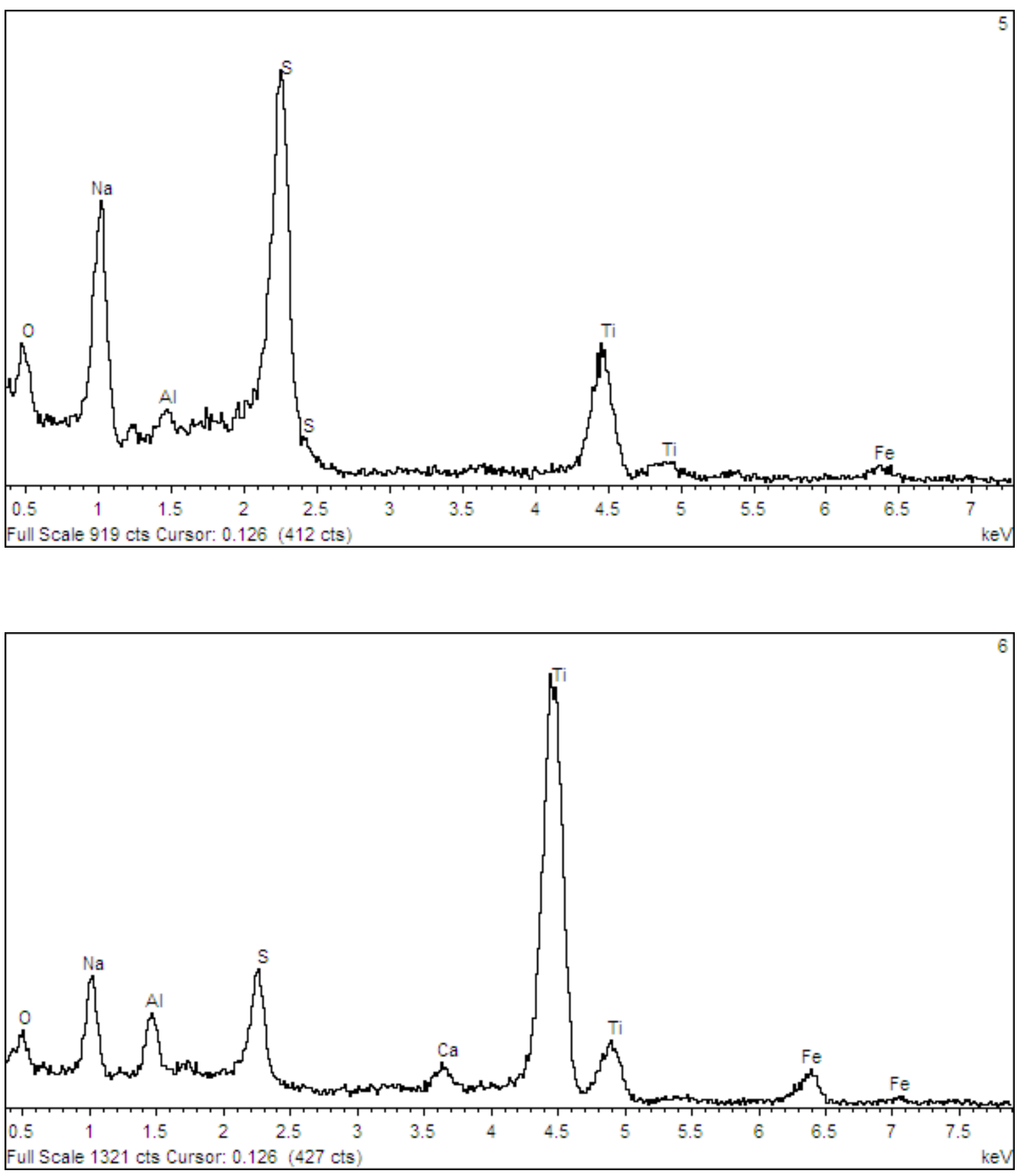
Appendix A: SEM Images and EDS Results for the DSS PF Sample (cont'd)

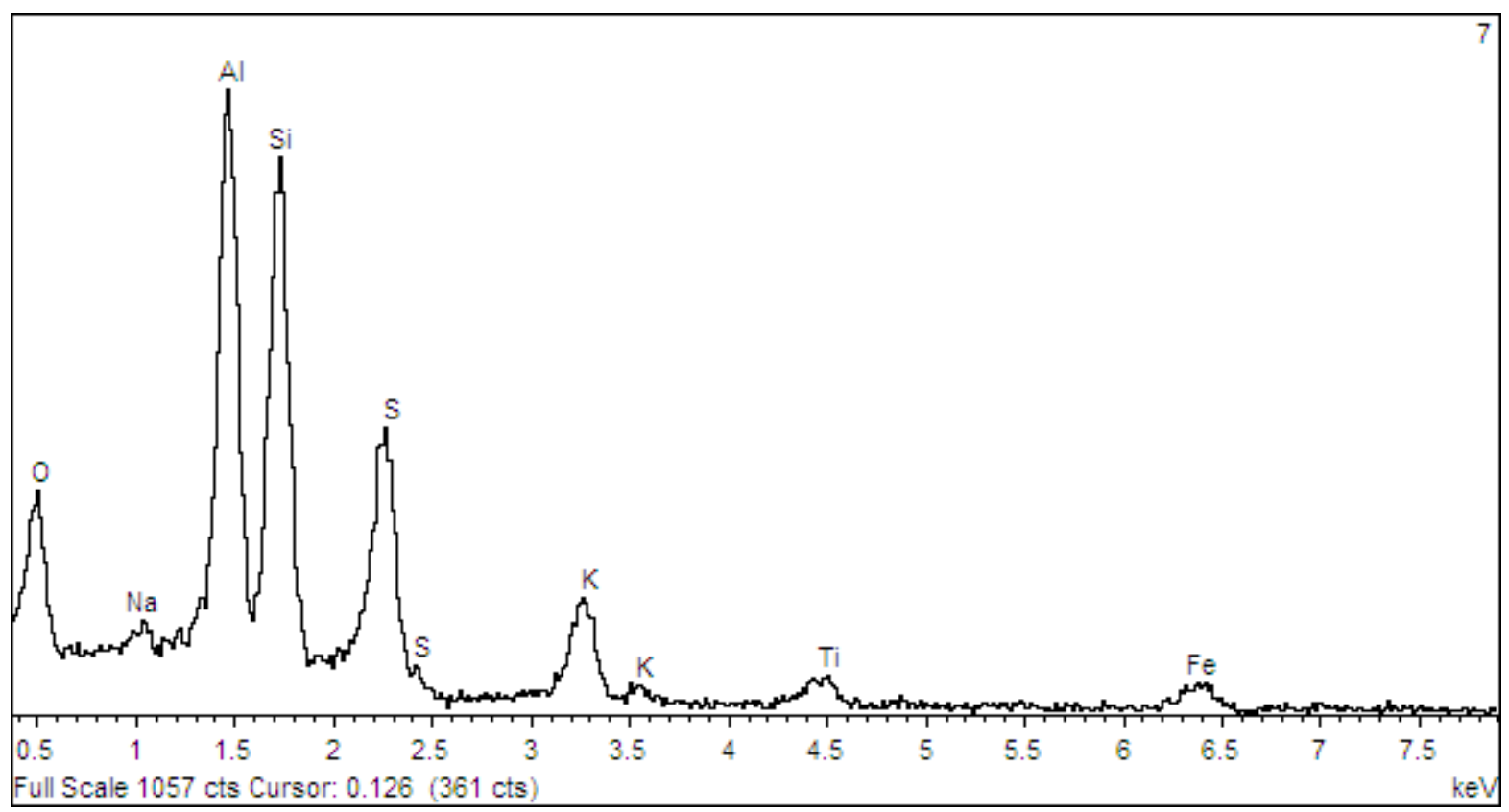




\section{Appendix B: SEM Images and EDS Results for the DSS Coalescer Sample}
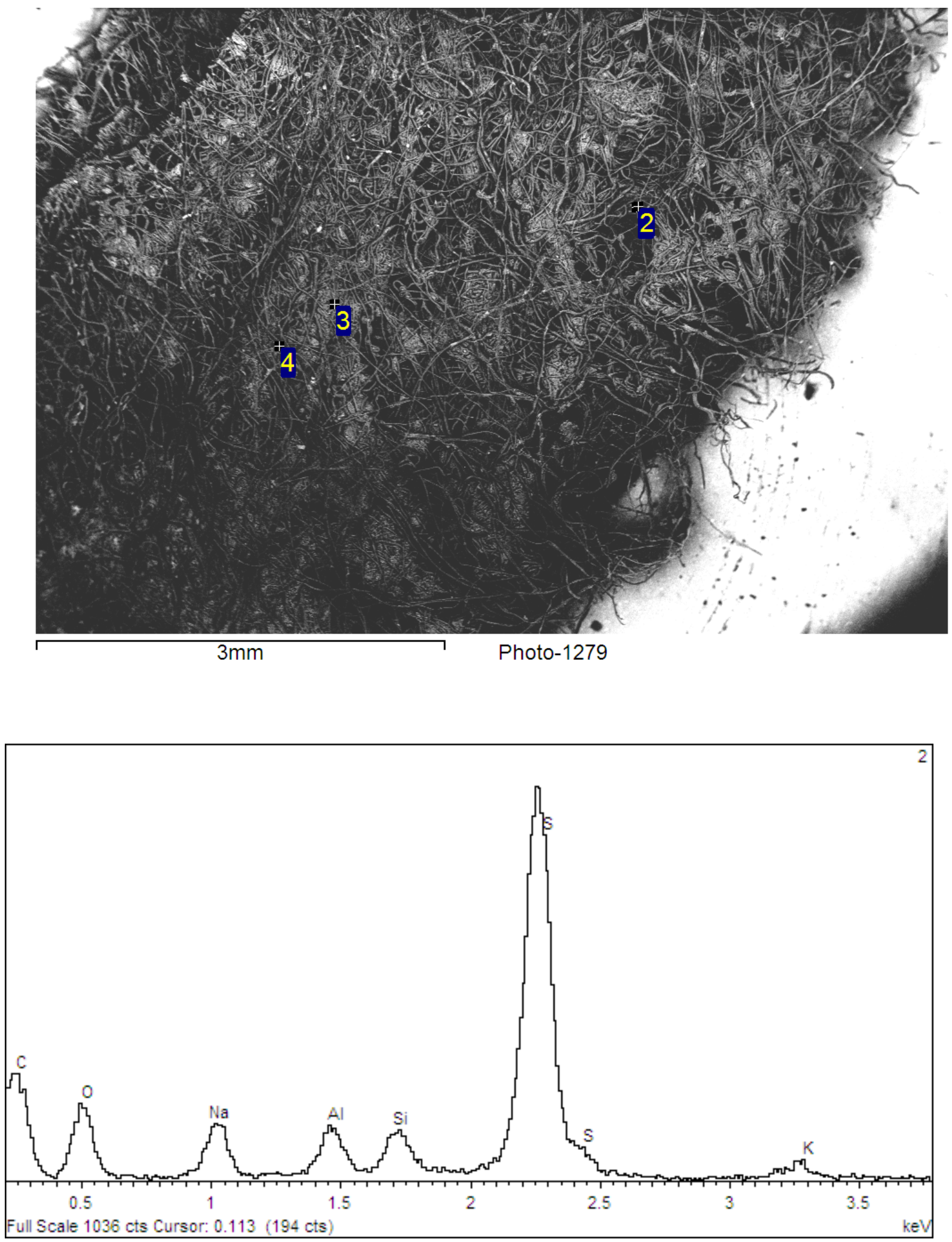
Appendix B: SEM Images and EDS Results for the DSS Coalescer Sample (cont'd)
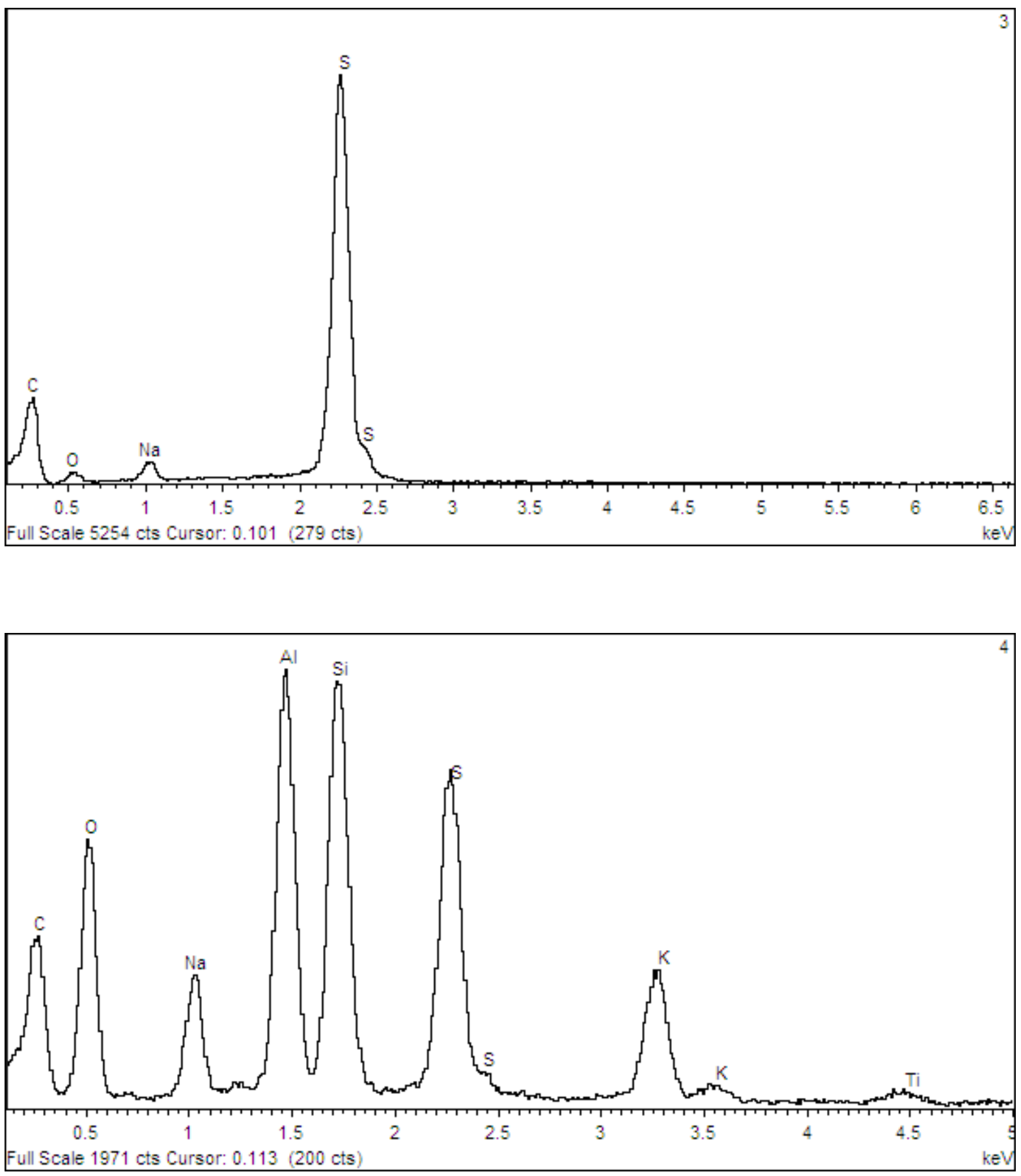
Appendix B: SEM Images and EDS Results for the DSS Coalescer Sample (cont'd)
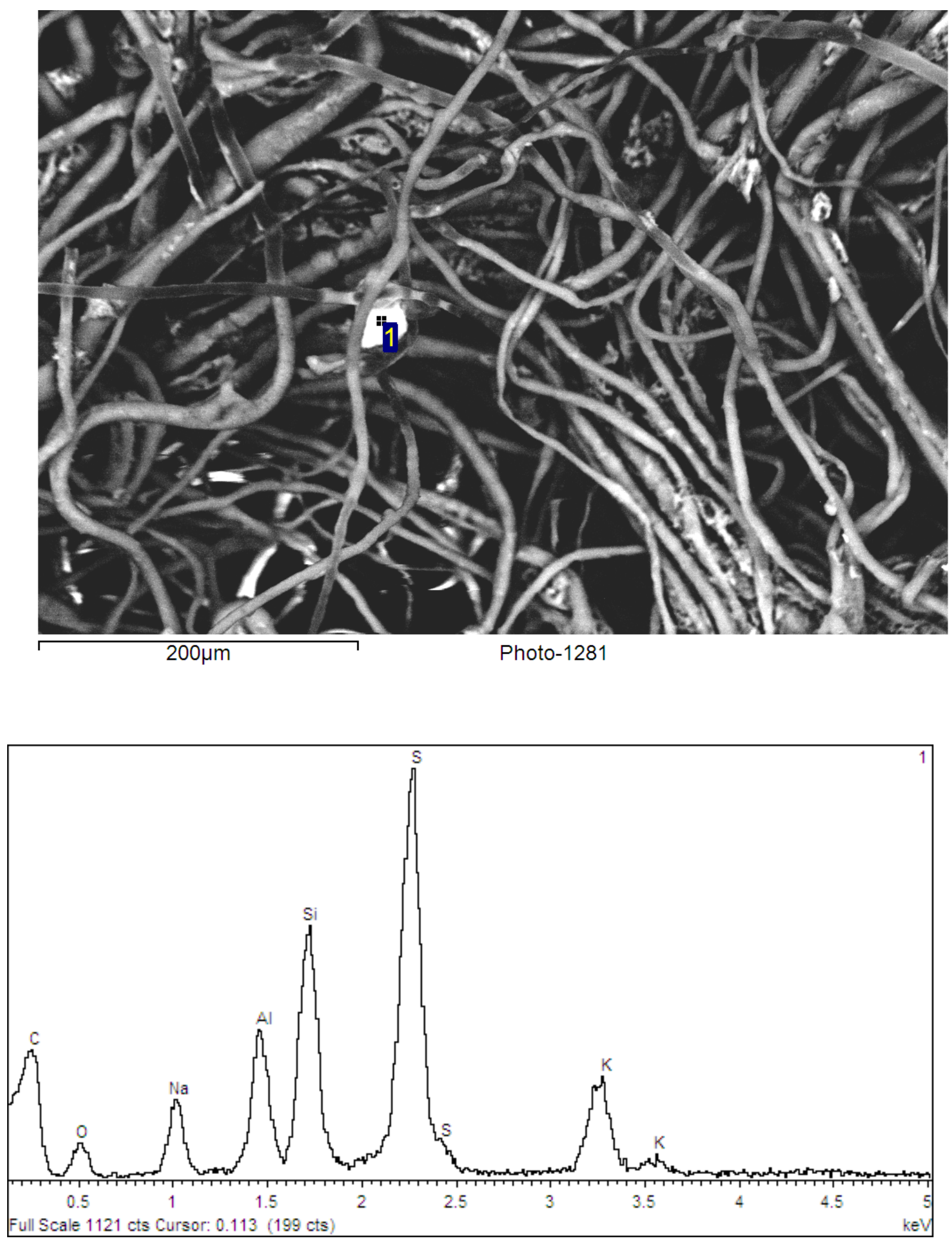
Appendix B: SEM Images and EDS Results for the DSS Coalescer Sample (cont'd)
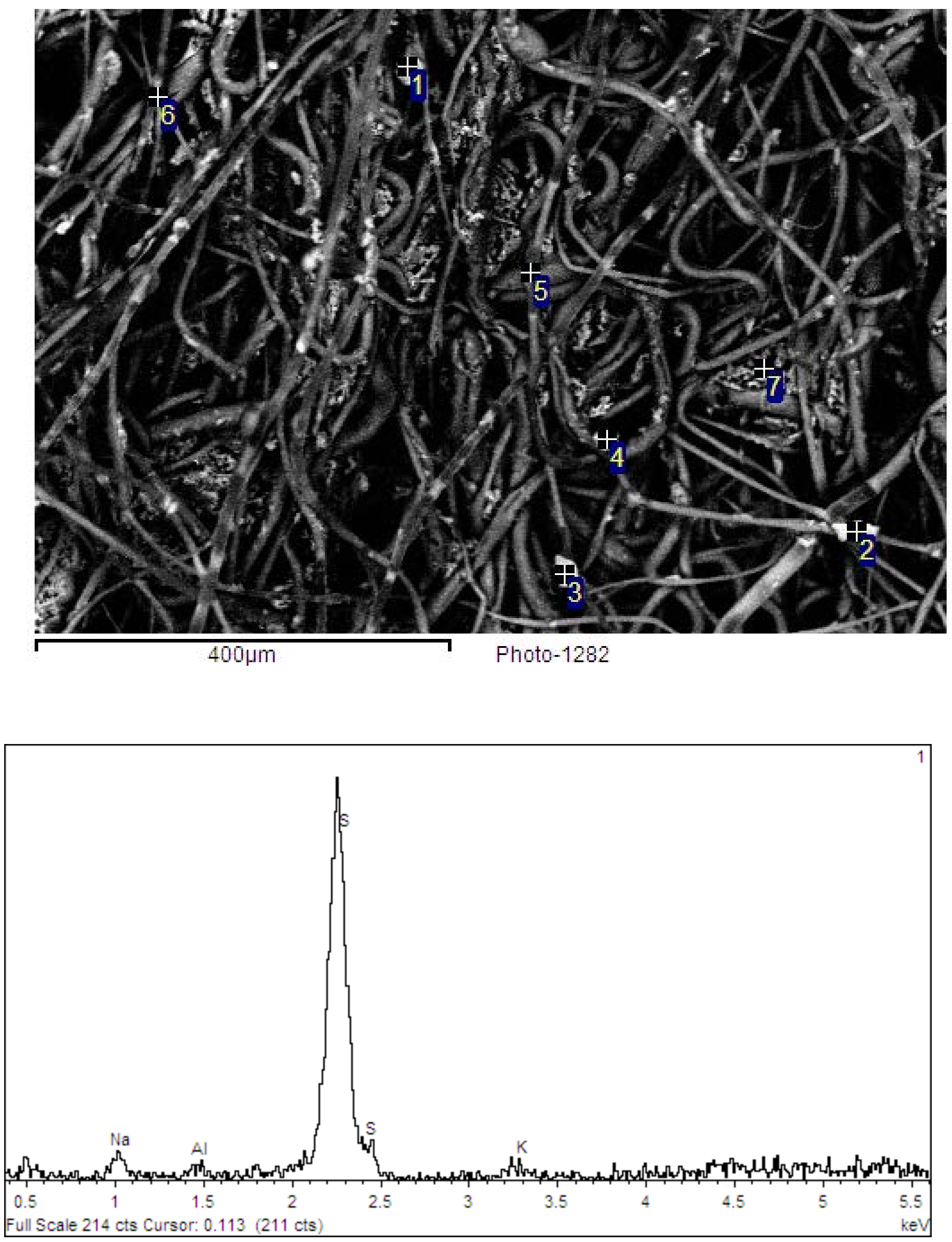
Appendix B: SEM Images and EDS Results for the DSS Coalescer Sample (cont'd)
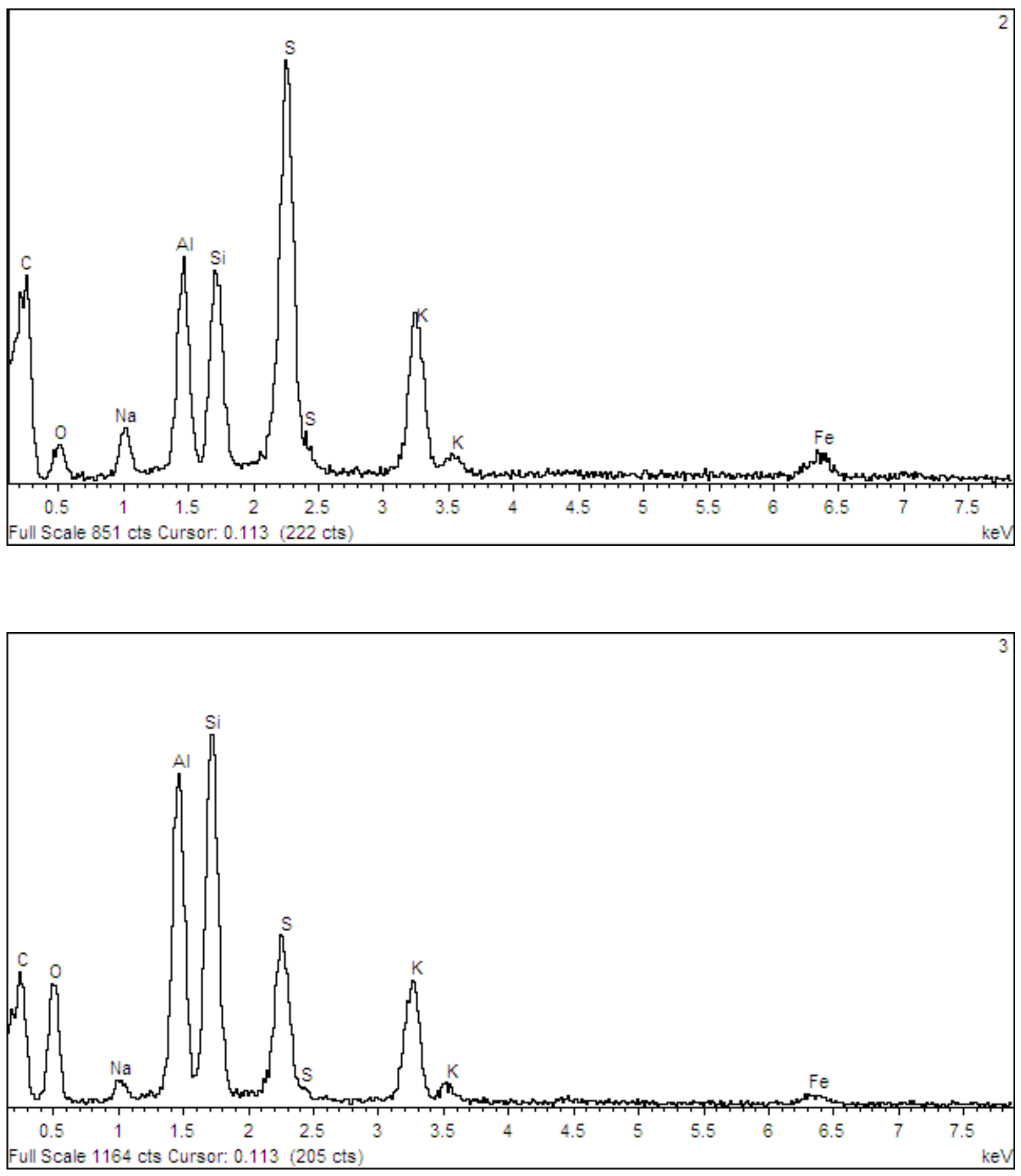
Appendix B: SEM Images and EDS Results for the DSS Coalescer Sample (cont'd)
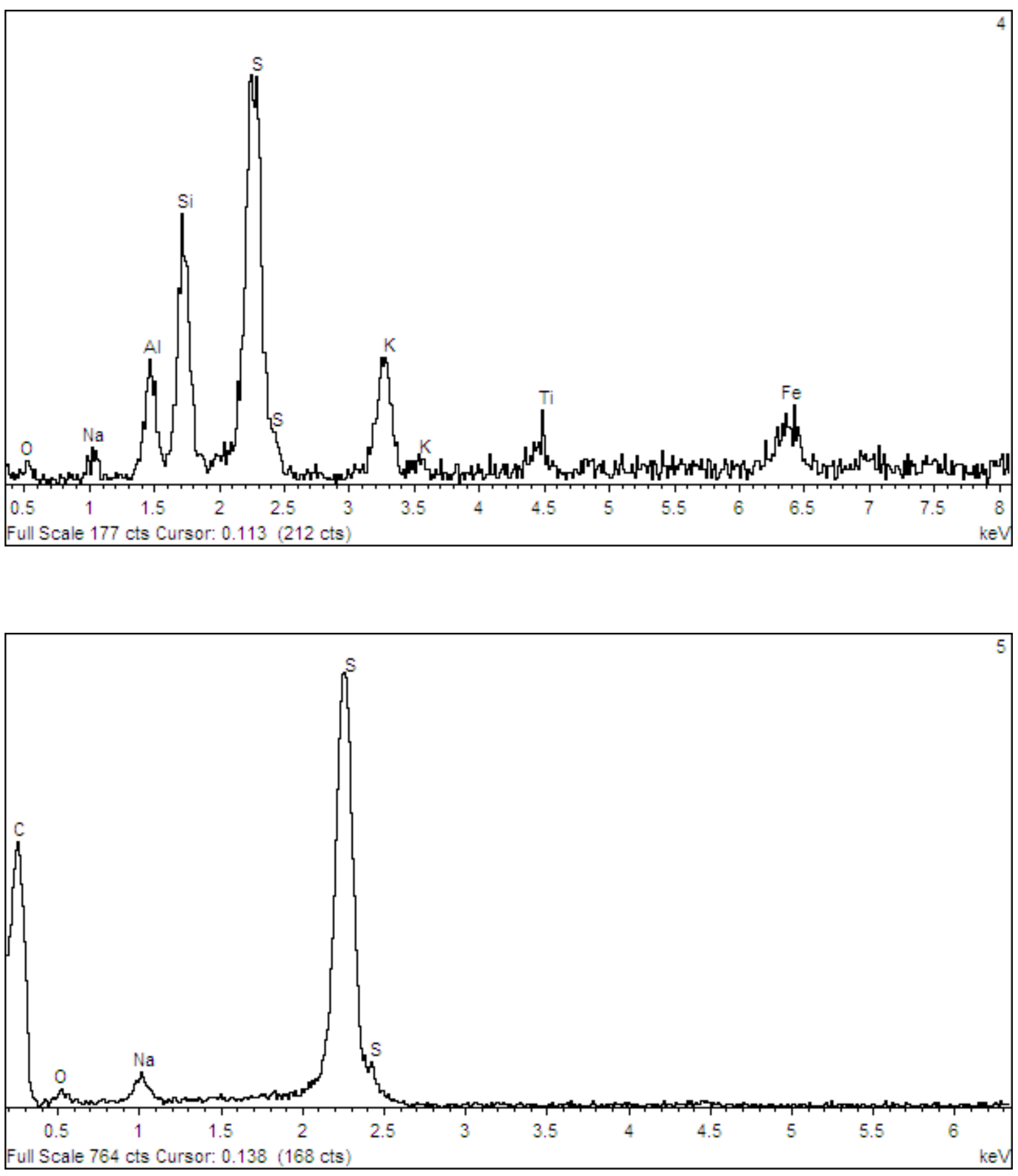
Appendix B: SEM Images and EDS Results for the DSS Coalescer Sample (cont'd)
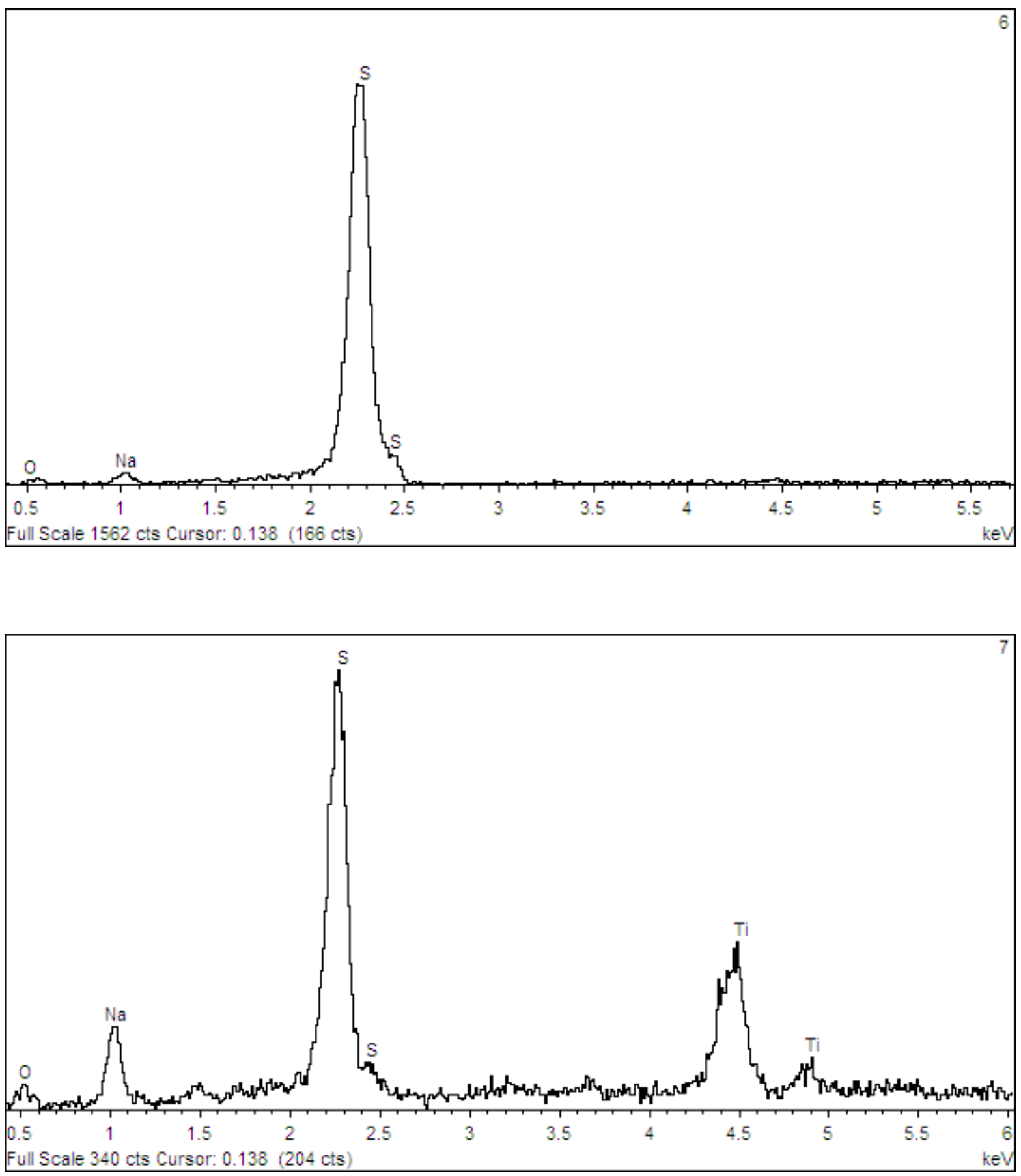
Appendix B: SEM Images and EDS Results for the DSS Coalescer Sample (cont'd)

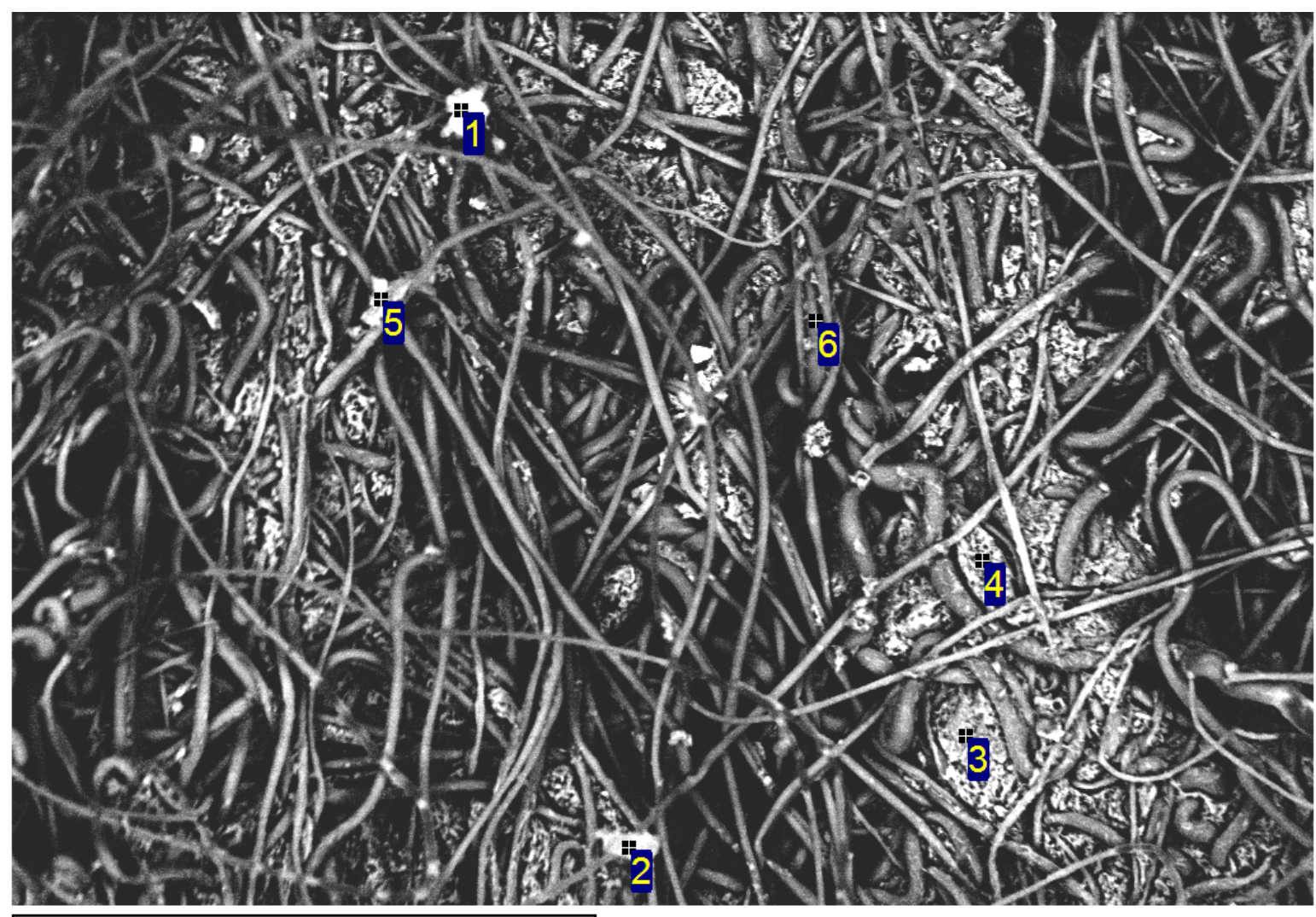

$600 \mu \mathrm{m}$

Photo-1285

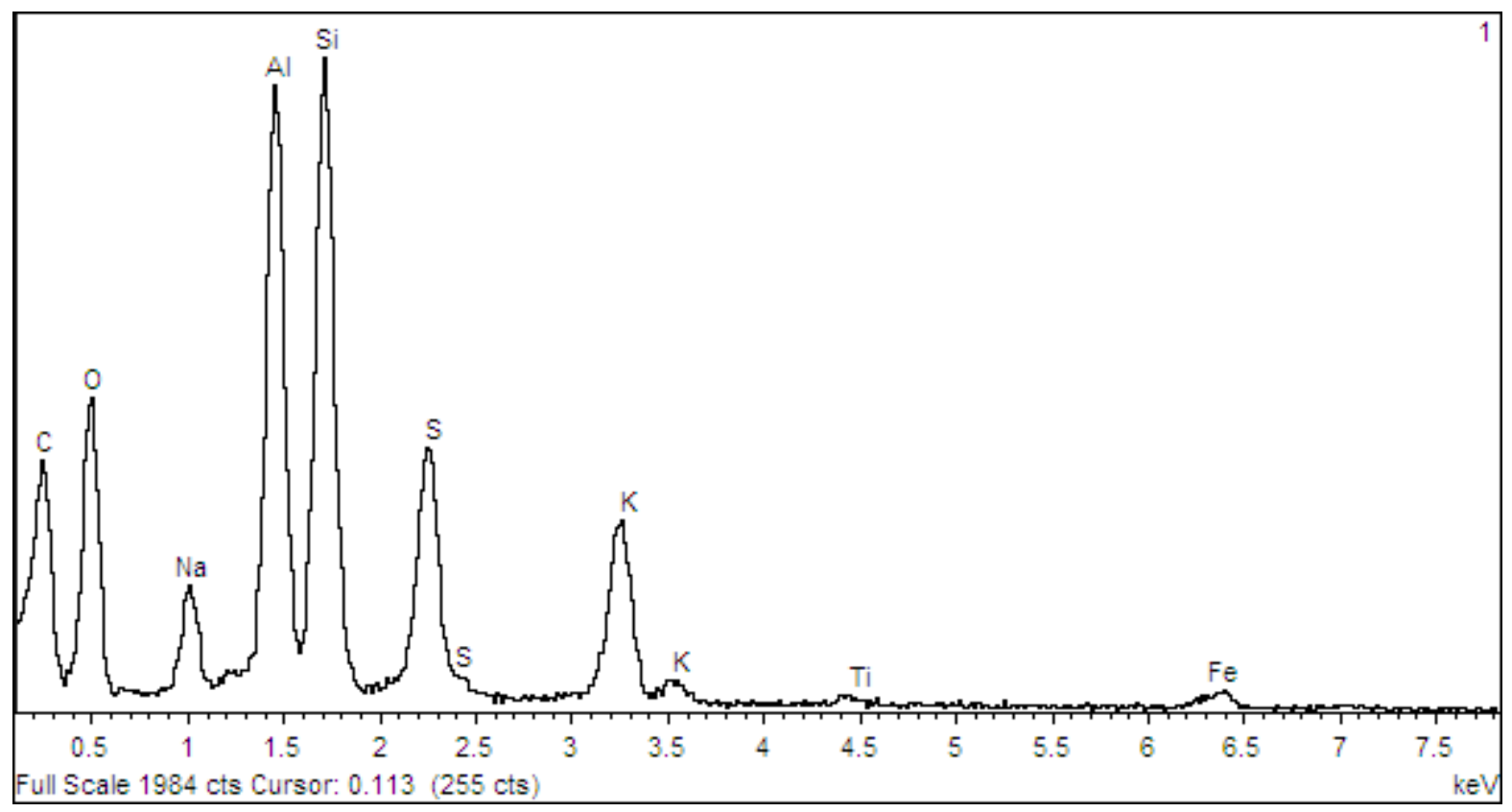


Appendix B: SEM Images and EDS Results for the DSS Coalescer Sample (cont'd)
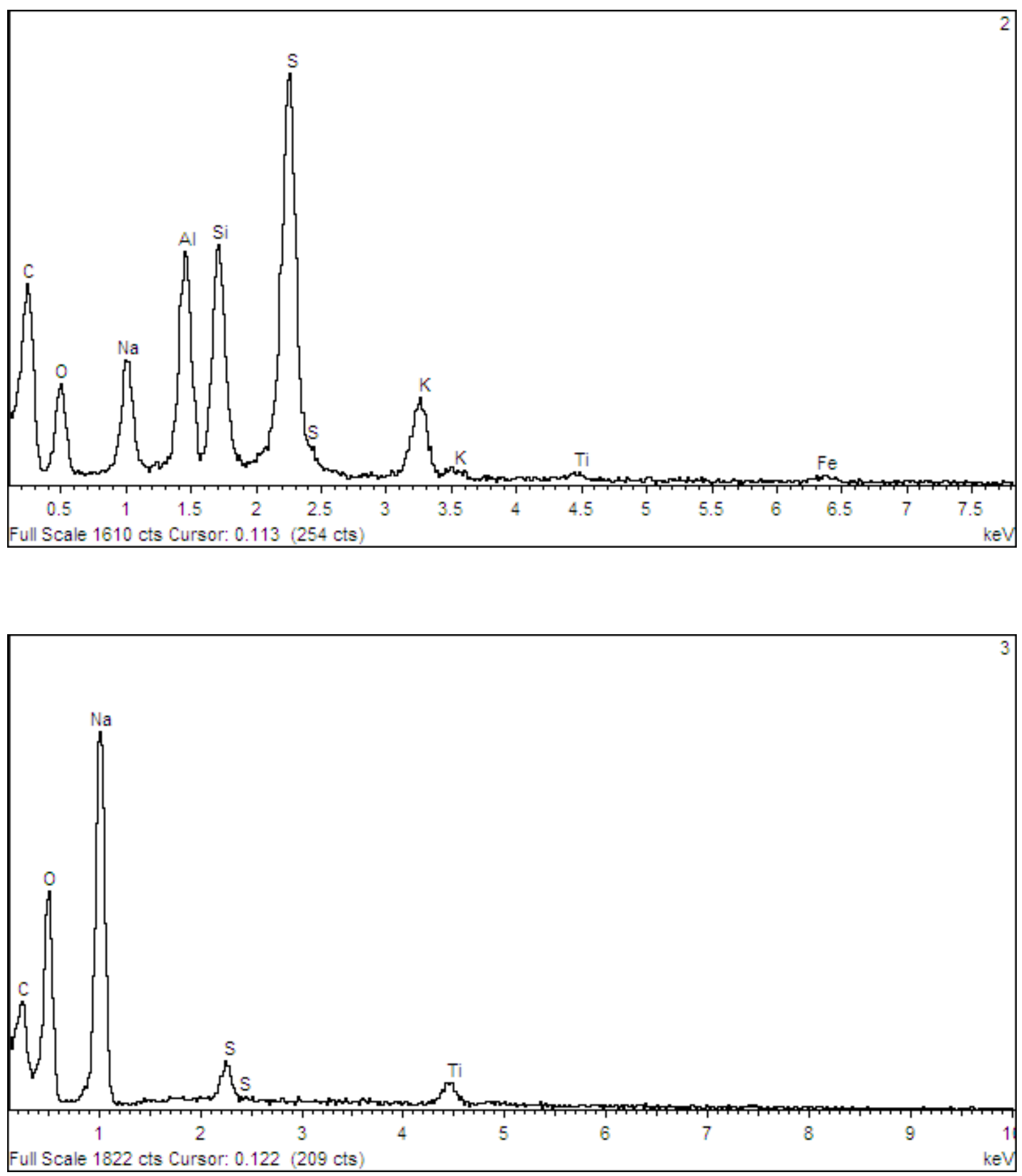
Appendix B: SEM Images and EDS Results for the DSS Coalescer Sample (cont'd)
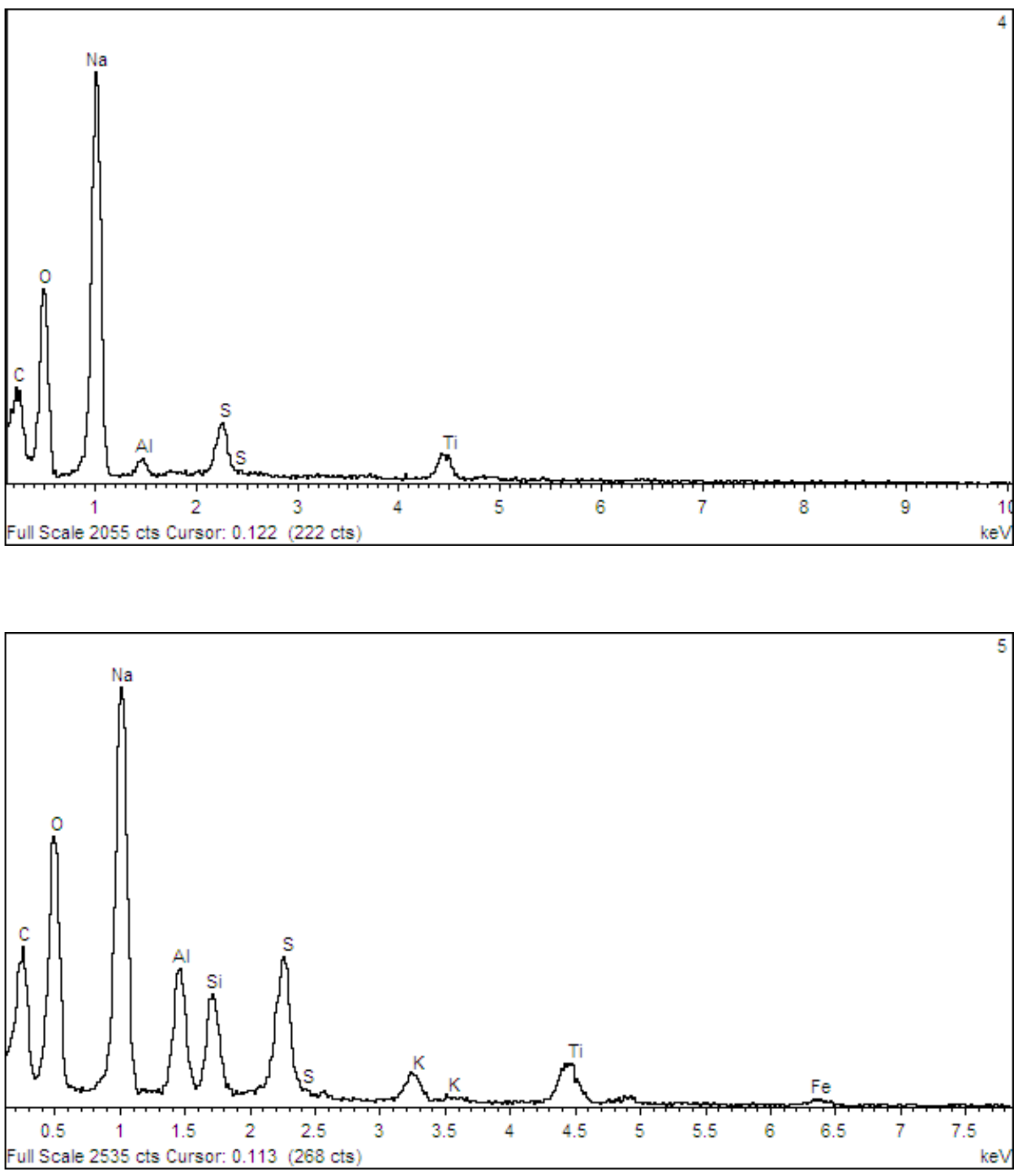
Appendix B: SEM Images and EDS Results for the DSS Coalescer Sample (cont'd)

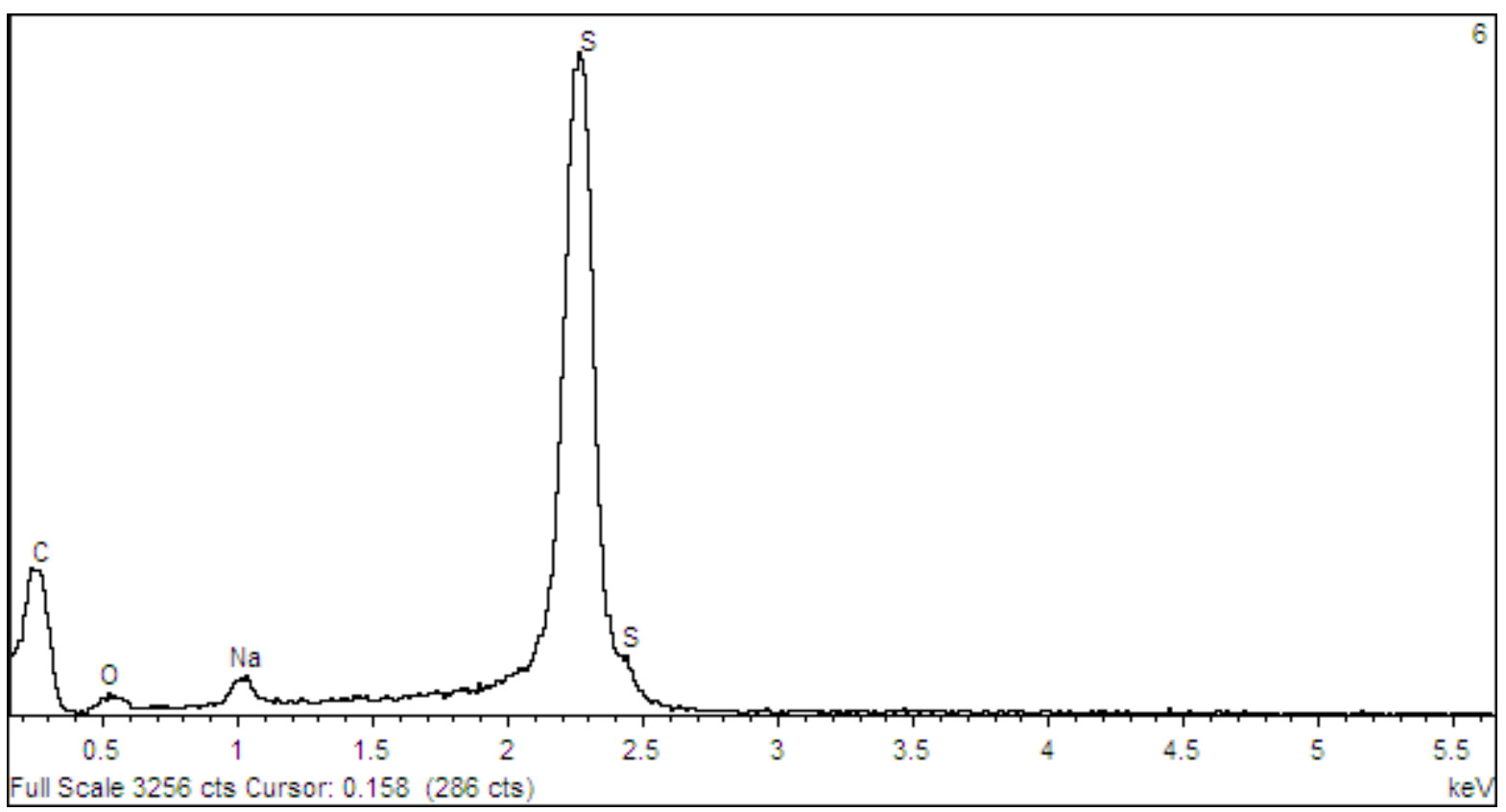




\section{Appendix C: SEM Images and EDS Results for the SE Coalescer Sample}
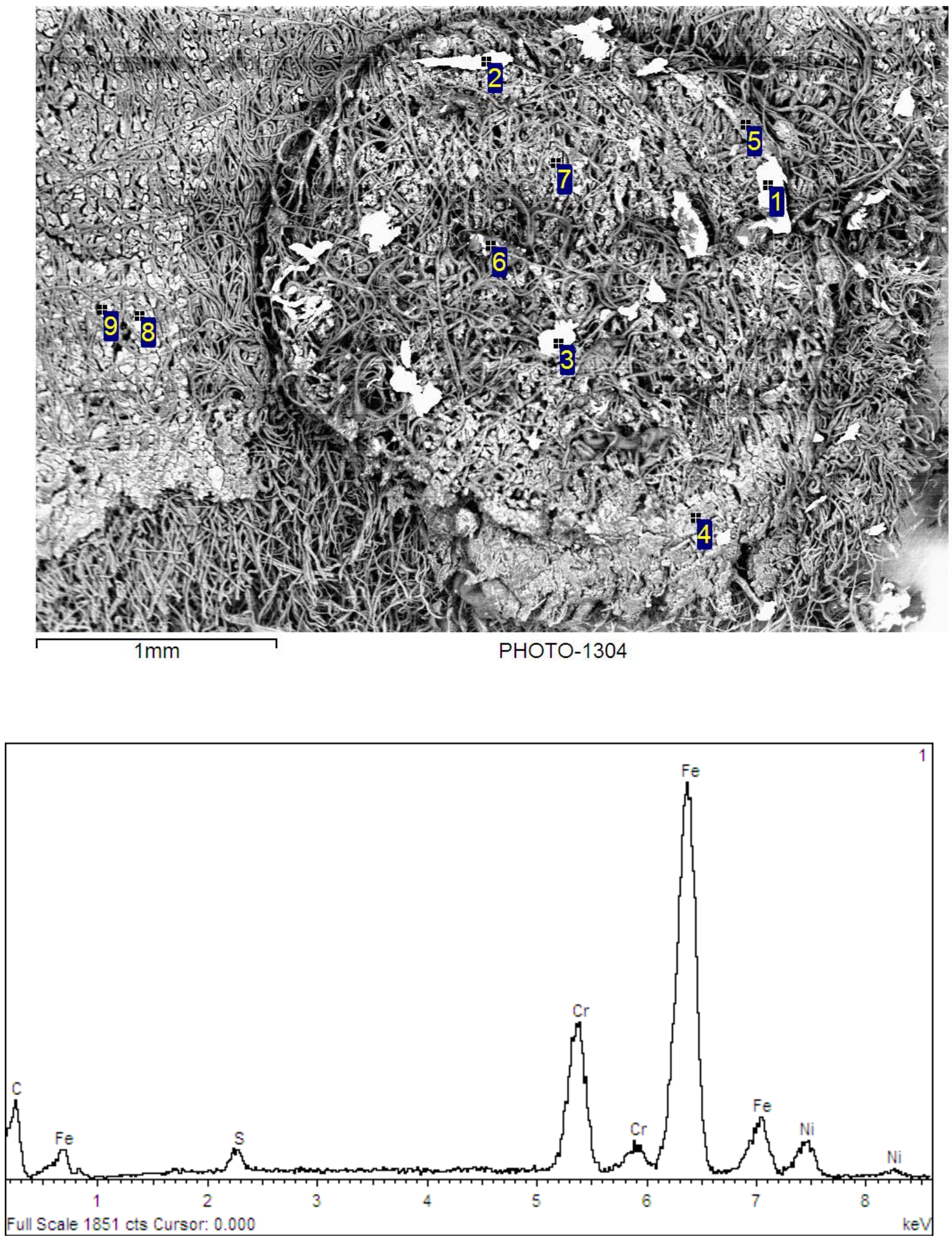
Appendix C: SEM Images and EDS Results for the SE Coalescer Sample (cont'd)
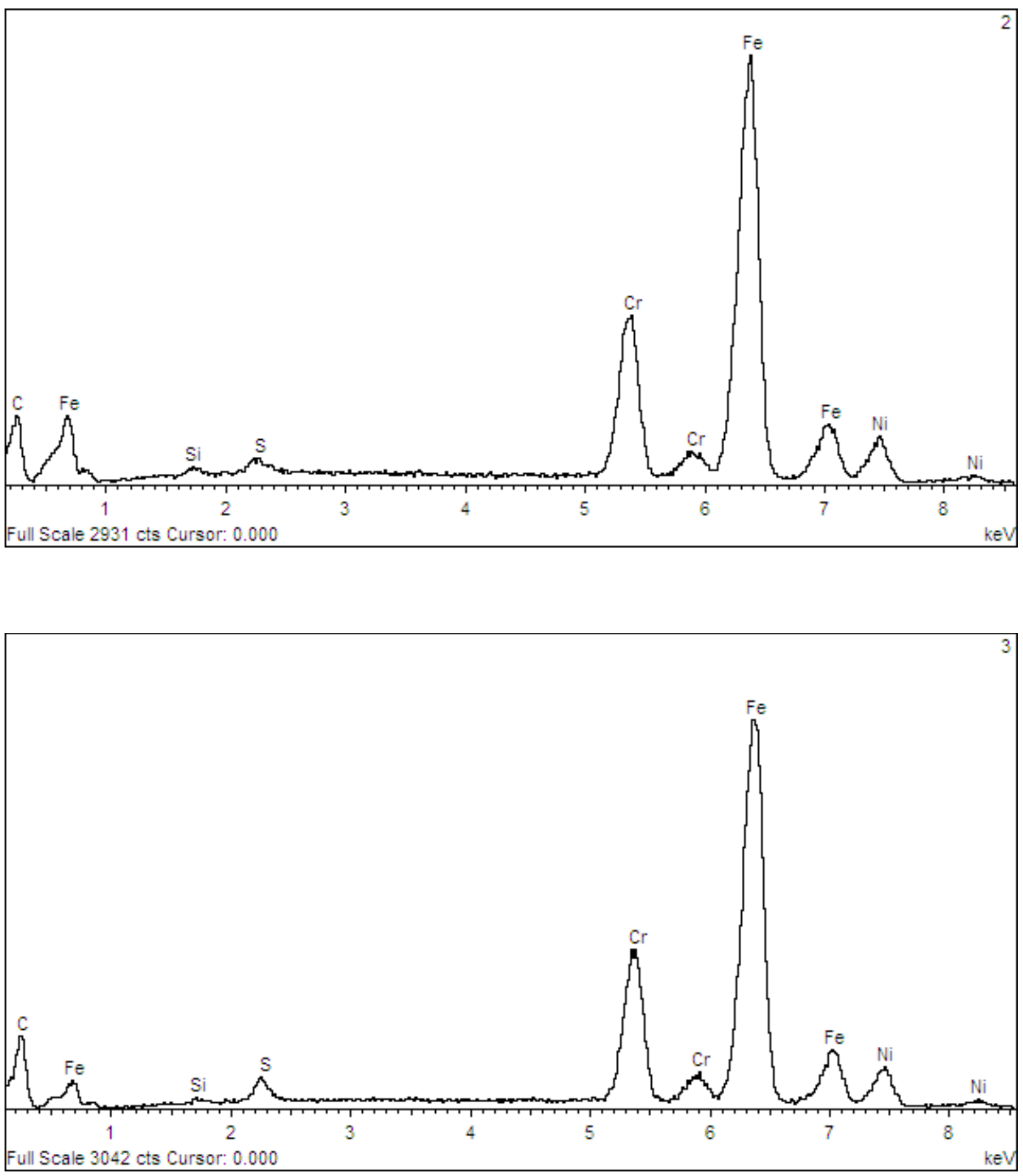
Appendix C: SEM Images and EDS Results for the SE Coalescer Sample (cont'd)
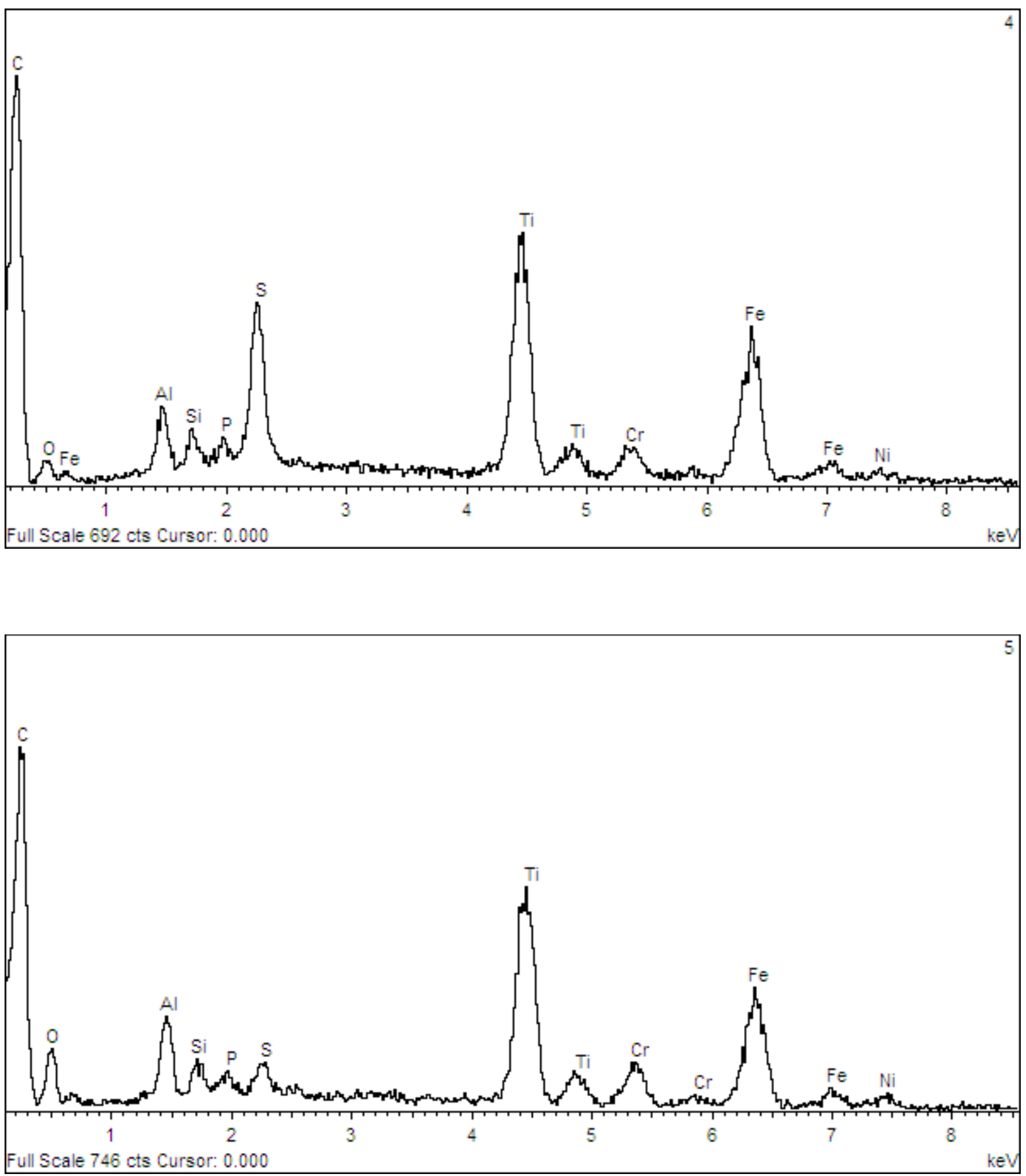
Appendix C: SEM Images and EDS Results for the SE Coalescer Sample (cont'd)
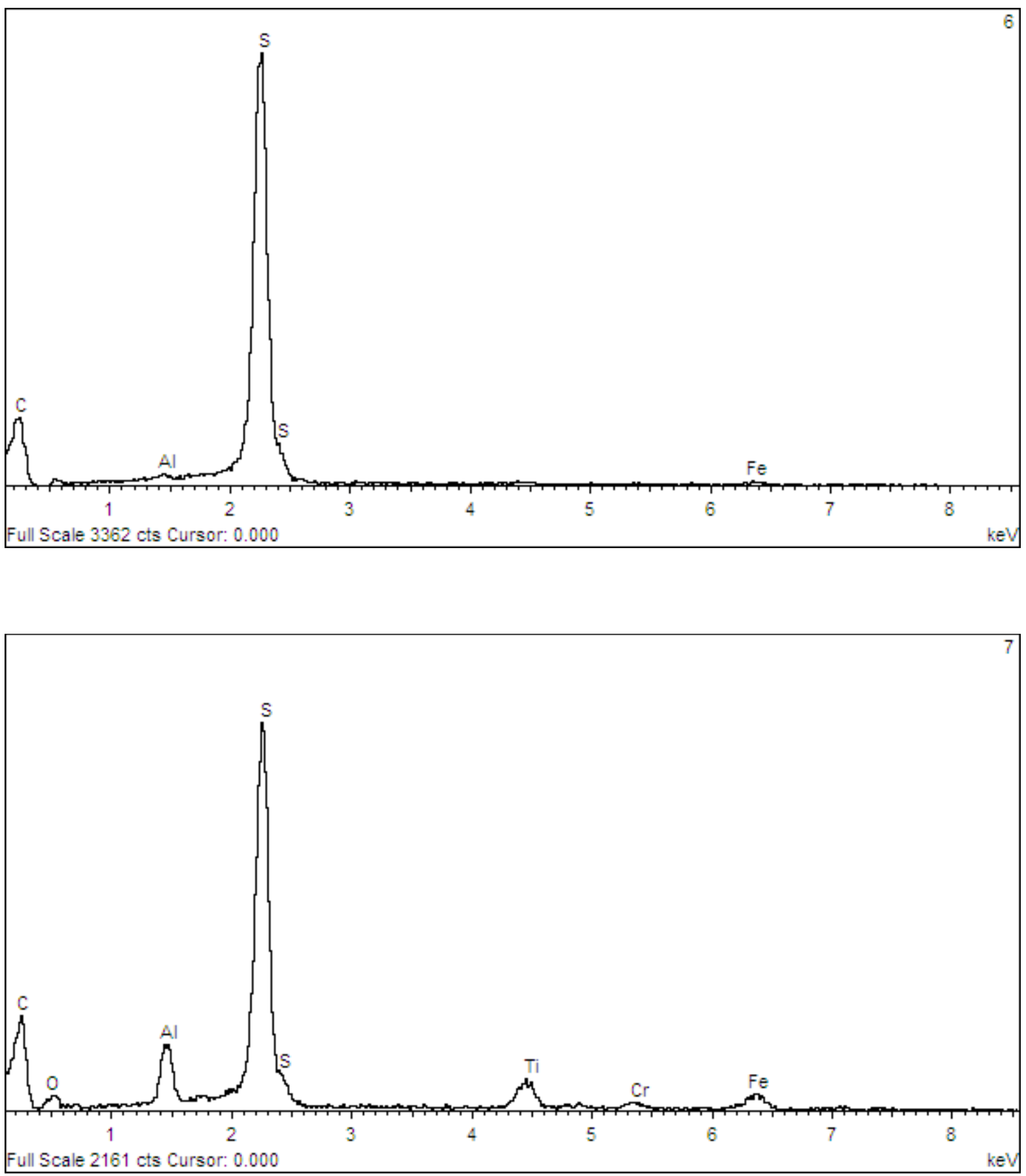
Appendix C: SEM Images and EDS Results for the SE Coalescer Sample (cont'd)
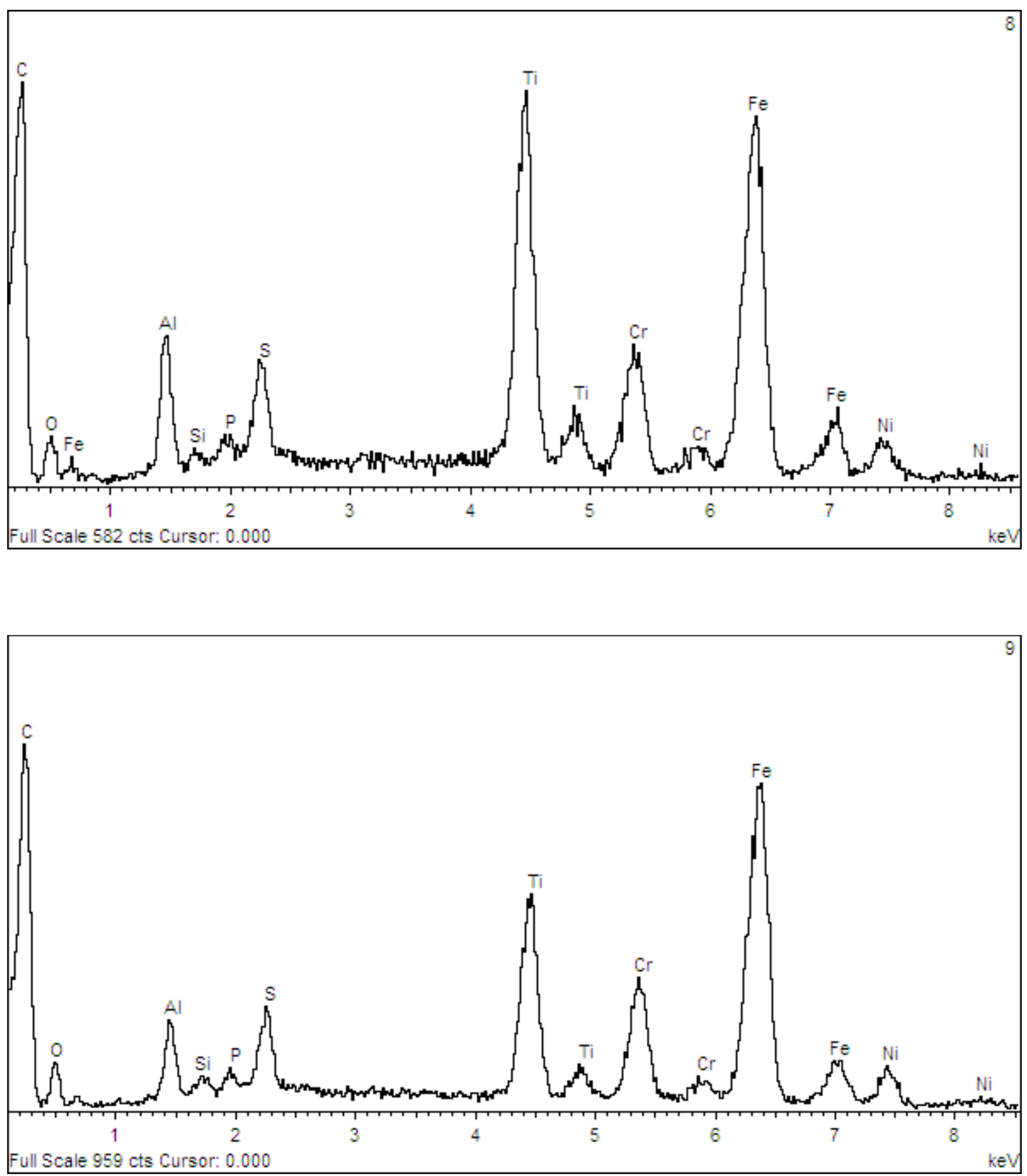
Appendix C: SEM Images and EDS Results for the SE Coalescer Sample (cont'd)
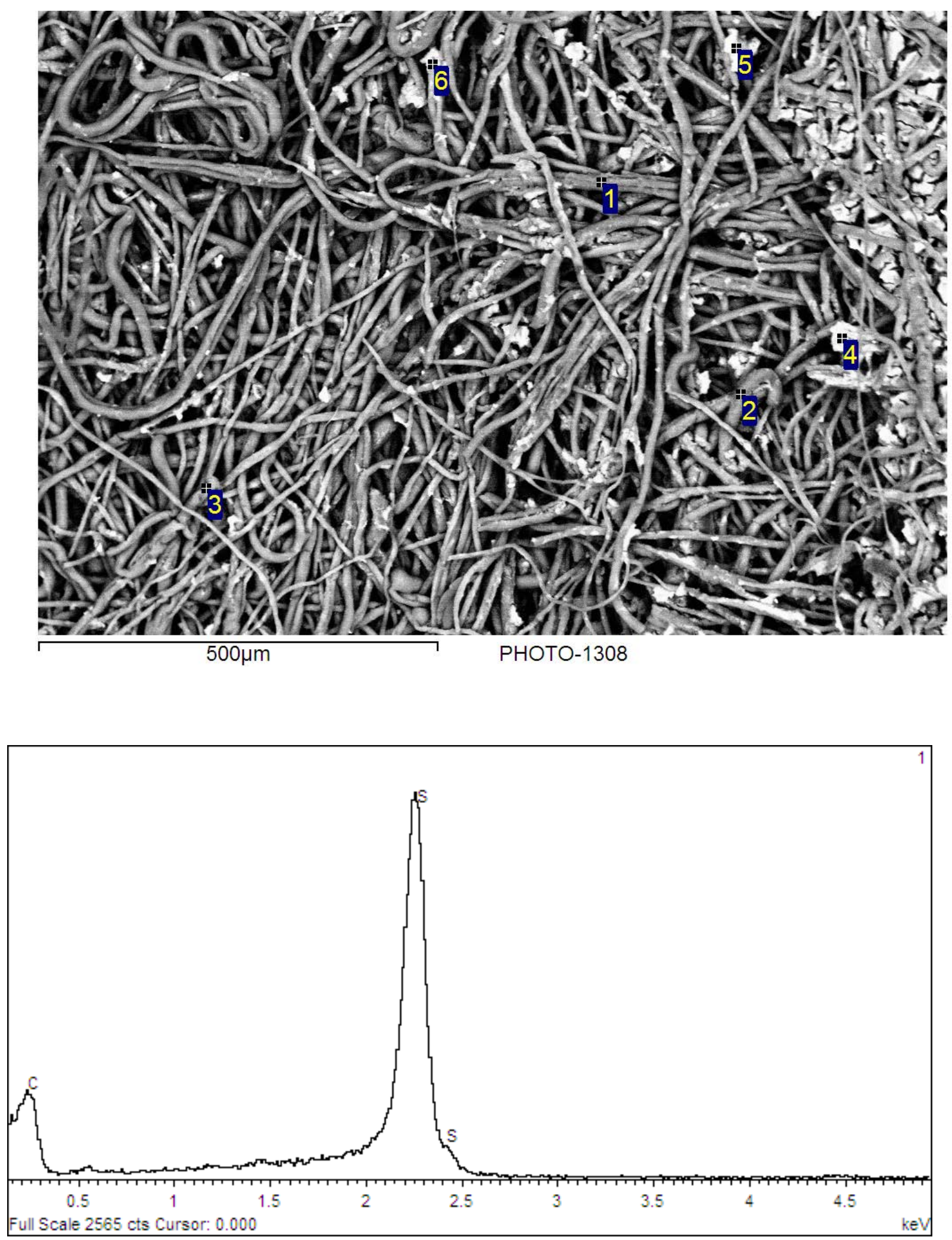
Appendix C: SEM Images and EDS Results for the SE Coalescer Sample (cont'd)
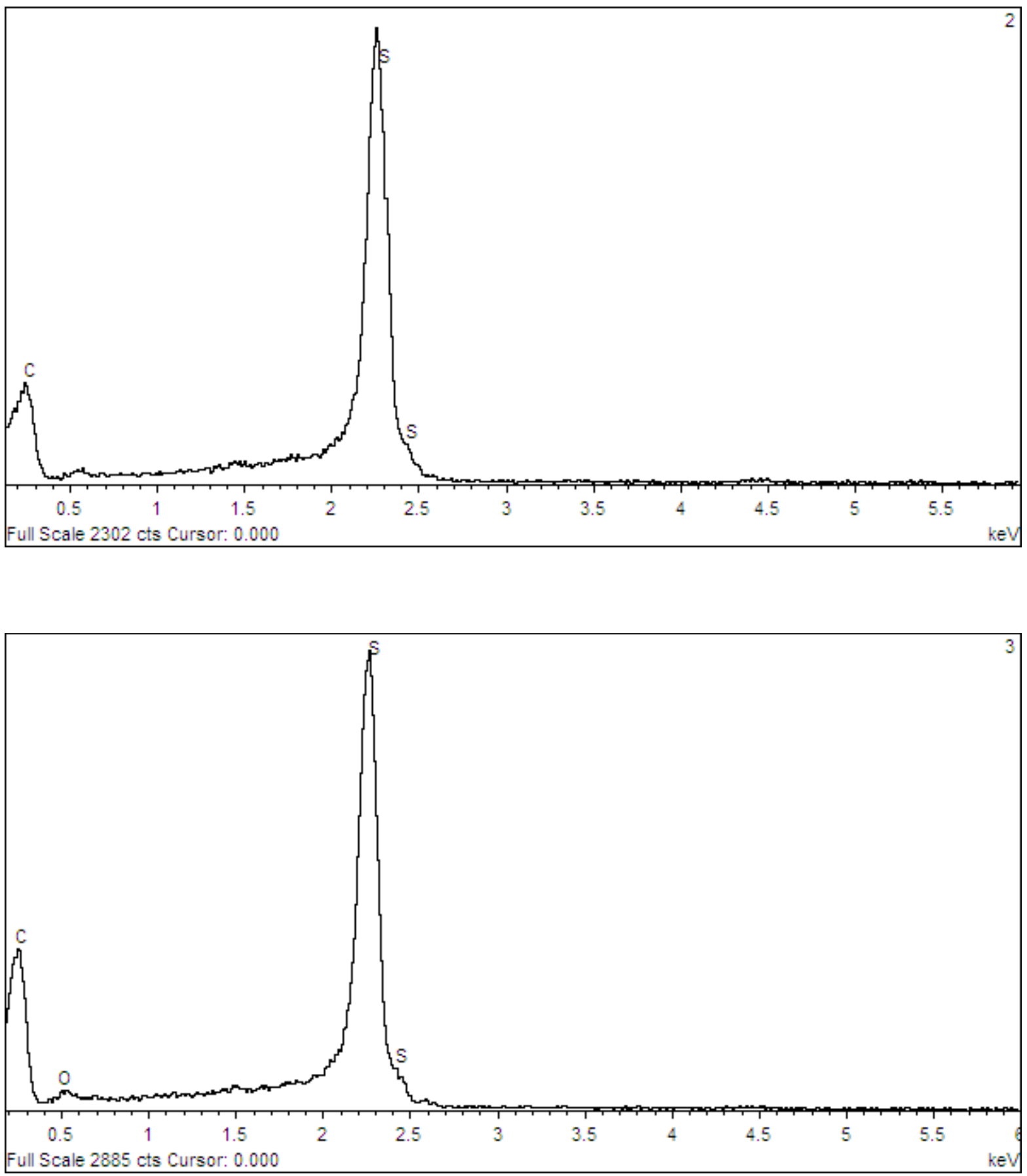
Appendix C: SEM Images and EDS Results for the SE Coalescer Sample (cont'd)
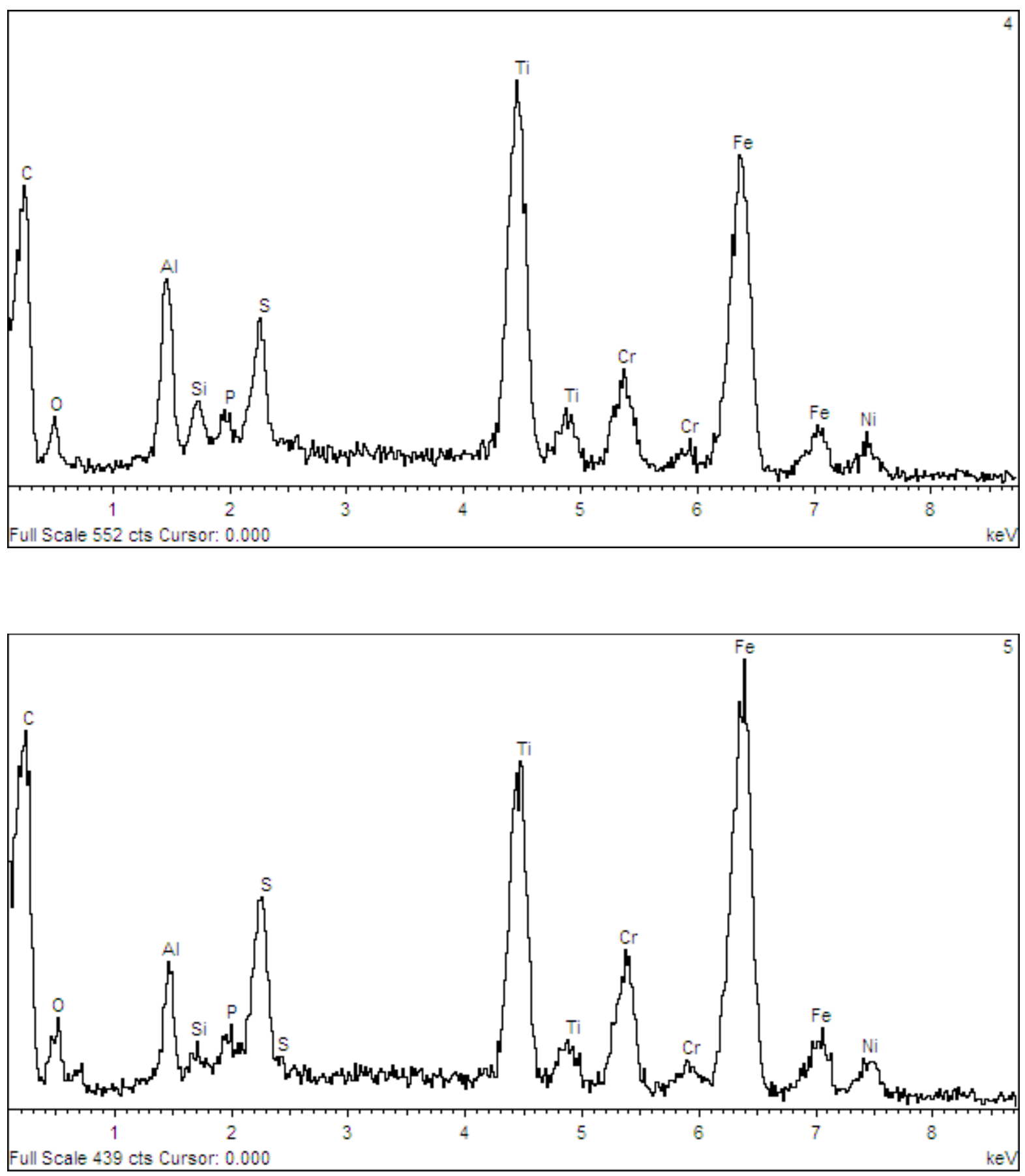
Appendix C: SEM Images and EDS Results for the SE Coalescer Sample (cont'd)
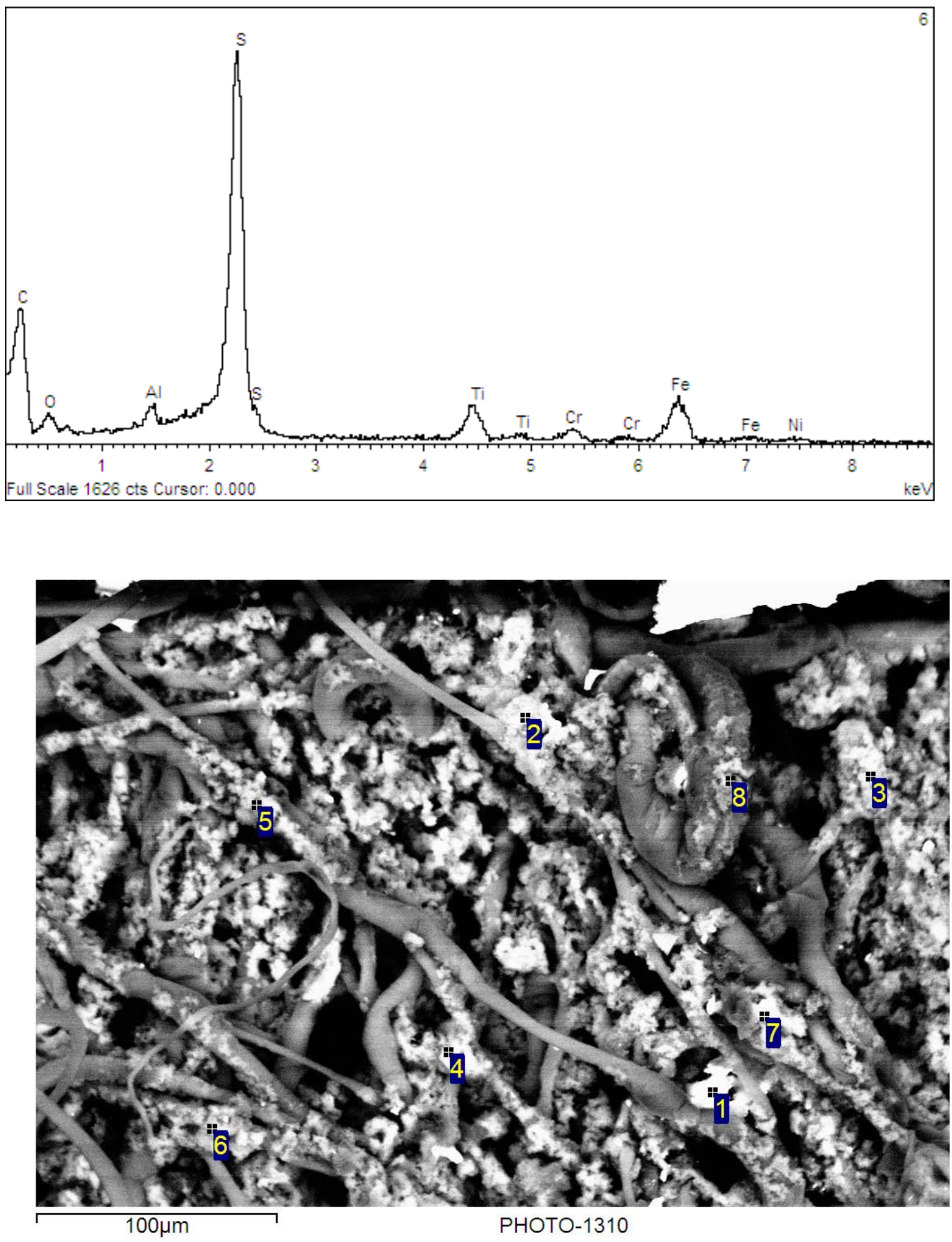
Appendix C: SEM Images and EDS Results for the SE Coalescer Sample (cont'd)
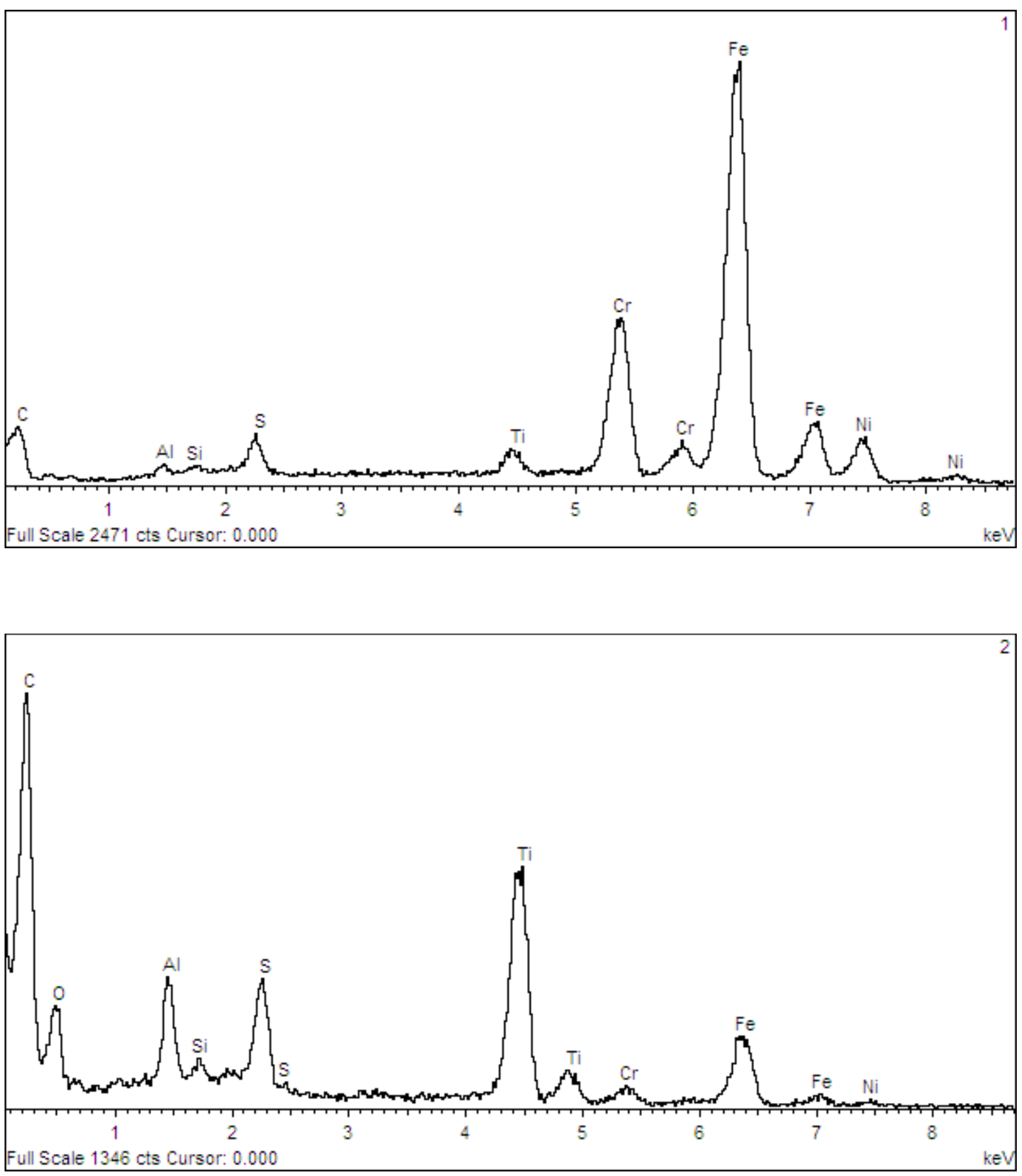
Appendix C: SEM Images and EDS Results for the SE Coalescer Sample (cont'd)
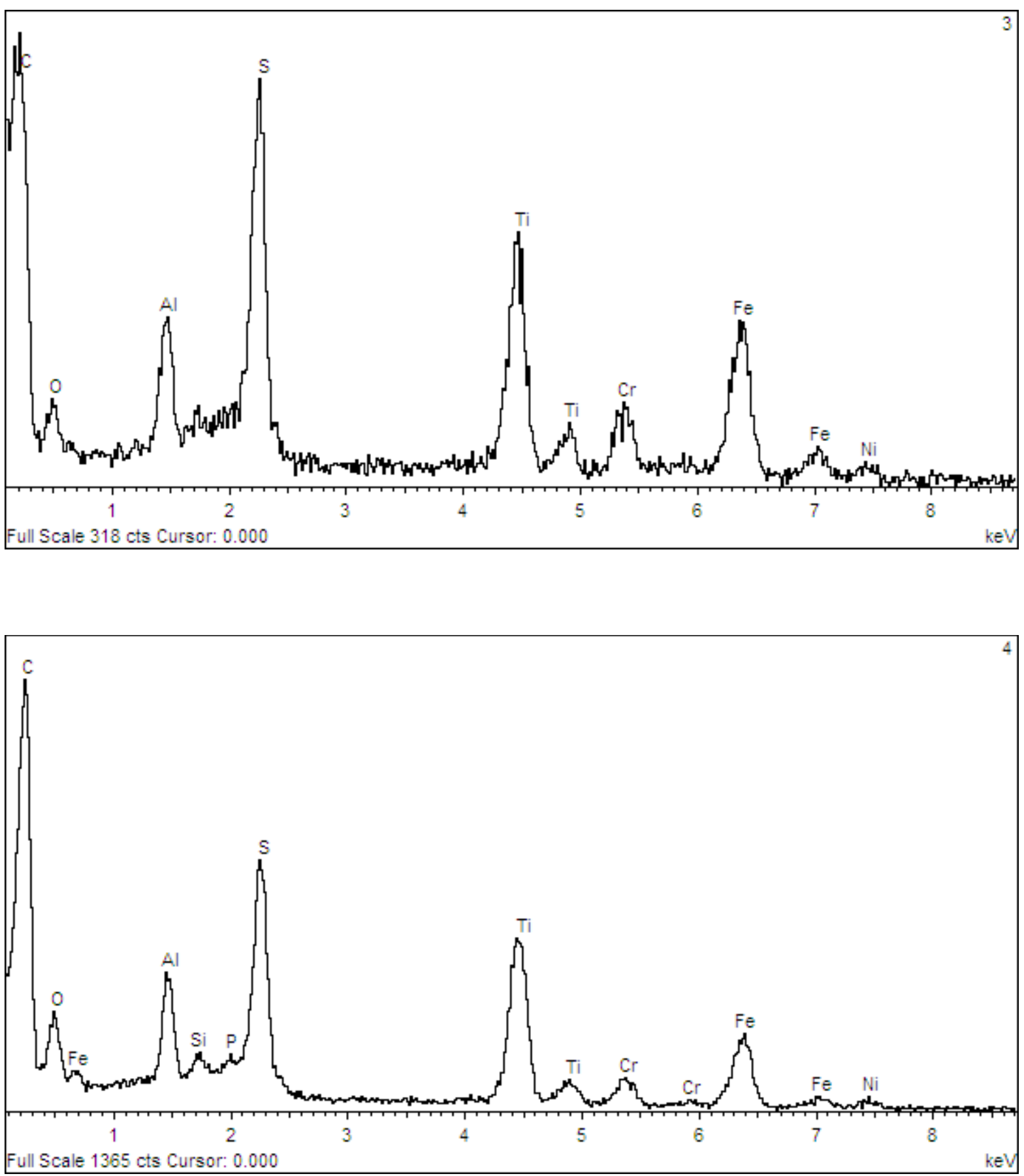
Appendix C: SEM Images and EDS Results for the SE Coalescer Sample (cont'd)
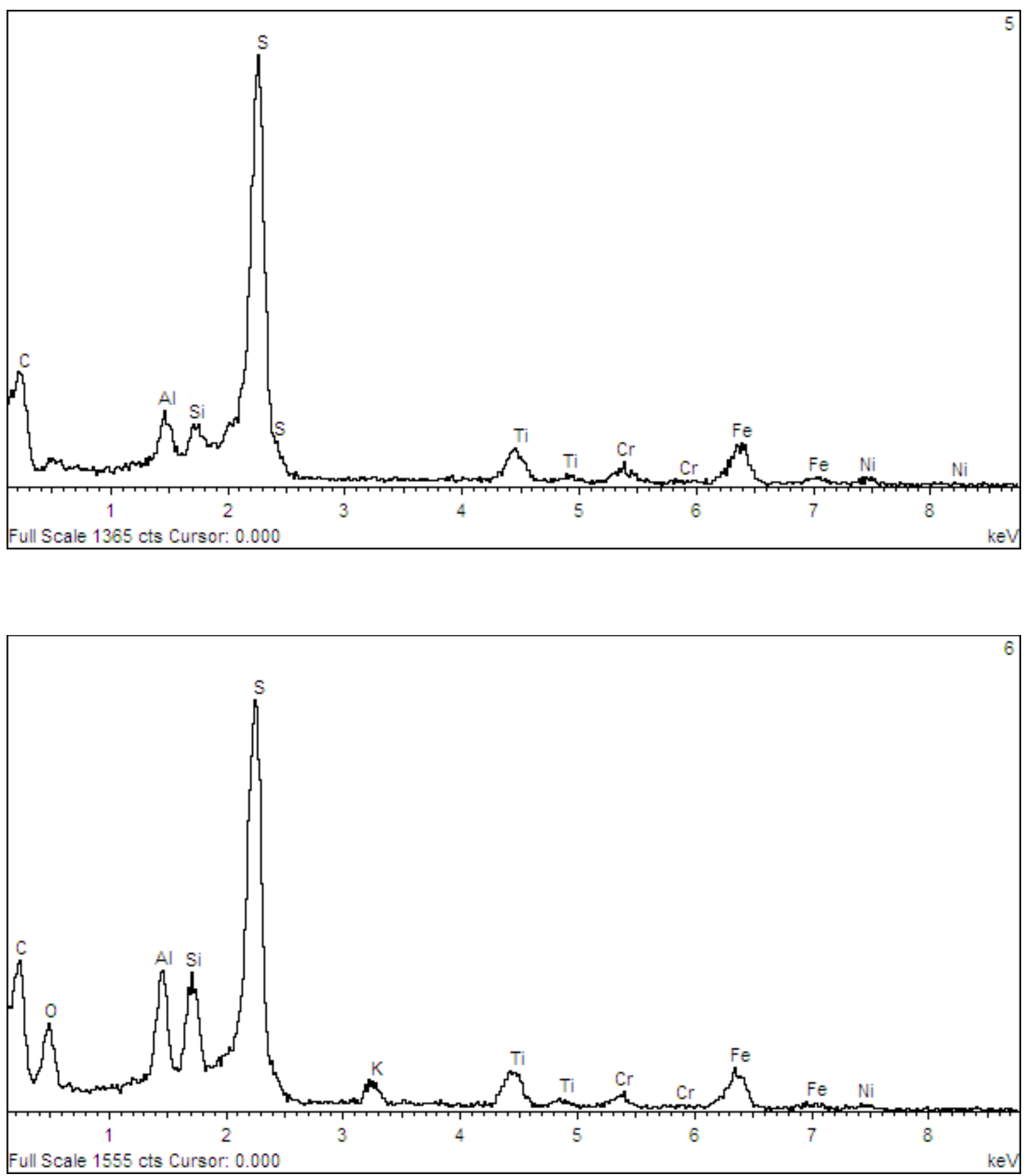
Appendix C: SEM Images and EDS Results for the SE Coalescer Sample (cont'd)
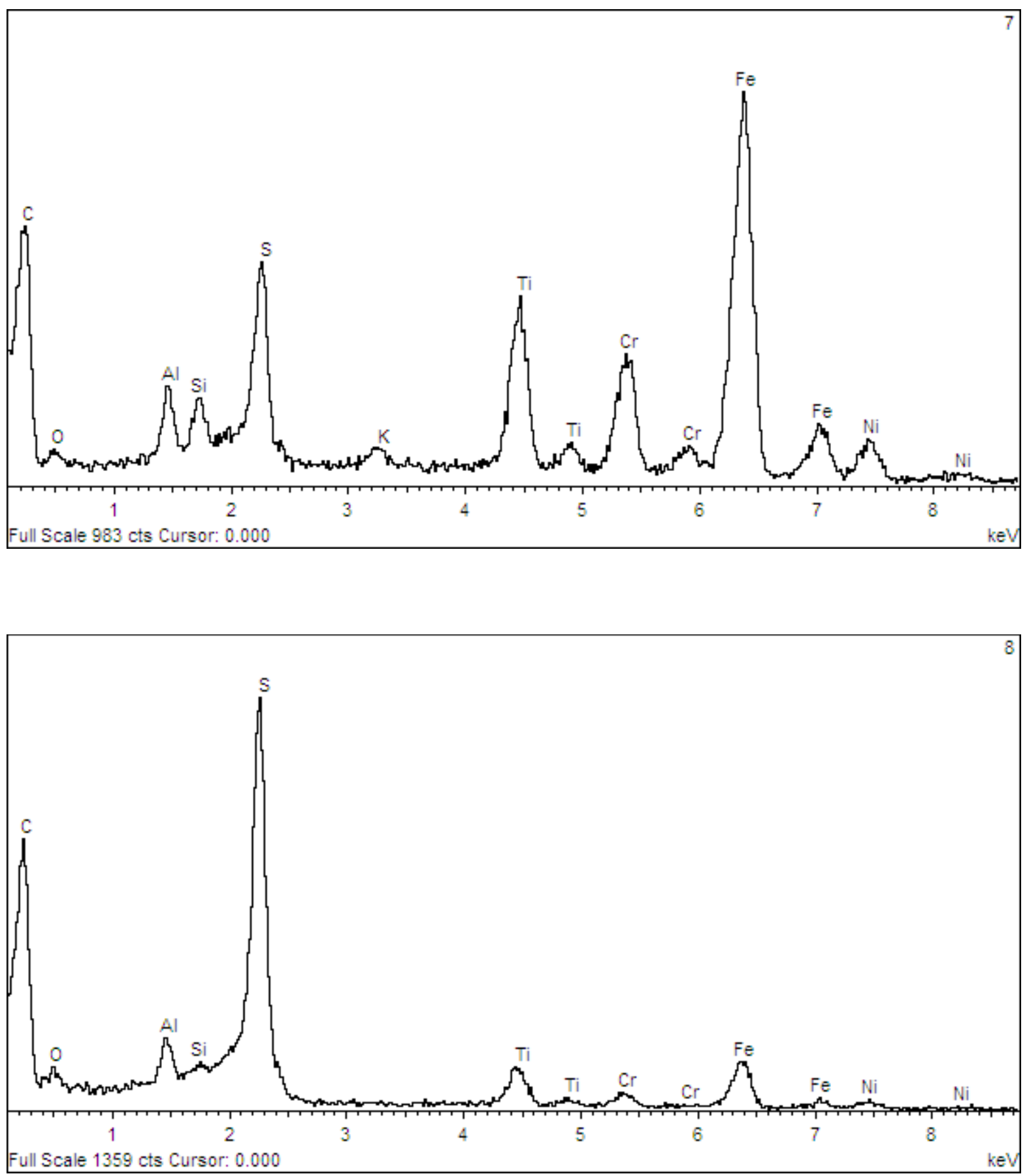
Appendix C: SEM Images and EDS Results for the SE Coalescer Sample (cont'd)
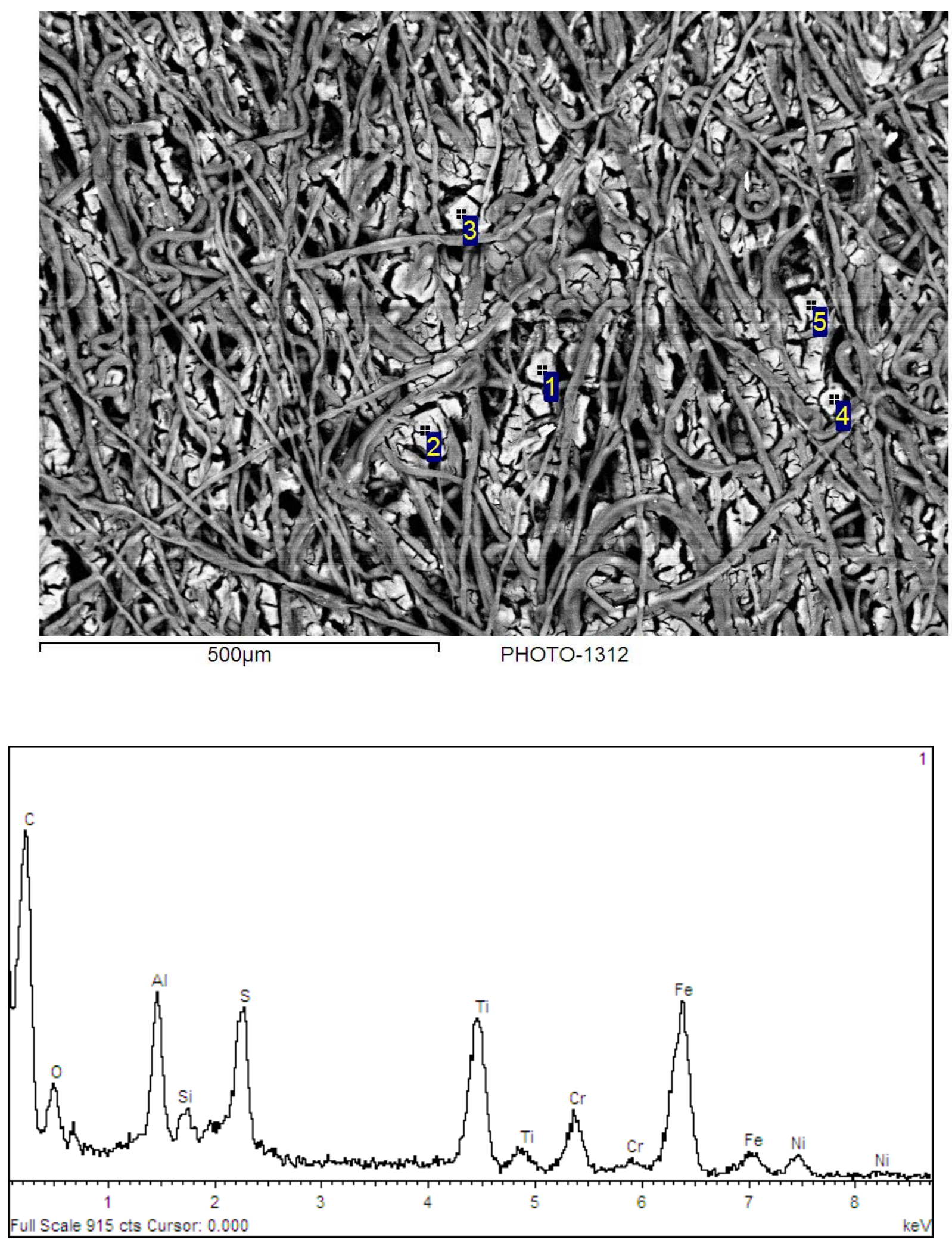
Appendix C: SEM Images and EDS Results for the SE Coalescer Sample (cont'd)
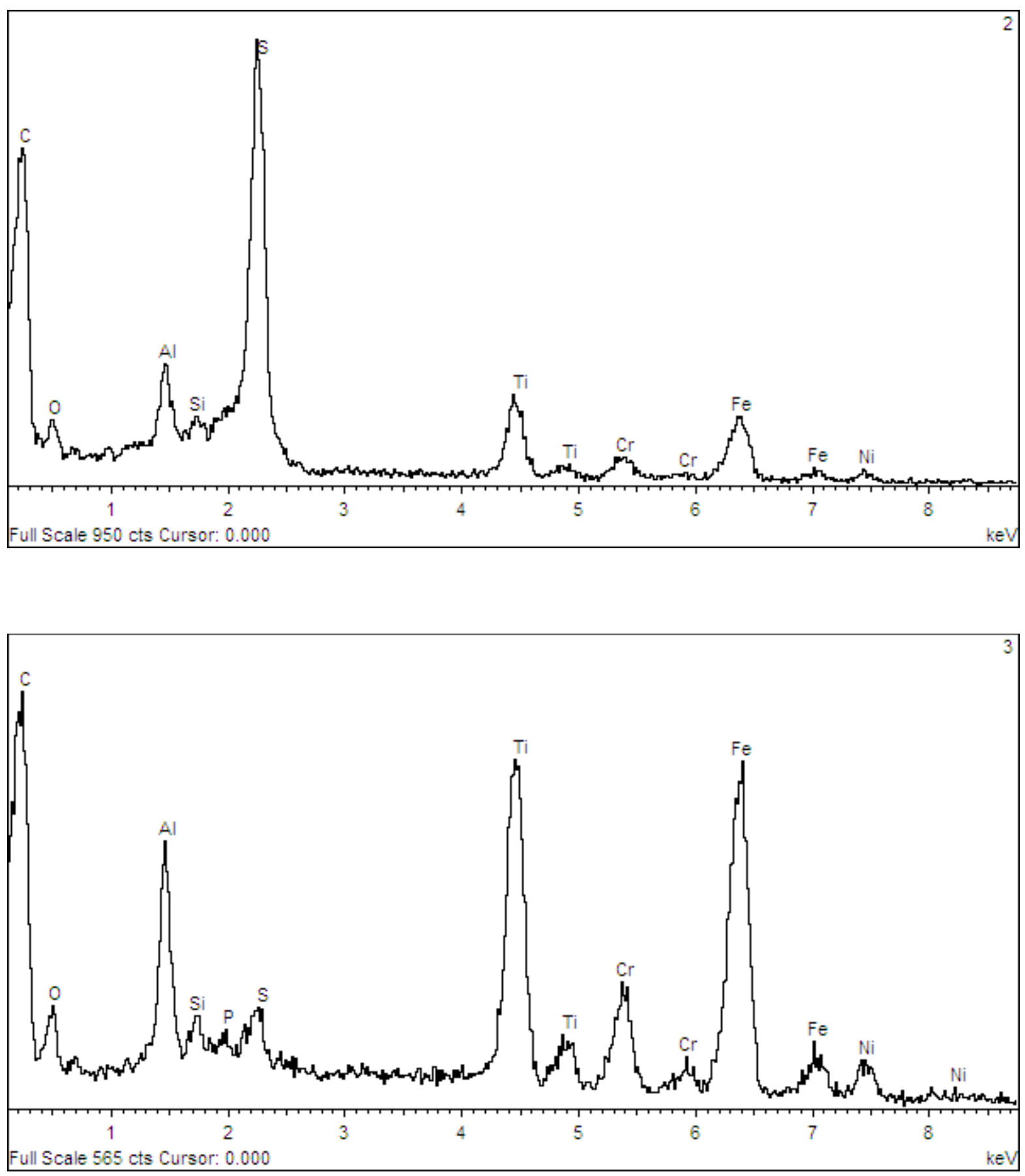
Appendix C: SEM Images and EDS Results for the SE Coalescer Sample (cont'd)
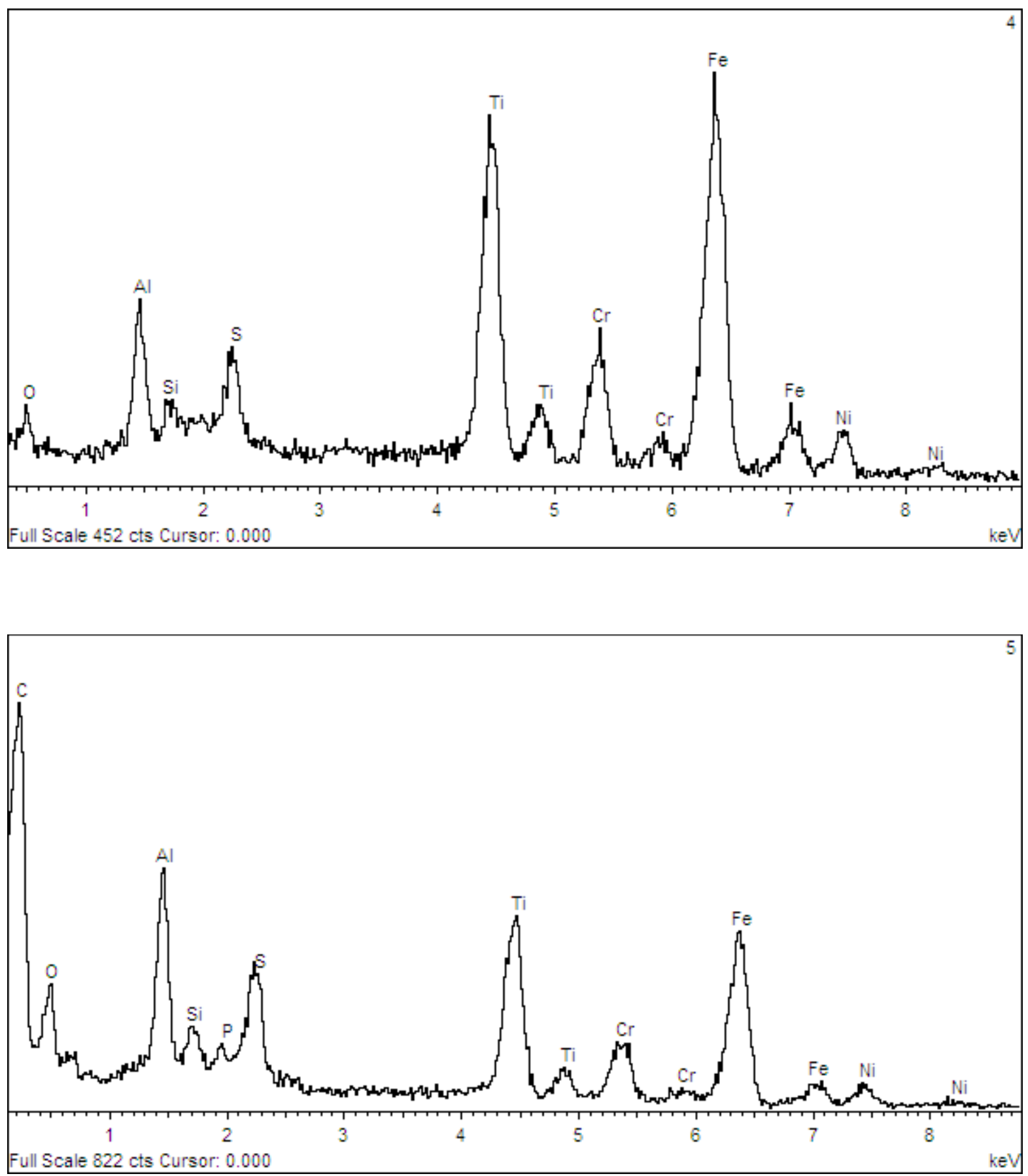


\section{Distribution:}

H. M. Ajo, 773-A

W. B. Brasel, 992-2W

T. B. Brown, 773-A

C. Conner, Parsons

N. R. Davis, 704-56H

S. D. Fink, 773-A

F. F. Fondeur, 773-A

B. A. Gifford, 704-56H

B. L. Green, 704-56H

K. D. Harp, 766-H

C. C. Herman, 773-A

E. N. Hoffman, 999-W

P. R. Jackson, 703-46A

M. T. Keefer, 704-56H

R. Lentsch, Parsons

R. K. Leugemors, 704-67S

S. L. Marra, 773-A

D. J. Martin, 241-152H

D. H. McGuire, 999-W

D. M. Missimer, 773-A

C. A. Nash, 773-42A

Q. L. Nguyen, 241-152H

F. M. Pennebaker, 773-42A

T. B. Peters, 773-42A

S. H. Reboul, 773-42A

P. C. Suggs, 704-S

D. J. Wheeler, 773-A

W. R. Wilmarth, 773-A

J. E. Young, 773-41A 